\title{
Research progress on selective laser melting (SLM) of bulk metallic glasses (BMGs): a review
}

\author{
Peilei Zhang ${ }^{1,2,3} \cdot$ Jie Tan $^{1,2} \cdot$ Yingtao $\operatorname{Tian}^{4}$ (1) $\cdot$ Hua Yan ${ }^{1,2} \cdot$ Zhishui $\mathrm{Yu}^{1,2}$
}

Received: 28 May 2021 / Accepted: 31 August 2021 / Published online: 26 September 2021

(C) The Author(s) 2021

\begin{abstract}
Bulk metallic glasses (BMGs) are a subject of interest due to their superior specific properties such as low coefficient of friction, high strength, large ductility in bending, high elastic modulus, high microhardness, and high resistance to corrosion, oxidation, wear, and so on. However, BMGs are difficult to apply in industry due to their difficulty in manufacturing and secondary operation. In the past few decades, many efforts have been carried out to overcome the defects in the manufacturing of BMGs. It is difficult to fabricate complex structures with the whole amorphous alloy owing to the limit of crystallization and critical cooling rate. Additive manufacturing (AM), such as selective laser melting (SLM), can obtain relatively high cooling rates during the "layer-by-layer" process, which makes it possible to surpass the dimensional limitation of metallic glass. In the SLM process, the high-speed cooling of molten pool and the avoidance of secondary processing are very beneficial to the production and application of amorphous alloys. In this paper, based on the research of SLM additive manufacturing BMGs in recent years, the factors affecting crystallization and forming ability are discussed from many aspects according to different material systems. The status and challenges of SLM manufacturing BMGs including Fe-based, Zr-based, Al-based, and some composite-based BMGs will be presented. Mechanical properties and physicochemical properties were introduced. This review aims to introduce the latest developments in SLM additive manufacturing BMGs, especially on the development of process parameters, structure formation, simulation calculation, fracture mechanism, and crystallization behavior. With the traditional fabricating methods, BMGs were mainly used as a structure material. It will provide another alternative to use BMGs as a functional material by introducing SLM technology in amorphous preparation with complex geometry. This review summarizes the technical difficulty and application prospects of BMGs preparation by SLM and discusses the challenges and unresolved problems. This review identifies key issues that need to be addressed in this important field in the future. These problems are related to the application of BMGs as high-strength structural materials and new functional materials in the future.
\end{abstract}

Keywords Bulk metallic glasses (BMGs) · Selective laser melting (SLM) · Additive manufacturing (AM) - Amorphous alloys · Crystallization

Peilei Zhang

peilei@sues.edu.cn

Yingtao Tian

y.tian12@lancaster.ac.uk

Zhishui Yu

yu_zhishui@163.com

1 School of Materials Engineering, Shanghai University of Engineering Science, Shanghai 201620, China

2 Shanghai Collaborative Innovation Center of Laser Advanced Manufacturing Technology, Shanghai 201620, China

3 Fraunhofer Institute for Laser Technology ILT, 52074 Aachen, Germany

4 Department of Engineering, Lancaster University, Lancaster LA1 4YW, UK

\section{Introduction}

Solid materials can be divided into two types according to the arrangement of particles: crystalline materials with periodic and regular arrangement of particles and amorphous materials with short, orderly, and long-term disorder [1]. Amorphous bulk metals or amorphous structural metals, i.e., amorphous metals with dimensions that permitted structural applications, were not produced until the seventies from specially composed alloys [2, 3]. Bulk metals of these alloys were produced by cooling from melt at a cooling speed of about $1000 \mathrm{~K} / \mathrm{s}$, but contained, i.e., the expensive metal palladium, which prevented larger volumes of production [4]. In the 1960s, Duwez of California Institute of Technology (Caltech) 
accidentally prepared amorphous alloys by using melt quenching to study $\mathrm{Au}-\mathrm{Si}$ binary alloys firstly [5]. These alloys were called as bulk metallic glasses (BMGs). At the end of the 1980s, Professor Inoue at the Tohoku University in Japan managed to develop various multi-component systems consisting of ordinary metallic elements which resulted in an amorphous bulk structure when cooling from melt $[6,7]$. In the years that followed, a great number of different amorphous metal systems have been found [8].

BMGs can be produced by quickly quenching and solidifying the molten metal to avoid crystallization [9-12]. Atoms in BMGs exist in a random or disordered manner, much like atoms in the liquid phase [13-15]. Compared with the traditional crystal metal, metallic glass has higher tensile strength, hardness, wear resistance, and corrosion resistance $[11,16$, 17]. Because of these excellent properties, amorphous alloys have attracted more and more attention. However, the fabrication of amorphous alloys by traditional methods has been plagued by size limitations $[18,19]$. The greatest problem in casting of three-dimensional bodies (bulk metal) of BMGs is to achieve a sufficient cooling speed. An insufficient cooling speed results in a crystalline material instead of an amorphous material. The cooling speed restricts the size and thickness of material to be produced [20]. The required cooling speed also makes it difficult to cast complicated geometries, thus making it necessary to produce several different components to be assembled. In practice, there will only be a limited choice of materials since there is a limited number of alloy systems that have a critical cooling speed that is practicably handleable in casting of structural components. At present, the maximum centimeter-grade iron-based amorphous alloys is $18 \mathrm{~cm} \mathrm{[21]}$ and the zircon-based amorphous alloys is $73 \mathrm{~cm}$ [22], which can be produced by the traditional copper mold pouring method. At present, the maximum centimeter-grade amorphous alloy is known to be palladium-based amorphous alloy produced by water quenching, reaching $80 \mathrm{~cm}$ [23]. In addition, amorphous alloys have poor forming performance at room temperature because of the high strength and high hardness $[8,24]$. These two points limited the application of amorphous alloy in industry [25].

In order to overcome the two forming and preparation limitations described above for metallic glass, many researchers have studied the manufacture of bulk metallic glass additively. Wang produced large pieces of titanium-based metallic glass through friction welding and studied the influence of interfacial friction temperature distribution on the quality of interfacial joints [26]. Wu used a $35-\mathrm{kHz}$ ultrasonic spot welder to explore the mechanism of $\mathrm{Ni}_{82.2} \mathrm{Cr}_{7} \mathrm{~B}_{3} \mathrm{Si}_{4.8} \mathrm{Fe}_{3}$ metallic glass prepared by ultrasonic bonding technology in the ultrasonic layer-by-layer additive manufacturing process [27]. Shao welded lead-based bulk metallic glass with a pulsed laser beam and studied the mechanical properties of the welded samples [28]. Wang used spark plasma sintering technology to fabricate titanium-based bulk metallic glass composites. The bulk metallic glass prepared by this method has the potential for engineering applications [29, 30]. Inspired by the seismic structure of skyscrapers, Li designed a tubular structure of $\mathrm{Ti}_{6} \mathrm{Al}_{4} \mathrm{~V}$ frame [31]. Under ultrasonic vibration, $\mathrm{Zr}_{35} \mathrm{Ti}_{30} \mathrm{Be}_{26.75} \mathrm{Cu}_{8.25}$ was used for $3 \mathrm{D}$ printing and thermoplastic molding with a large metal glass matrix to form a sandwich structure of large metal glass composite material. This work provides a promising way for the development of metal-glass composite materials. The sintering of 3D-printed Fe-based metallic glass parts was preliminarily realized by $\mathrm{Wu}$, and the feasibility of preparing Fe-based metallic glass using pneumatic injection additive manufacture was verified [32].

With the rise of laser additive manufacturing, people try to use this new method to make amorphous alloys [33]. Laser additive manufacturing has been a hot topic in the field of additive manufacturing [33, 34]. According to the different ways of powder delivery, laser 3D printing technology can be divided into two categories: laser engineering near-net shaping-LENS and selective laser melting (SLM) [35]. SLM is an important branch of 3D printing technology [36]. SLM scans the metal powder bed layer by layer according to the path planned in the 3D CAD slice model [37]. The scanned metal powder melts and solidifies to achieve the effect of metallurgical bonding, and finally obtains the metal parts modeled [38]. Due to the interaction between the laser and the metal powder, the SLM process involves the formation of physical and thermal phenomena (phase transitions related to the melting and solidification of the metal powder), metallurgical phenomena (diffusion), mechanical phenomena (due to the presence of residual stresses), temperature gradients in the process, and hydrodynamic phenomena (convection in the molten pool) [39]. According to the SLM process, a layer of metal powder is applied to a heat-conducting base and a limited area of the layer is melted by laser and the area is cooled so that the melted area solidifies into amorphous metal [40, 41]. The melting process is successively repeated on new limited areas on the powder layer until a continuous layer of amorphous metal is formed. Instead of casting and melting all the material at the same time, when the laser scans the deposited metal powder, only a very thin layer of powder $(20-50 \mu \mathrm{m})$ and a small part of the solidified layer of the previous layer are melted [42]. The cooling rate in SLM process can reach $10^{5}-10^{8} \mathrm{~K} / \mathrm{s}$ [43], which is much higher than the critical cooling rate for general metallic glass to form an amorphous state, which is very useful for manufacturing BMG. Obviously, it is very attractive for the preparation of complex structure of metallic glass, which provides hope for truly manufacturing BMG components [44].

A large number of research have been done on titanium alloy, magnesium alloy, aluminum alloy, steel, and other metal materials manufactured by SLM [45-49]. Considering that 
amorphous alloy is difficult to manufacture and process; it requires a great solidification speed and suppression of crystal nucleation and growth during solidification of the alloys [50]. SLM has the following two advantages that are particularly suitable for the manufacture of BMGs: (1) the grain structure is fine and uniform. In the process of SLM forming, the grain growth is greatly inhibited due to the extremely fast cooling rate, and the segregation of alloying elements is effectively inhibited by the rapid solidification [51]. (2) Complex structures cannot be processed by traditional methods. For some three-dimensional hollow structures, the traditional casting, welding, machining, and other methods cannot complete the manufacturing of these structures, and the SLM technology can simplify the complex three-dimensional structure into two-dimensional plane processing, through layer-by-layer processing, finally obtain three-dimensional complex components [52]. Compared with the traditional methods for process BMGs, a small molten pool can be obtained in the SLM process, and this is very helpful to obtain a large solidification speed. A large solidification speed is essential to obtain a completely amorphous alloy. According to the three-dimensional finite element analysis model considering Marangoni convection and laser optical penetration, it can be known that the heat transfers from powders to solid, and explored how process parameters would affect the temperature distribution and the dimensions of the molten pool in SLM [53]. The dimensions of the molten pool strongly depend on the process parameters [54]. So, obtaining accurate heat input by optimizing laser parameters is very important for obtaining pure amorphous alloys. However, due to the poor macroscopic plasticity of BMGs, when the thermal stress accumulated during SLM manufacturing exceeds a threshold, the shear band tends to nucleate and propagate into cracks [55]. Therefore, for the SLM manufacturing process, the macroscopic plasticity of metallic glass at room temperature must be improved [56]. In a word, it can be seen that SLM techniques have great potential for the fabrication of not only large-sized BMGs with complex geometry but also BMGs with tailorable microstructures for possible enhancement of properties [33].

As mentioned above, layers of metal powder ranging from approximately 20 to $100 \mu \mathrm{m}$ in thickness are spread across a platform and selectively melted by a laser beam energy source in SLM process [57]. Since the spot diameter of laser beam is small (about 20-150 $\mu \mathrm{m}$ ), the size of molten pool formed by focusing the laser beam on the powder is small [58]. This size of the molten pool is much smaller than that of laser cladding and laser direct deposition which is about $3-5 \mathrm{~mm}$ or larger [59]. The heat of the molten pool diffuses quickly through the deposited part and the substrate. The cooling rate of the small molten pool formed by laser as a heat source can reach on the order of $10^{3}-10^{4} \mathrm{~K} / \mathrm{s}$, which is observably higher than the critical cooling rate of most metallic glasses forming amorphous state [60]. In addition, SLM is able to produce near net- shaped components with complex and intricate geometries, unmatched by current BMG production techniques [61]. The SLM of glass-forming or composite-forming alloys offers a unique opportunity for creating tunable properties by controlling parameter settings, where homogenous, monolithic powders are typically used.

At present, many review articles on related research on the manufacturing technology of metallic glass have been published $[62,63]$. For example, research on traditional manufacturing technology and performance of metallic glass [64], laser processing methods of metallic glass [34], additive manufacturing technology of metallic glass and its composite materials [33, 65], laser additive manufacturing of Fe-based magnetic amorphous alloys, crystallization phenomenon in the additive manufacturing process of metallic glass [66], application of functionally graded materials for metallic glass [67], and other related academic literature [68]. However, there is no comprehensive overview of the research on SLM manufacturing metallic glass, which is one of the fastest growing, most advanced, and most promising technologies in metallic glass manufacturing technology.

This review paper consists of three major parts. The first part will introduce the fabrication of different BMG material systems using metal additive manufacturing-SLM based on literature. The current status and challenges of additive manufacturing of BMGs including Fe-based, Zr-based, and some composite based alloys will be presented. The second part will focus on the properties of BMGs processed by SLM including mechanical properties and physicochemical properties. The third part will provide a perspective for the additive manufacturing of BMGs. With the traditional fabricating methods, BMGs were mainly used as a structure material. It will provide another alternative to use BMGs as a functional material by introducing SLM technology in amorphous preparation with complex geometry. This review aims to introduce the latest developments in SLM additive manufacturing BMGs, especially on the development of process parameters, structure formation, simulation calculation, fracture mechanism, and crystallization behavior in the manufacturing process of amorphous alloys such as zirconium-based, ironbased, and aluminum-based SLM for different metallic glasses alloy systems. This review summarizes and comments the research status and progress of almost all published literatures on the preparation of BMGs by SLM, summarizes the technical difficulty and application prospects of BMGs preparation by SLM, and discusses the challenges and unresolved problems.

\section{SLM process of BMGs}

Recently, many researchers have attempted to produce BMGs using SLM method. A Swedish company, Exmet AB, was the first group to demonstrate the feasibility of this technique in $2011[20,120]$. In these two patents, method of producing 
BMGs by SLM was provided. However, the details about the materials, equipment, and results of the fabrication of BMGs were not presented. Table 1 shows all the typical BMGs developed by SLM manufacturing processes in the past decade, such as Fe-based, Zr-based, Al-based, and composite-based amorphous alloys according to the literature published. It can be seen in Table 1 that SLM fabrication of BMGs started in 2013 by Simon Pauly [69] and over half of the total research papers were published in the last 18 months. This definitely proves that the preparation of amorphous alloys with SLM technology has become a research hotspot in the field of BMGs. Researchers have focused on the fabrication of Febased and Zr-based metallic glasses by SLM because of the good glass-forming ability (GFA) of two BMGs systems [121, 122].

\subsection{Fe-based BMGs by SLM}

\subsubsection{Parameters of SLM}

Amorphous alloys possess much higher strength and hardness, but relatively lower Young's modulus, compared with traditional crystalline materials [121]. Among all the BMG systems, Fe-based BMGs are a special family with the higher strength and hardness value. The elastic modulus is similar to that of traditional stainless steels but the strength and hardness are even 3-4 times higher than those of super high-strength steels [64]. Fe-based bulk metallic glass is the most widely used in industrial systems. In 2013, Pauly was the first to report that the Fe-based bulk metallic glass was formed by SLM technology, and the 3D scaffold structure was successfully manufactured [69]. Additive manufacturing of amorphous alloy powder by SLM requires the regulation of laser power, scanning speed, scanning distance, and powder thickness. These parameters affect two important standards of amorphous $3 \mathrm{D}$ printing production: formation and crystallization. Figure 1 is the cooling curve of Fe-based amorphous additive manufacturing demonstrated by Pauly. The cooling rate $R_{\mathrm{SLM}}$ of Fe-based amorphous in SLM process is much higher than its critical crystallization cooling rate $R_{\mathrm{C}}$ of Febased BMGs.

Although a higher cooling rate can inhibit crystallization, it is inevitable that high-speed cooling rate will lead to the instability of the molten pool, resulting in bad molding in SLM. Thus, inhibition of crystallization and the perfect formation tend to be two conflicting requirements in the process of amorphous alloy manufacturing. Many experimental studies show that the amorphous structures with good molding and high amorphous ratio can be obtained within a specific range of parameters for the BMGs studied.

A large number of experimental studies by Jung have shown that the laser scanning rate to form completed amorphous structure should not be higher than $2500 \mathrm{~mm} / \mathrm{s}$ [70].
When the laser scanning rate was too high, the powder particles cannot completely melt, resulting that many unmelted spherical particles can be observed in the internal metallograph. When the scanning rate was $1500 \mathrm{~mm} / \mathrm{s}$, the structure with a density of more than $99 \%$ can be obtained which is shown in Fig. 2 a. X-ray diffraction (XRD) test showed that the amorphous samples with few nanocrystals could be obtained. Wang set a record to make the size of $45 \mathrm{~mm} \times 20 \mathrm{~mm}$ block with $\mathrm{Fe}_{55} \mathrm{Cr}_{25} \mathrm{Mo}_{16} \mathrm{~B}_{2} \mathrm{C}_{2}$ bulk metallic glass, and amorphous samples with different parameters were also carried out [75]. The as-printed microstructure stays in a fully amorphous state, and good relative density has been realized. When the laser power was $100 \mathrm{~W}$ and the scanning rate was $300 \mathrm{~mm} / \mathrm{s}$ (at the red box in Fig. 2b), almost completely dense and completely amorphous samples are obtained. Compared with the research of Jung, the parameters such as power and scanning rate vary greatly. Considering the difference of powder and device, difference in parameters is acceptable. In the SLM process, the general energy density is determined by the formula $E=P /(V \times t \times h), P$ is the laser power, $v$ is the laser scanning speed, $t$ is the powder layer thickness, and $h$ is the scanning spacing distance. On the other hand, as the energy density increases and the heat input increases, the formation capacity of the printed sample will undoubtedly increase. The parameters are different according to the powder composition, particle size, sphericity, and even the difference of equipment. According to most studies, the reasonable energy density is in the range of $30-100 \mathrm{~J} / \mathrm{mm}^{3}[50,79,80$, 83-86]. Hofmann studied the effect of processing on the microstructure and properties of an $\mathrm{FeCrMoBC}$ glass-forming alloy through a variety of manufacturing parameters by SLM [74]. In this study, energy densities ranging from 20 to $300 \mathrm{~J} / \mathrm{mm}^{3}$ were used and high energy density resulted in overmelted parts that would crack during solidification and low energy density resulted in loosely sintered parts. A single composition, fully amorphous powder feedstock, can be used to create an assortment of phases and microstructures in a single print: from fully amorphous to dendrite-reinforced metal matrix composite to fully crystalline.

\subsubsection{Crystallization in SLM}

Thus, the GFA of BMG powders are significantly lower compared to high-purity cast material [123]. SLM process parameters need to be carefully balanced to avoid crystallization while securing sufficient densification of the fabricated BMGs [97]. Wang pointed out that although the temperature in the heat-affected region can be higher than $\mathrm{Tg}$, the corresponding time window/life of the high-temperature period is quite short, about $0.8 \mathrm{~ms}$ [75]. Crystallization is theoretically possible during this time, but in practice, an incubation period of about $1.87 \mathrm{~ms}$ is required. In this case, nucleation cannot be completed, and the amorphous structure still existed due to 


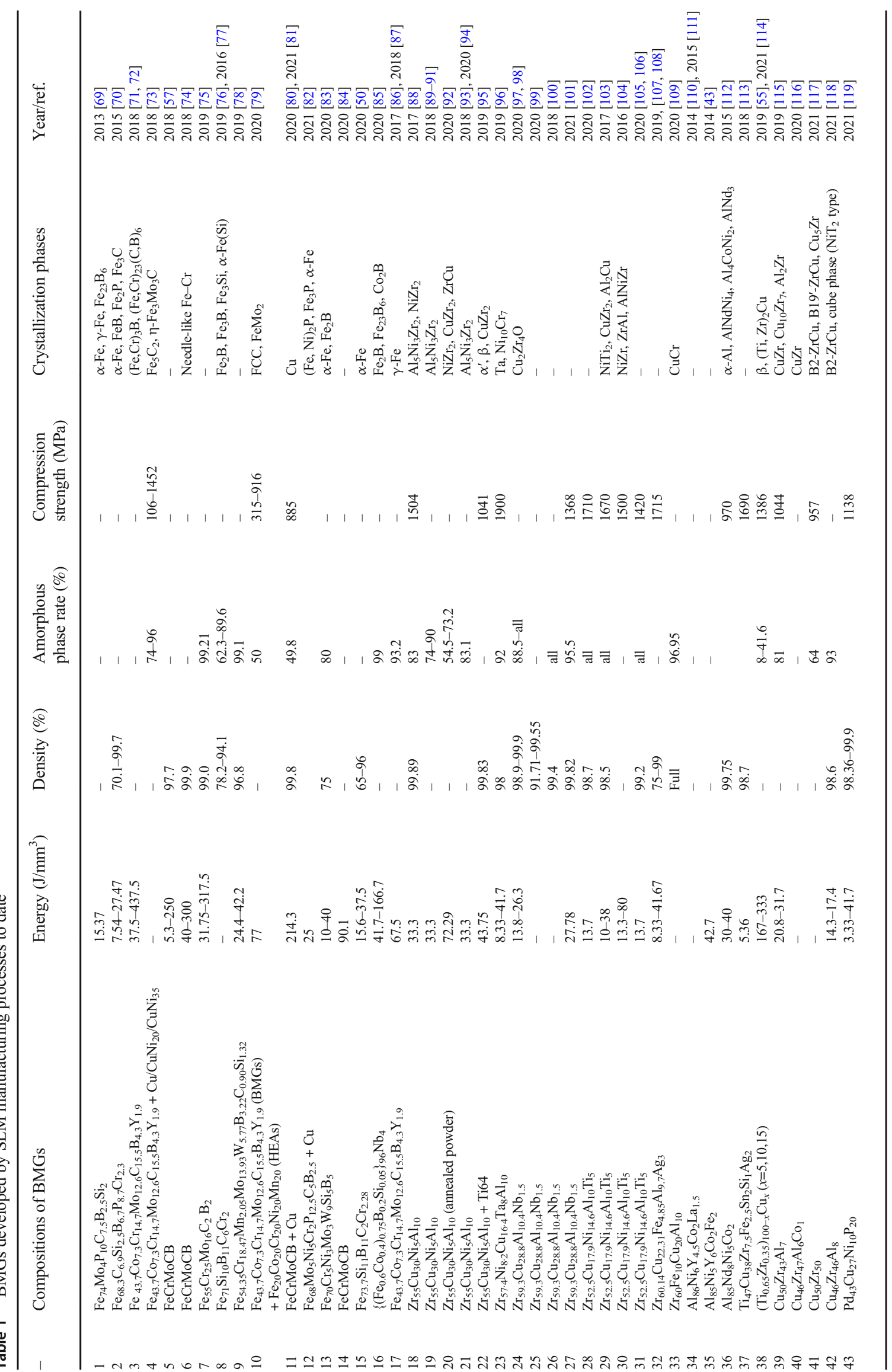




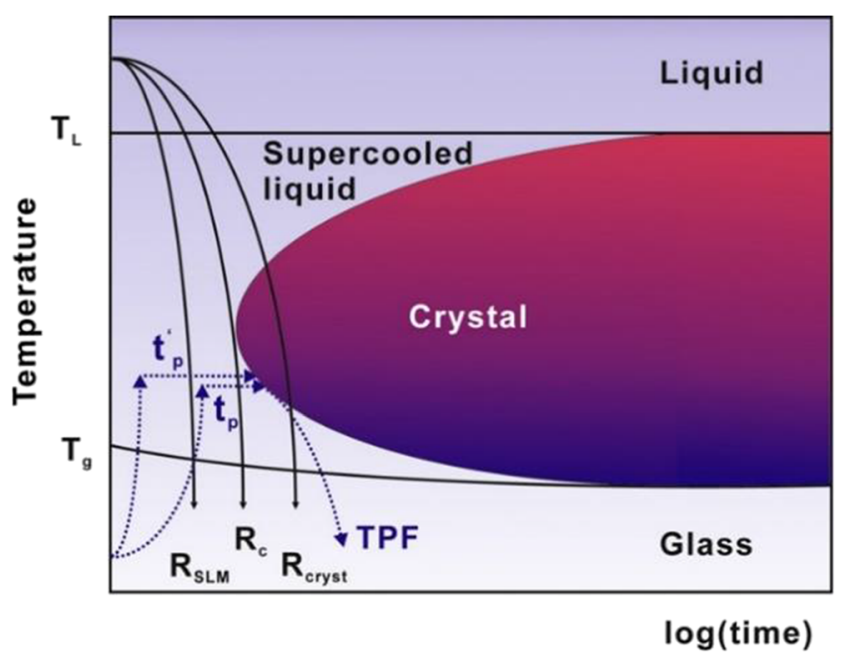

Fig. 1 CCT of Fe-based bulk metallic glass [69]

kinetic factors. It was clarified that the lifetime of the molten pool is at the millisecond scale, corresponding to a rapid cooling rate of $\sim 1.38 \times 106 \mathrm{~K} / \mathrm{s}$. During printing, other locations of the sample experience either low temperatures $(<\mathrm{Tg})$ or very short exposure time to high heat input, therefore avoiding crystallization due to thermodynamic and/or kinetic reasons and ensuring an amorphous structure across the whole as-printed sample. Mahbooba used electron back scatter diffraction (EBSD) method (shown in Fig. 3) to detect smaller grains in microstructures because EBSD has a higher resolution than XRD. EBSD analysis showed that there were clusters of nanoparticles with low concentration [57]. Temperature, contamination, and mechanical stress are the main causes driving the nucleation of metallic glass [124]. Prolonged thermal exposure and thermal cycling during SLM may be the cause of nanocrystalline nucleation in his work. EBSD analysis showed that the nano-grains existed only in localized clusters in the whole cylinder. However, grain nucleation due to hot annealing usually shows uniform distribution [125].

In addition, although the heat flow in AM is directional, the nanoparticles are relatively equiaxial. Based on the localized and equiaxial nanocrystals, thermal annealing is unlikely to provide energy for grain nucleation. Alternatively, nucleation may be the result of oxygen contamination and mechanical stress. Oxygen can promote the formation of metastable quasicrystal which has lower activation energy than the competitive primary phase $[126,127]$. However, information about the role of oxygen in Fe-BMGs is limited. Li reported that the GFA in FeMoCSiBP BMG was improved when oxygen addition was 0.02 to $0.15 \%$ [64]. It has been speculated that the critical level of oxygen lowers the liquidus temperature and inhibits the precipitation of primary phase. FeNiPC BMG has been reported to have similar results, with oxygen up to $0.0252 \%$ improving thermal stability without causing crystallization [128]. Interestingly, the composition of the alloy affects the oxygen content; in addition to the process elements, Zhang observed the top surface morphology of SLM Fe-based amorphous on stainless steel and found that some light gray sediments formed and tend to be distributed along the pool in the powder bed [87]. It was suggested that yttrium first reacts with oxygen during the melting of the amorphous alloy in the SLM process. Yttrium has a strong deoxidation capacity and yttrium oxide was easily formed, so the low gravity oxide will be pushed away and distributed along the molten pool. It was found that oxygen could be extracted with the aid of element $\mathrm{Y}$ to produce low-density oxides that floated onto the surface of metal parts. The conclusion is that adding appropriate elements can realize the purification of impurities in the SLM process and use in metal materials. Based on the localized and equiaxial nature of the nanograins in the SLM of FeCrMoCB alloy, it is unlikely that thermal annealing during DMLS processing provided the energy for grain nucleation [57]. A low concentration of nano-grains was exposed within the BMG microstructure.

\subsubsection{Defects in SLM}

Cracks Cracks are one of the main defects in the process of preparing amorphous alloys by SLM. To ensure a high cooling rate, a big scanning rate is bound to cause the instability of the molten pool. Rapid cooling makes the internal stress cannot be released and cracks are easily generated. Wei thinks that the microcracks are mainly caused by the huge thermal stress concentration around the micropores formed in the SLM process [72]. The thermal stress concentration is more serious around the micropores between the molten pool and the heat-affected zone. However, the reduction of the amorphous rate may be the cost of improving the crack simply by the process parameters. Similar results were obtained on SLM of $\mathrm{Fe}_{43.7} \mathrm{Co}_{7.3} \mathrm{Cr}_{14.7} \mathrm{Mo}_{12.6} \mathrm{C}_{15.5} \mathrm{~B}_{4.3} \mathrm{Y}_{1.9}$ (at.\%) BMGs [86]. Due to the brittleness of Fe-based metallic glasses, there are many crisscross cracks. The tendency of cracks can be reduced by adjusting the parameters, but it is difficult to completely avoid them. Many scholars consider methods other than process parameters to reduce cracks. Laser heat treatment can reduce the thermal gradient between the molten material and the solidified material, so it can promote in situ stress release. The laser scanning pattern determines the temperature distribution in the top layer of the SLM manufacturing material. Zou used the checkerboard strategy instead of the traditional scanning strategy to reduce residual stress to $29 \%$

Fig. 2 Fe-based BMGs fabricated by SLM. a Density of $\mathrm{Fe}_{68.3} \mathrm{C}_{6.9} \mathrm{Si}_{2.5} \mathrm{~B}_{6.7} \mathrm{P}_{8.7} \mathrm{Cr}_{2.3} \mathrm{Mo}_{2.5} \mathrm{Al}_{2.1}$ by SLM in different parameters [70]; $\mathbf{b}$ density of $\mathrm{Fe}_{55} \mathrm{Cr}_{25} \mathrm{Mo}_{16} \mathrm{~B}_{2} \mathrm{C}_{2}$ by SLM in different parameters [75]; c amorphous content by SLM with different energy densities [71]; d images and processing parameters for $\mathrm{FeCrMoBC}$ BMGs trial build trays by SLM [74] 


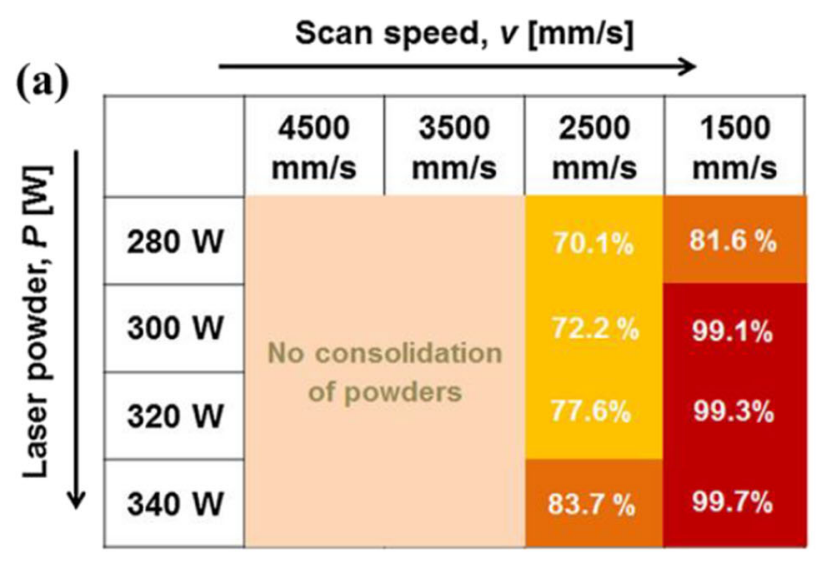

(c)

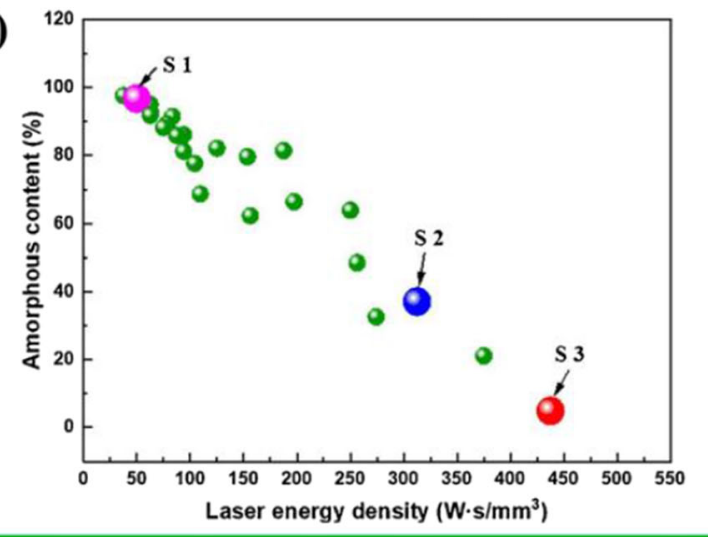

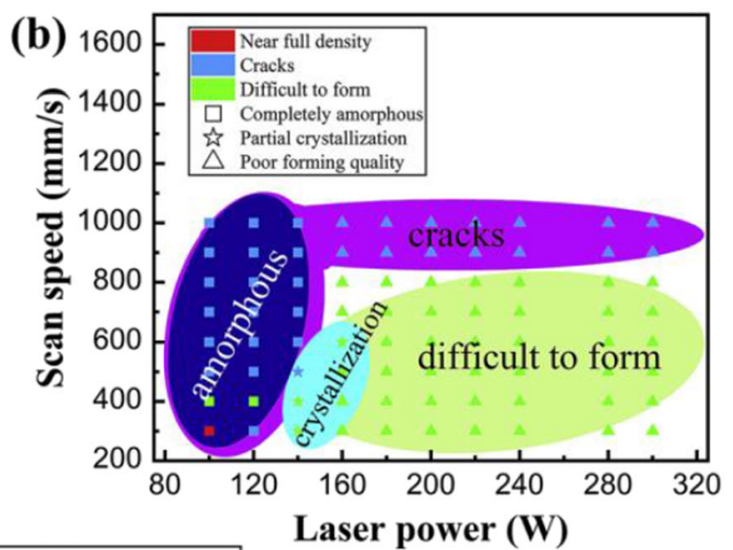

Laser power (W) (d)

Single exposure

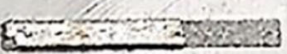

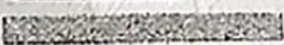
Pand

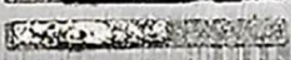

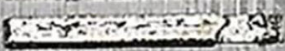

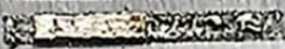

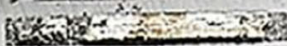

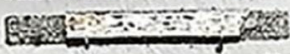

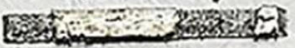

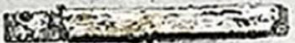
(9ox) $-2=-2$

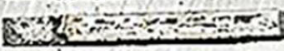
Has Wrot

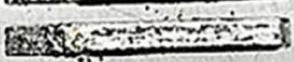

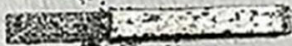
52018 $\mathrm{Q}=5$

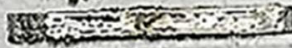

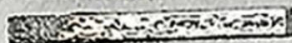

$1 / 2$ double $\& 1 / 2$ triple exposure

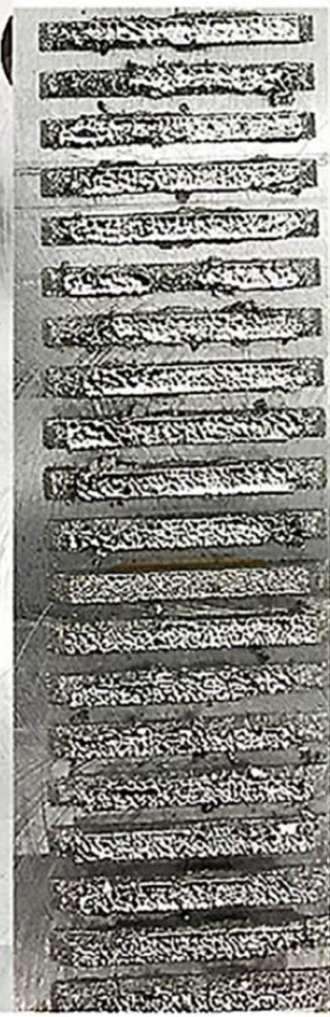

\begin{tabular}{|c|c|c|c|}
\hline $\begin{array}{l}\text { Scan Speed } \\
\text { Left Column } \\
(\mathrm{mm} / \mathrm{s})\end{array}$ & $\begin{array}{c}\text { Scan Speed } \\
\text { Right Column } \\
(\mathrm{mm} / \mathrm{s})\end{array}$ & $\begin{array}{l}\text { Energy Density } \\
\text { Left Column } \\
\left(\mathrm{J} / \mathrm{mm}^{3}\right)\end{array}$ & $\begin{array}{c}\text { Energy Density } \\
\text { Right Column } \\
\left(\mathrm{J} / \mathrm{mm}^{3}\right)\end{array}$ \\
\hline 1400 & 3360 & 95 & 79 \\
\hline 1435 & 3430 & 93 & 78 \\
\hline 1470 & 3500 & 91 & 76 \\
\hline 1505 & 3570 & 89 & 75 \\
\hline 1540 & 3640 & 87 & 73 \\
\hline 1575 & 3710 & 85 & 72 \\
\hline 1610 & 3780 & 83 & 71 \\
\hline 1645 & 3850 & 81 & 69 \\
\hline 1680 & 3920 & 79 & 68 \\
\hline 1715 & 3990 & 78 & 67 \\
\hline 1750 & 5040 & 76 & 79 \\
\hline 1785 & 5145 & 75 & 78 \\
\hline 1820 & 5250 & 73 & 76 \\
\hline 1855 & 5355 & 72 & 75 \\
\hline 1890 & 5460 & 71 & 73 \\
\hline 1925 & 5565 & 69 & 72 \\
\hline 1960 & 5670 & 68 & 71 \\
\hline 1995 & 5775 & 67 & 69 \\
\hline 2030 & 5880 & 66 & 68 \\
\hline 2065 & 5985 & 65 & 67 \\
\hline
\end{tabular}


Fig. 3 Grain cluster in the bulk cylinder: EBSD micrograph collected at a nano-grain cluster in the $\mathrm{FeCrMoCB}$ bulk cylinder [57]. a, b Offset scanning from the outside of the sample to its center; $\mathbf{c}, \mathbf{d}$ chess board scanning; e, f unidirectional vectors, which were rotated by $90^{\circ}$ in superposed layers

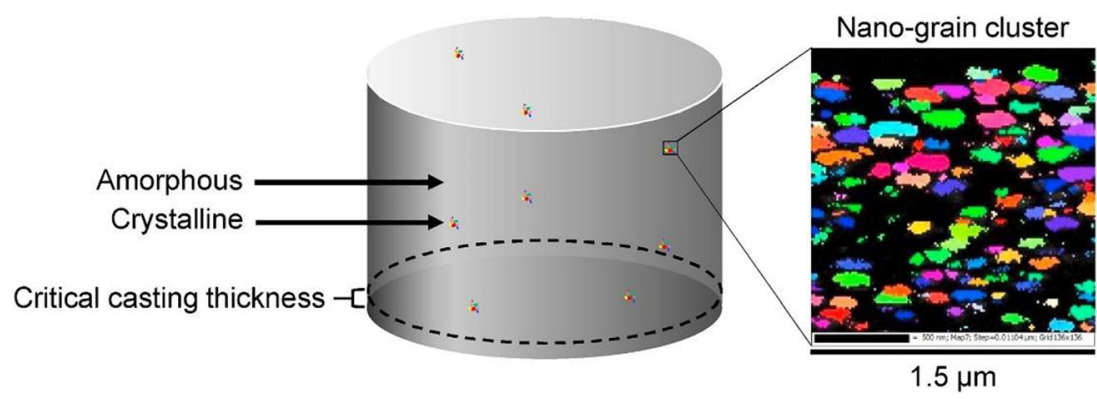

[84]. When the checkerboard scanning strategy is implemented, the long scan vector is replaced by the rotating short scan vector. Thus, the direction of the heat flux as the laser rotates is tracked between successive layers. In this case, scan lines in each adjacent subregion are orthogonal, which reduces the thermal stress accumulation along a single direction and reduces partial residual stress along the scanning direction. In addition, as the scanning continues, the temperature gradient of the melt trajectory tends to be in a dynamic equilibrium state, and the thermal stress gradually decreases. At the same time, the scanned islands transfer heat to neighboring islands to achieve the effect of preheating, thereby reducing the temperature gradient. As a result, these laser trajectories gradually alter the residual stress field layer by layer to achieve a more uniform heat distribution. Subsequent laser remelting can heat the melted powder layer to a supercooled liquid region where residual stress can be eliminated by plastic flow [43]. Even better, Żrodowski used the Point-Random (P-R) strategy to improve the internal stress [76, 77]. During the first melting, the checkerboard strategy was used with 1-mm edge length and the laser power of $20 \mathrm{~W}$, exposure time $500 \mu \mathrm{s}$, point distance $100 \mu \mathrm{m}$, and hatch distance $100 \mu \mathrm{m}$. Within each checkboard, a standard alternating (with $90^{\circ}$ rotation) scanning strategy was applied. The second melting, that followed the first melting on every layer, was performed with the Point-

a
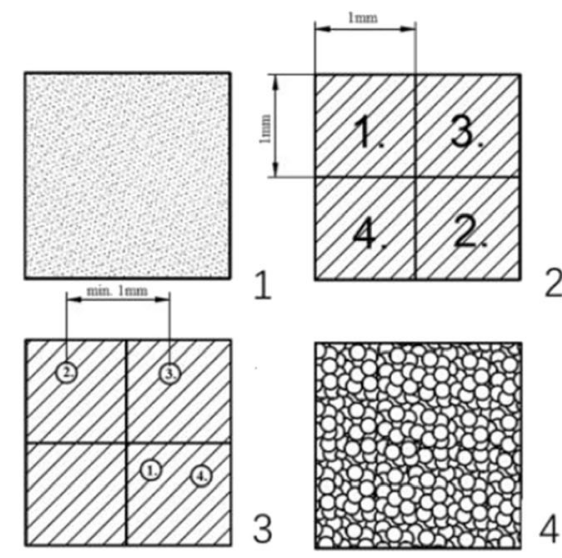

Fig. 4 Fabrication scheme of one layer of metallic glass with the chessboard scanning strategy. a P-R scanning strategy: (1) loose powder; (2) first melting of loose power with checkerboard strategy; (3) second melting of the previously melted layer by random pulses e numbers represent the melting order; (4) fully remelted layer after P-R
Random (P-R) strategy and maximum laser power $120 \mathrm{~W}$. Minimum distance between subsequent points, during the $\mathrm{P}$ $\mathrm{R}$ strategy, was set to $1 \mathrm{~mm}$. The scheme of the P-R strategy is shown in Fig. 4 a-d. For the SLM of FeSiBCCr alloys, the value of amorphization degree improved from 62.3 to $89.6 \%$ by optimizing the scanning strategy.

A double-scan strategy has been employed with the aim of amorphous phase fraction enhancement as well as densification [50]. Double scanning effectively fills voids generated due to partial melting of powders and leads to relative density of up to $96 \%$. More importantly, the double-scan strategy stimulates reflow in the melt pool, securing compositional uniformity, and eventually enhances amorphous phase fraction to a value as high as $47 \%$. Luo applied the snake-shaped line scanning in the $X-Y$ plane combined with alternatively $90^{\circ}$ altering between the adjacent layers [85]. When the regional energy density during SLM is reduced by reducing the laser power or increasing the scanning speed, a microstructure transition from crystallization to partial crystallization to almost completely amorphous state is observed.

In addition to the change in scanning strategy, other researchers have tried to reduce the cracks by adding a second particle. Both Li [73] and Zou [80] considered introducing second-phase particles to suppress the generation of cracks. However, to answer the role of $\mathrm{Cu}$ particles in inhibiting crack

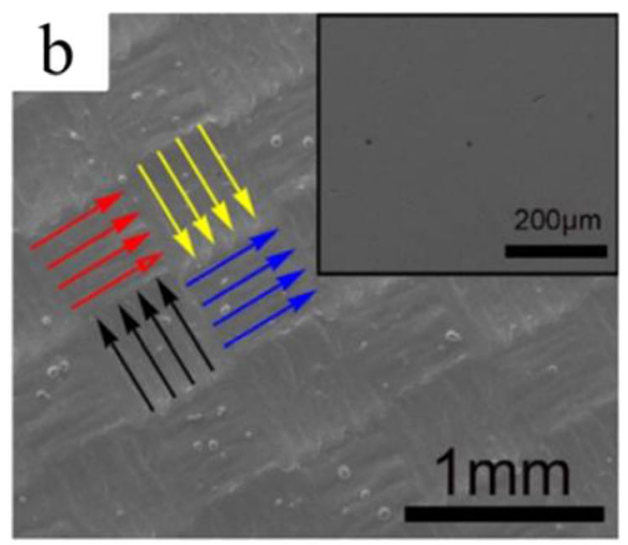

scanning strategy [76]; b scanning electron microscope (SEM) morphology of the SLM-fabricated samples: Chessboard scanning strategy with different chessboard length: C-600, $d=600 \mathrm{~mm}$; chessboard combined with laser re-melting [84] 
generation, the two have different explanations, which is based on their different views on the causes of crack generation. Zou believes that the reason for the crack is the accumulation of element $C$, while the addition of copper particles will strengthen the convection effect of Marangoni, which will accelerate the rearrangement rate, thus improving the particle distribution uniformity in the final solidification matrix and reducing the stress concentration. A crack-free sample can be obtained when $\mathrm{Cu}$ accounts for $40 \%$. Li believes that the high-density dislocations generated in $\mathrm{Cu}$ grain consume the thermal stress by releasing the strain energy, thus preventing the generation of micro cracks. Of course, there are also similarities between the two; the second-phase particles in the crystal have produced a high density dislocation.

Pores In addition to many cracks in the process of preparing iron-based metallic glass by SLM, pores are also one of the common defects. Porosity has been found in many studies on the preparation of iron-based metallic glasses [69-71, 85]. Because the amorphous has a high requirement for temperature cooling rate, the heat input is not enough to easily lead to porosity and incomplete melting. Mahbooba believes that density is not only related to processing parameters, but also to sample location [57]. The results showed that the density increased from 96.5 to $97.7 \%$ with the increase of sample height. On the one hand, the formation of pore is caused by the unmelted powder; on the other hand, the high-speed cooling rate during the SLM process makes the stomata difficult to overflow. The presence of pores also directly affects the density of the printed sample [57]. Both irregular and spherical pores can be obtained in the SLM parts [70, 78]. Irregularshaped pores are caused by insufficient molten metal filling the gap. The spherical pores are formed by the gas entrained in the atomized powder. Therefore, it was recommended to reduce the scanning speed and/or increase the laser power to eliminate these holes.

For the preparation of iron-based metallic glass by SLM, the existence of holes (including pores and pores) and cracks are the main forming problems faced by the preparation of large-size samples. Since the amorphous forming ability of iron-based metallic glass is inherently poor, it requires a larger cooling rate, that is, a faster scanning speed and a smaller heat input. The result is the lack of melt flow in the molten pool (prone to holes) and excessive internal stress caused by rapid cooling (prone to cracks) [72].

\subsection{Zr-based BMGs by SLM}

\subsubsection{Parameters of SLM}

Compared with iron-based amorphous, Zr-based amorphous alloys have better glass forming ability [129]. Therefore, although SLM technology was first used in the manufacture of iron-based amorphous, the research on Zr-based amorphous SLM is more extensive, according to the cooling conditions of Zr-based amorphous, as shown in Fig. 5. Because of the stability of zirconium atoms, the cooling conditions for the formation of Zr-based amorphous structure are less severe than that of Fe-based amorphous structure. On the one hand, this shows that the Zr-based amorphous alloy is not easy to crystallize; on the other hand, this reduces the difficulty of manufacturing. According to many studies [93, 97], the reasonable energy density range of SLM manufacturing Zr-based amorphous alloy is from 10 to $50 \mathrm{~J} / \mathrm{mm}^{3}$, in which, when the energy density is less than $20 \mathrm{~J} / \mathrm{mm}^{3}$, it is easier to form a completely amorphous structure [104].

Many studies have focused on improving crystallization and forming in addition to the process parameters. Wei [91] analyzed the residual stress of Zr-based amorphous alloy in the process of selective laser melting: (1) experimental and finite element simulation results show that, compared with $X$ and $Y$ strategies, the residual stress of $X Y$ cross-scanning strategy is relatively low, and the residual stress increases with the increase of bar thickness. On the other hand, residual stress can be adjusted by annealing or preheating the substrate. (2) Theoretical analysis shows that the $X Y$ cross-scanning method to reduce the thermal gradient and preheating the matrix can improve the uniform shrinkage during rapid cooling, thus reducing the residual stress. Multiple scans resulted in a more homogenous distribution of the constituent elements within the melt pool and therefore increased the amount of the amorphous phase. Single scan is likely to induce an unevenly distributed force which would cause elemental segregation to occur within the melt pool, which results in a very inhomogeneous and random distribution of the constituent elements. $\mathrm{Li}$ [104] used the one-way single scanning, two-way single scanning, and two-way double scanning, as shown in Fig. 6, and found that single scanning is easy to cause segregation of elements, while molten pool flow can exist for a long time

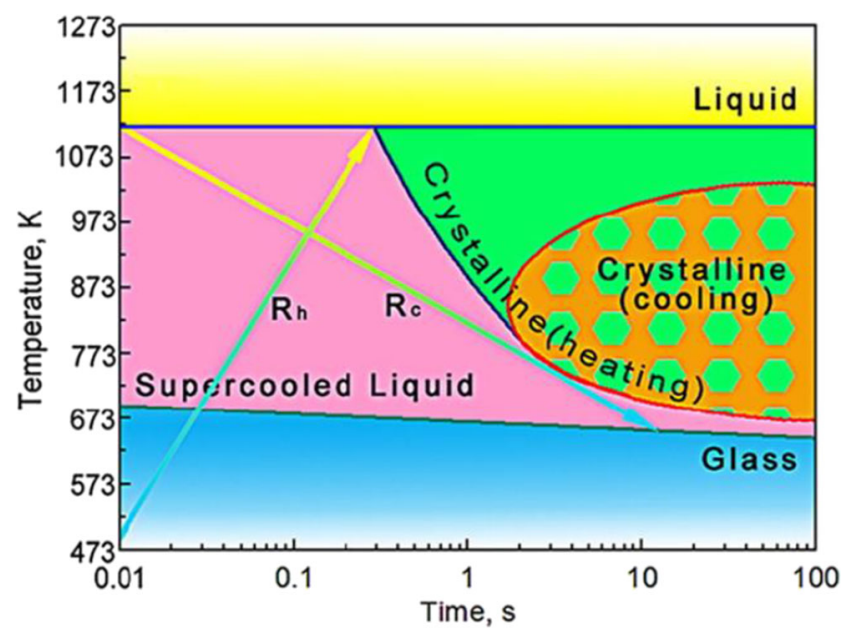

Fig. 5 Schematic diagram of Zr-based bulk metallic glass cooling [130] 
(a)

(b)

(c)

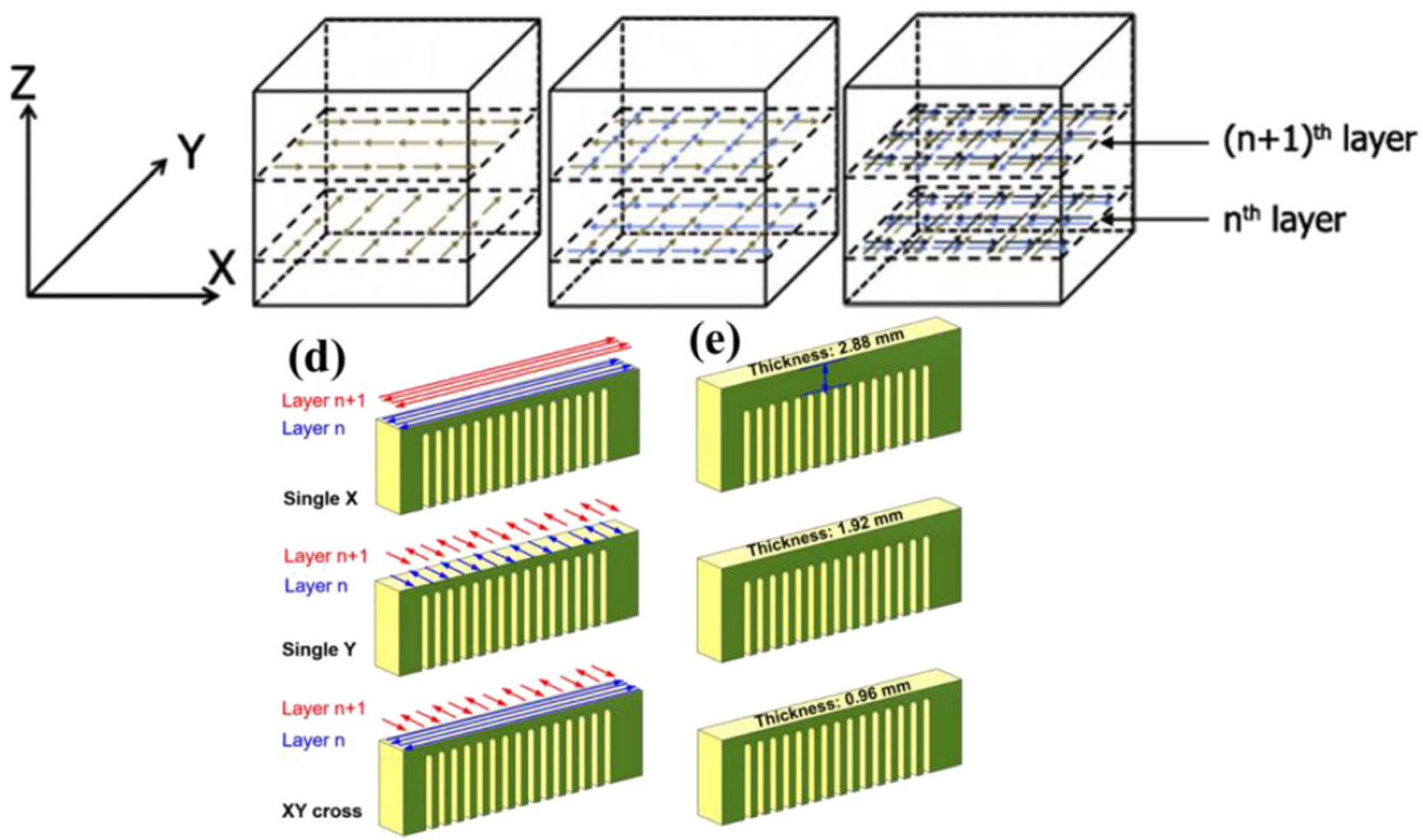

Fig. 6 Schematic diagram of different scanning strategies. (a) $X$ or $Y$, once; (b) $X$ and $Y$, once; and (c) $X$ and $Y$, twice [104]. (d) Laser scanning strategies; (e) bar thicknesses [91]

so as to improve the element distribution by multiple scanning, which makes it more even to get more amorphous structure. In contrast to single scan, multiple scans can result in an averaging of the melt flow and therefore a more homogenous distribution of the elements [104]. The method of using multiscanning to increase the amorphous rate is applicable to both iron-based and zirconium-based amorphous materials. However, whether the method of high energy density is beneficial to increase the amorphous rate remains to be verified.

\subsubsection{Crystallization in SLM}

Ouyang $[93,94]$ studied the heat treatment in Zr-based amorphous alloy SLM process. It was found that the toughness of the sample was strengthened, and the macroscopic performance was reduced after heat treatment. Due to the huge thermal stress during heat treatment, cracks are easy to form between the molten pool and the heat-affected area, which should be improved by controlling the reasonable cooling rate. In addition, structural heterogeneity was found between the molten pool and the heat-affected region, as shown in Fig. 7. It tends to be completely amorphous, and there are some crystalline phases in the heat-affected region, which is also proved by the differential scanning calorimetry (DSC) curve. Other peaks appear after the wider crystal peaks, while the different diffraction ring diameters of the amorphous phase indicate that the two amorphous phases are also different.

According to the high-resolution TEM observation of the microstructure after annealing, the microstructure in the molten pool is the clumps of very fine nanocrystals, and the mixture of fine nanocrystals and coarse crystals (the growth of the original nanocrystals) is in the heat-affected zone, which also proves the structural heterogeneity between the molten pool and the heat-affected zone. In fact, there is no difference in the phase transition temperature of alloys produced by different synthesis methods. The difference in phase transition temperature may be caused by the difference in nanocrystal and oxygen content. It was confirmed that the SLM sample had more supercooled liquid regions $\left(T_{x}-T_{g}\right)$ and the transition time was very short during the isothermal heat treatment, and the oxygen content in the SLM sample was high. It was found that the nanocrystallized particles were rich in aluminum and oxygen, as shown in Fig. 8. It was found that different metastable crystal phases appeared in the initial crystal phases of SLM and castings. This difference is caused by different oxygen levels. But with the disappearance of metastable state and the formation of thermodynamically stable phases $\mathrm{CuZr}_{2}$ and $\mathrm{Al}_{3} \mathrm{Zr}_{4}$ at high temperature, the final crystallization stage is similar. The results show that reheating of the consolidated material and higher oxygen content lead to the formation of 

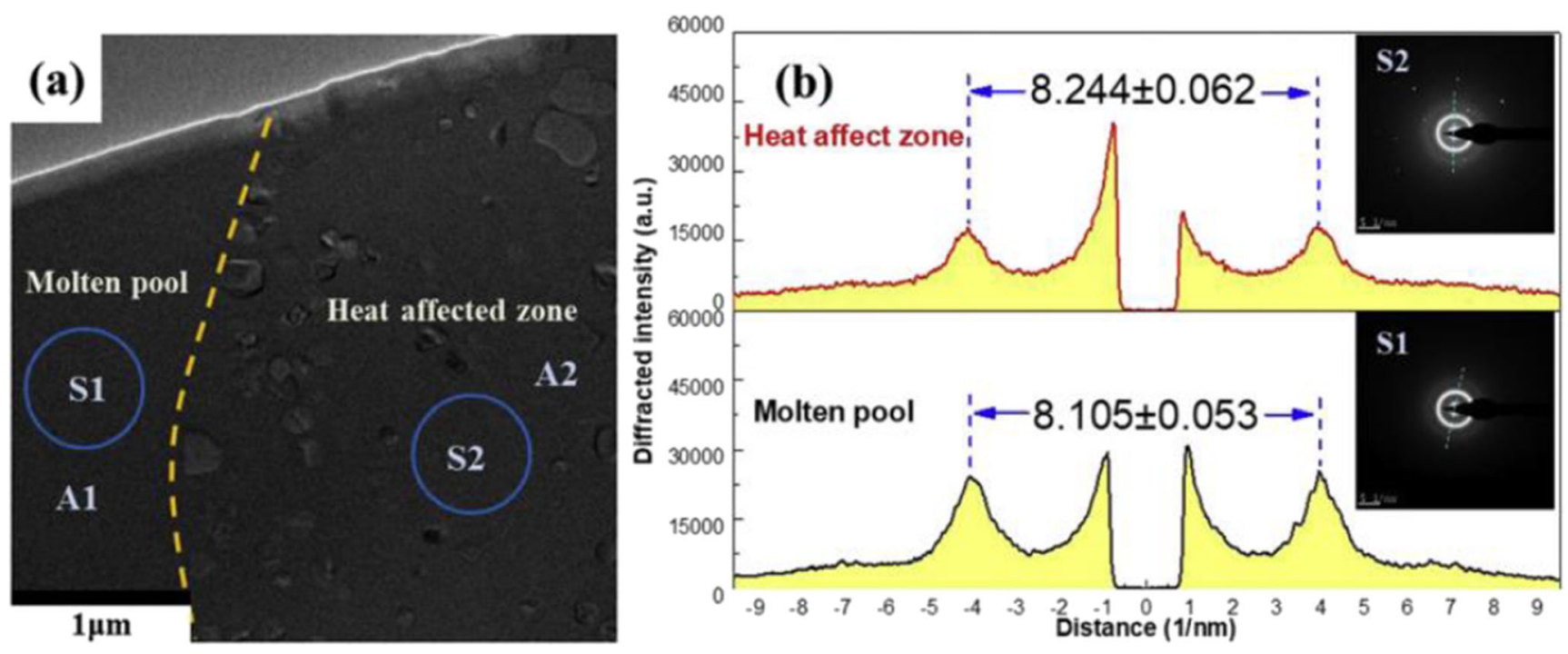

Fig. 7 a Transmission electron microscopy (TEM) bright-field image of HAZ and molten pool; $\mathbf{b}$ diffraction intensity distribution of electron diffraction pattern in molten pool and heat-affected region [93]

nanocrystals in the SLM component. This is because the density produced by SLM is lower than that of as-cast [131]. Ouyang studied two representative BMG alloys with different GFA, $\mathrm{Zr}_{55} \mathrm{Cu}_{30} \mathrm{Ni}_{5} \mathrm{Al}_{10}$ (named as $\mathrm{Zr} 55$ with high GFA), and $\mathrm{Zr}_{60.14} \mathrm{Cu}_{22.31} \mathrm{Fe}_{4.85} \mathrm{Al}_{9.7} \mathrm{Ag}_{3}$ (named as $\mathrm{ZrAg}$ with low GFA) metallic glass by SLM [132]. The results show that the 3Dprinted BMG with low GFA always has higher amorphous phase content than the BMG with high GFA. ZrAg BMG followed the mode of primary-type crystallization with multiple phase formation, leading to a low crystal growth rate, while Zr55 BMG follows the mode of polymorphous-type crystallization, which is characterized with formation of a simple crystalline phase, thus leading to a high crystal growth rate.

Zhang [92] studied the crystallization behavior of SLM Zr55 alloys samples with the powder under different annealing conditions. The XRD patterns and DSC curves of different Zr55 powders are shown in Fig. 9 a and b. As shown in Fig. 9 a, for the original powder and the powder after $600 \mathrm{~K}$ annealing treatment, a superposition of a typical broad halo peak and a specific set of weak peaks (mixing of amorphous matrix and $\mathrm{Al}_{5} \mathrm{Ni}_{3} \mathrm{Zr}_{2}$ phase) can be observed. When the annealing temperature is $800 \mathrm{k}$, severe crystallization will occur; in addition to the $\mathrm{Al}_{5} \mathrm{Ni}_{3} \mathrm{Zr}$ phase, $\mathrm{NiZr}_{2}, \mathrm{Al}_{2} \mathrm{Zr}_{3}$, and $\mathrm{Cu}_{10} \mathrm{Zr}_{7}$ phases are generated. During annealing at $1000 \mathrm{~K}$, the main crystallization peaks correspond to the $\mathrm{CuZr}_{2}$ phase and $\mathrm{Al}_{2} \mathrm{Zr}_{3}$ phase. This indicates that during the high temperature annealing process, the metastable phases of $\mathrm{NiZr}_{2}$ and $\mathrm{Cu}_{10} \mathrm{Zr}_{7}$ gradually decomposed and disappeared. They were replaced by the stable phases of $\mathrm{CuZr}_{2}$ and $\mathrm{Al}_{2} \mathrm{Zr}_{3}$. Figure $9 \mathrm{c}$ and $\mathrm{d}$ are the XRD diffraction patterns and DSC curves of SLM samples with different powder compositions. The X-ray diffraction patterns of all deposits are mainly composed of broad halo peaks and crystal diffraction peaks of different intensities shown in Fig. 9 c. Compared with the unannealed powder, the peak relative intensity of the $\mathrm{ZrCu}$ and $\mathrm{CuZr}_{2}$ crystals in the deposit prepared by the annealed powder decreased significantly, indicating that the volume fraction of the crystals decreased accordingly. The remelting zone (upper left corner or upper right corner of Fig. 10) shows a featureless structure, which can remain amorphous. It should be noted that the majority of deposits and dendrites are made of unannealed powder (Fig. 10), except for the size of the annealed powder (Fig. 10f, h), which indicates that more serious crystallization from unannealed powder. The influence of three different shielding gases $\left(\mathrm{N}_{2}, \mathrm{Ar}\right.$, and $\left.\mathrm{Ar}_{98} \mathrm{H}_{2}\right)$ on the SLM process and the resulting structural, mechanical, and thermophysical properties of $\mathrm{Zr}_{59.3} \mathrm{Cu}_{28.8} \mathrm{Al}_{10.4} \mathrm{Nb}_{1.5}$ were investigated by Wegner [98]. Applying high-purity $\mathrm{Ar}$ as shielding gas led to fully amorphous processing with a relative density of $99.8 \%$. The usage of $\mathrm{N}_{2}$-shielding gas led to a reduction of the processable parameter range accompanied by severe cracking and crystallization. Despite a similar impurity as the applied $\mathrm{N}_{2}$, the introduced $\mathrm{Ar}_{98} \mathrm{H}_{2}$ as shielding gas led to comparable results as Ar. Introducing hydrogen as a reducing element, therefore, appears as a promising approach to reduce the influence of oxygen impurities in the introduced gases. In the recent study carried out by Wegner, the influence of different oxygen contents, partial crystallinity, and the usage of flow-aid in the feedstock of the commercially available gas atomized $\mathrm{Zr}$ based BMG-forming alloy AMZ4 during SLM was investigated [133]. It should be emphasized that the laser-induced melting in the SLM process is sufficient to eliminate the thermal history and preexisting crystals in the powder feedstock. Therefore, the originally introduced method of widening the grain size distribution for fluidity can be used as a promising technique to improve machinability. However, increasing the size distribution range is at the expense of the attainable surface quality, so further optimization is needed. The detrimental 


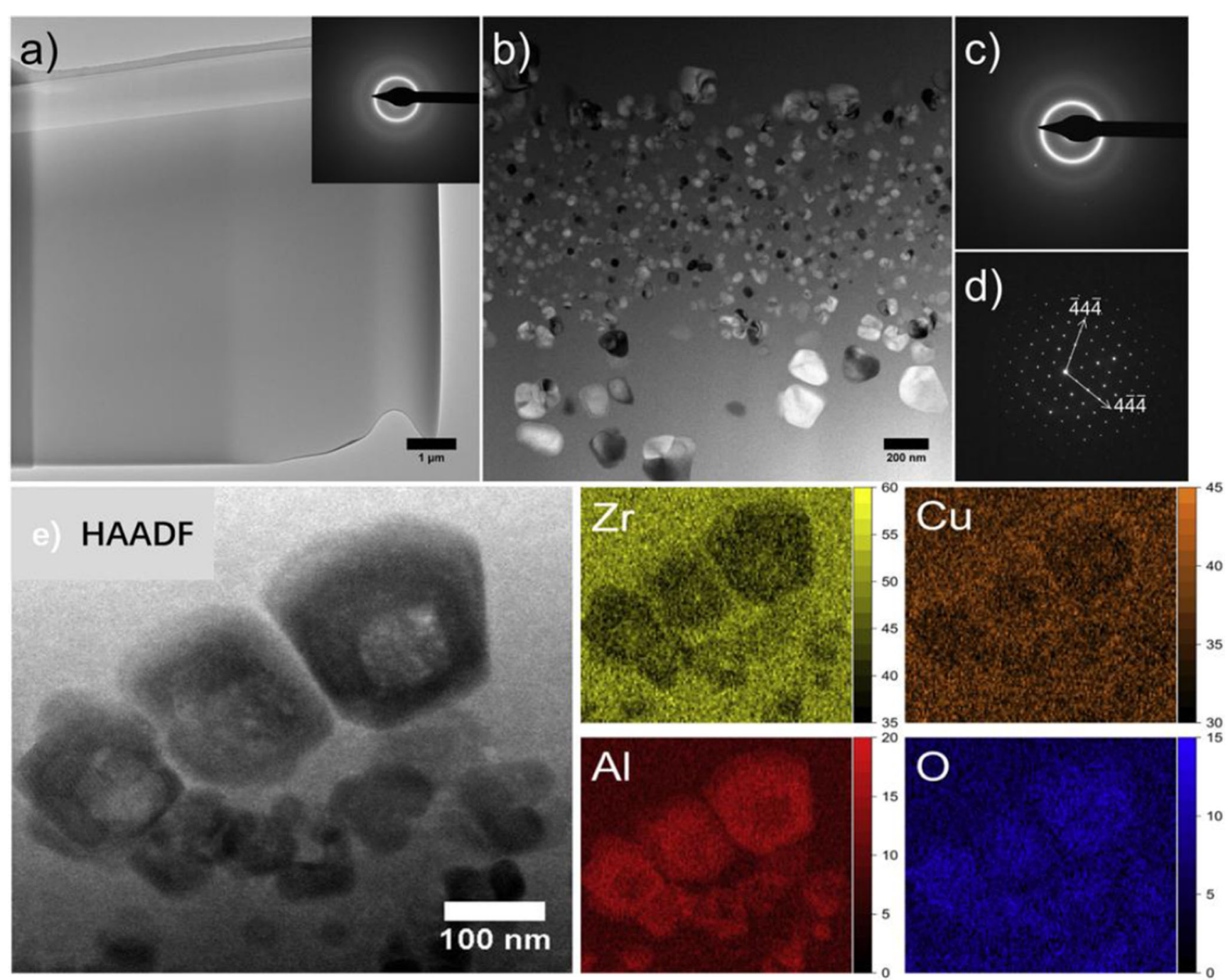

Fig. 8 (a) TEM image of the cast sample with a selected area electron diffraction (SAED) pattern shown in the inset. (b) BF TEM image of the SLM sample, showing presence of crystalline particles in an amorphous matrix. (c, d) The SAED patterns for the amorphous matrix and a particle indexed to the $\mathrm{Cu}_{2} \mathrm{Zr}_{4} \mathrm{O}$ phase oriented in the zone axis. (e) $\mathrm{Z}$-contrast

effect of oxygen on the GFA is reflected by a reduction of the applicable parameter range for amorphous processing. A detailed study on $\mathrm{Zr}_{59.3} \mathrm{Cu}_{28.8} \mathrm{Al}_{10.4} \mathrm{Nb}_{1.5}$ was carried out by Sohrabi [101]. Nanocrystals were detected in the heat-affected zones (HAZs) close to the melt-pool boundary. The incubation time at temperatures close to the melting point is very short, but that cooling was not fast enough to avoid any crystallization. Meticulous characterization via synchrotron experiments and electron microscopy was required to observe the nanocrystals, which may not be detectable via laboratory XRD. A benchmark was printed and showed excellent geometrical accuracy with deviations of only $5-40 \mu \mathrm{m}$ after sandblasting. The various results show that SLM is a great choice for the fabrication of complex BMG parts, with no required post-processing steps except for surface finishing. Ericsson fitted the scattering data to a spherical particle model and it revealed a higher number density
(HAADF) image of the crystalline particles in the SLM sample and corresponding distribution of $\mathrm{Zr}, \mathrm{Cu}, \mathrm{Al}$, and $\mathrm{O}$ measured by energydispersive X-ray spectroscopy (EDS). The scale shows the atomic percentage for each element [131]

of particles and smaller average particle size in the SLM processed $\mathrm{Zr}_{59.3} \mathrm{Cu}_{28.8} \mathrm{Al}_{10.4} \mathrm{Nb}_{1.5}$ material [134]. The high density of particles is due to the increased oxygen content of the material during SLM processing, which reduces the energy barrier of nucleation.

\subsubsection{Defects in SLM}

Cracks For the preparation of zirconium-based metallic glass by SLM, since the amorphous-forming ability of zirconium-based metallic glass is much stronger than that of iron-based metallic glass, the required cooling rate is much lower. The process parameter window of SLM is also wider. In many research literatures, printed samples of zirconium-based metallic glass without cracks have been successfully prepared $[88,103,104]$. 

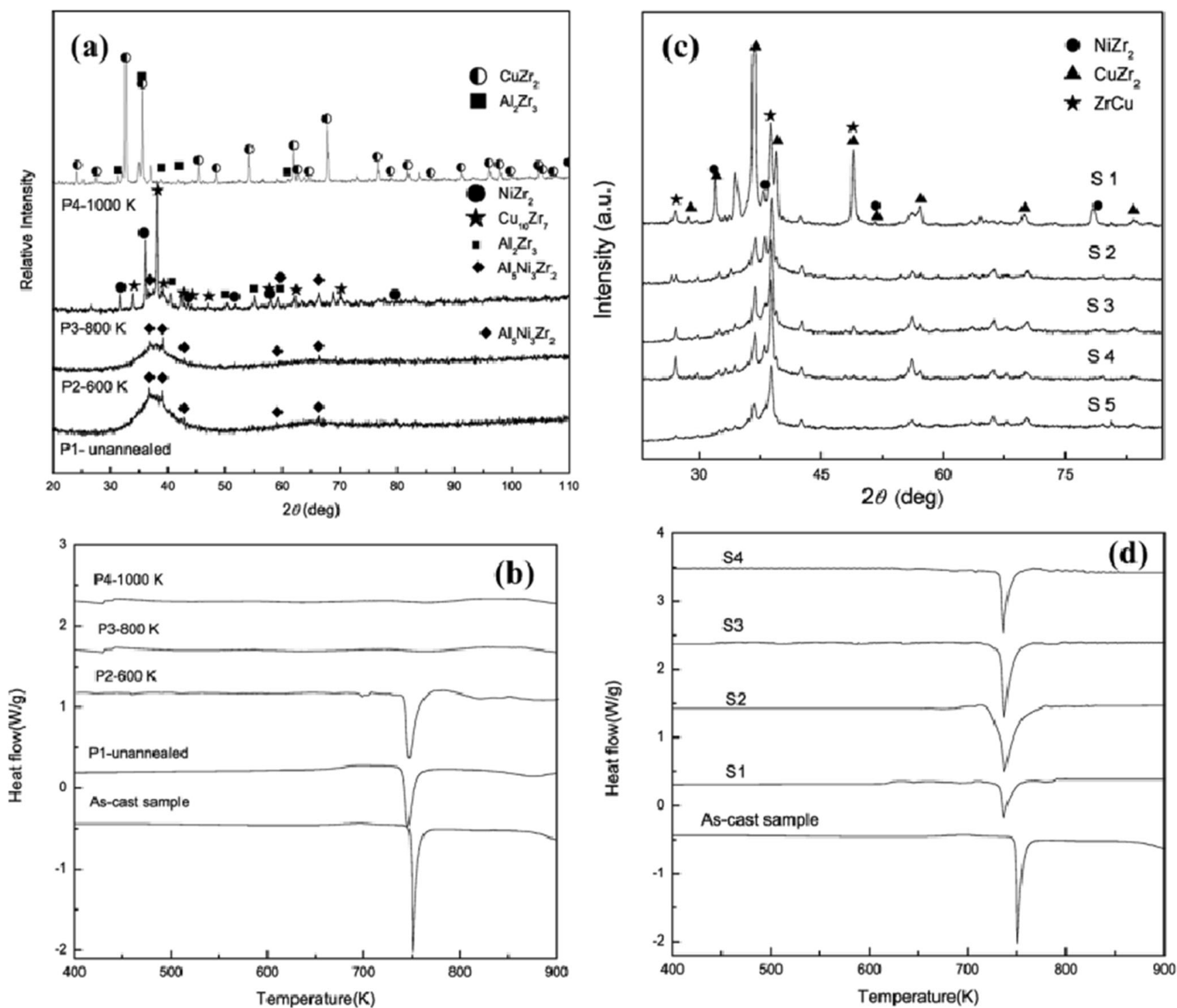

Fig. 9 XRD patterns (a) and DSC curves (b) of Zr55 original unannealed powders and the powders annealed at different temperatures. XRD patterns (c) and DSC curves (d) of Zr55 deposited layers [92]

High stress can cause cracking, delamination, deformation, and fatigue failure of 3D-printed parts, especially for these amorphous alloys with inherent brittleness and low fracture toughness [91]. However, some studies have also found that cracks also appear when zirconium-based bulk metallic glasses prepared by SLM [109]. $\mathrm{Zr}_{60} \mathrm{Fe}_{10} \mathrm{Cu}_{20} \mathrm{Al}_{10}$ BMG was prepared by selective laser melting technology, and the laser parameters used to manufacture fully dense amorphous samples can be obtained. The results showed that BMG had a good deformability in the micro-compression test. However, if the heat input is too low or the laser irradiation time is too short, it will cause cracks. It should be noted that if the energy input is too high, recrystallization may occur, which will cause microcracks and ultimately reduce the mechanical properties of the 3D-printed BMG samples [108]. For $\mathrm{Zr}_{59.3} \mathrm{Cu}_{28.8} \mathrm{Al}_{10.4} \mathrm{Nb}_{1.5}$ metallic glass, different protective gases have slightly different effects on cracks. When using nitrogen as a protective gas, not only more cracks were found, but also severe crystallization occurred. When argon and mixed gas $(98 \%$ argon $+2 \%$ hydrogen) were used, the number of cracks was greatly reduced [98].

Compared with traditional smelting processing methods, the rapid solidification and repeated heating in the SLM manufacturing process endow the alloys manufactured by SLM with unique characteristics [135]. Rapid solidification promotes the formation of amorphous alloys, but the rapid cooling process will cause the stress in the alloy to increase greatly, leading to the formation of micro-cracks [136]. In the past years, many scholars all over the world took various measures to overcome the crack defect in the SLM of BMGs as heat treatment [94], optimizing scanning strategy [91, 104], decreasing the heat input [103], changing the oxygen content [131], compositing the plastic materials into alloys [96], designing lattice structures [137], and so on. 

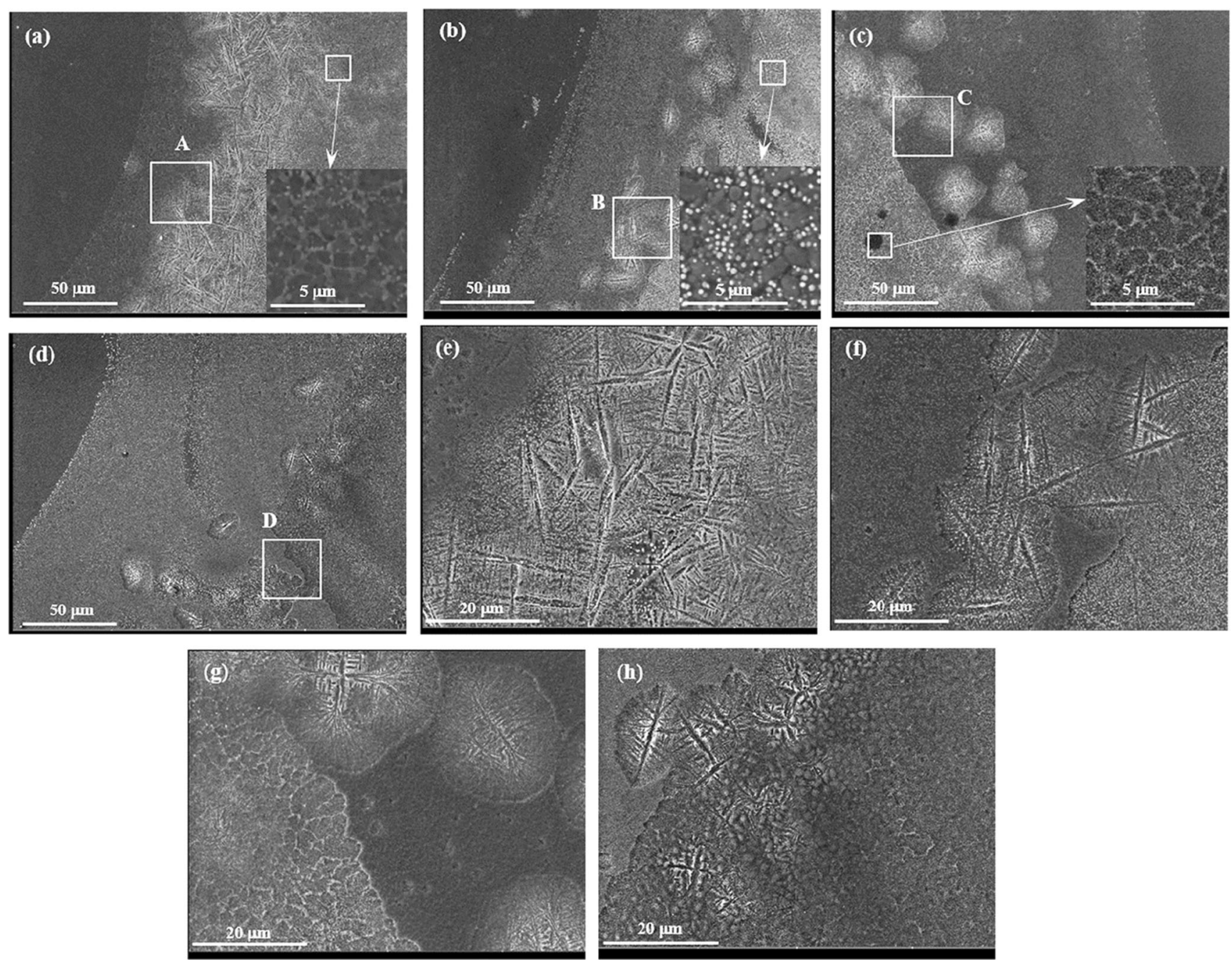

Fig. 10 SEM images of crystalline zone between the adjacent tracks in Zr55 deposits: a S1; b S2; c S3; d S4; magnification of region A (e), region B (f), region $\mathrm{C}(\mathbf{g})$, and region $\mathrm{D}(\mathbf{h})[92]$

Pores The Archimedes drainage method is generally used to measure the density of 3D-printed samples, but the surface of the printed samples is generally rough, and this roughness will capture small bubbles, thereby reducing the overall density. X-ray tomography (XRT) is a good choice to test the density of SLM samples. Ouyang [88] and Pauly [103] used XRT to measure the density of SLM parts, and the obtained density was higher than the Archimedes method. Most studies believe that density depends mainly on energy density. Pauly found that although process parameters largely determine density, optimizing different scanning strategies (such as fill scanning, checkerboard scanning, and unidirectional vector scanning) can also increase sample density, as shown in Fig. 11. According to the result of XRT, mainly small pores are detected and the few, larger defects are mainly found in the center of the rod. The analysis of the reconstruction results in a relative density of $99.8 \%$, which is higher than measured by the Archimedean density measurement (98.5\%) [103]. Interestingly, the chessboard strategy, which divided the cross-section into nine chessboard squares, does not reflect in the pore distribution [103]. It rather appears that the pores concentrate either at the margins or at the center of every melt track. Even though the energy density is almost identical in sample, using unidirectional scanning vectors that were rotated by $90^{\circ}$ in neighboring layers, the porosity in this sample is less and the distribution of pores more random. A possible explanation is the higher laser power employed to produce the sample.

A non-destructive high-resolution X-ray micro-computed tomography (micro-CT) technique was applied to evaluate the inner 3D pore structure by Shi [99]. The printed amorphous parts can reach a total volumetric porosity as small as $0.45 \%$. The distribution of pore size and pore sphericity were evaluated for the PBF-processed BMG samples with different porosities, where two observed pore features were irregular large lack-of-fusion pores, and smaller gas-induced round pores. It can be seen in Fig. 12 that neither the pore size nor the pore shape is uniform in the tested samples in both two and three 

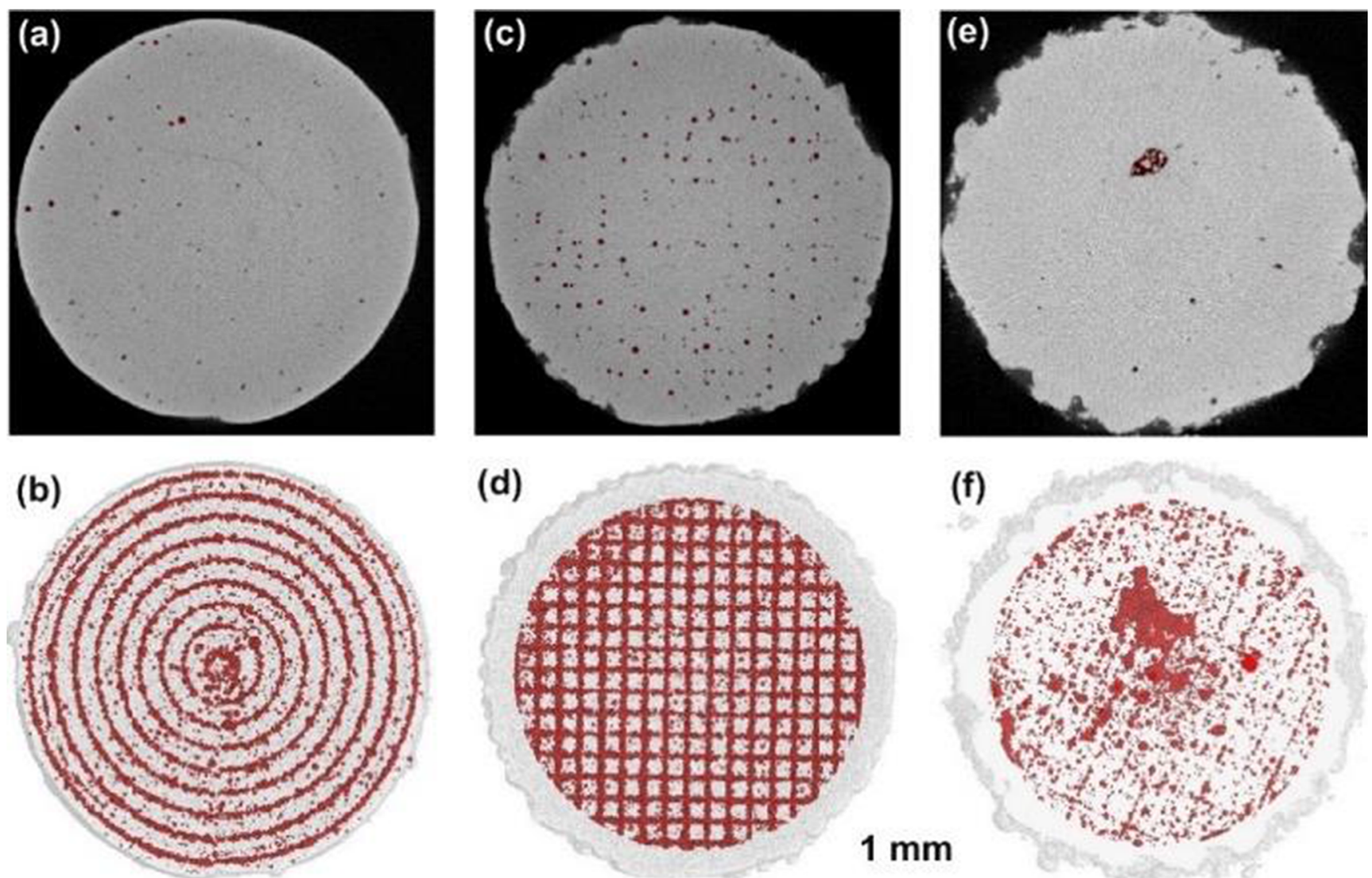

(f)

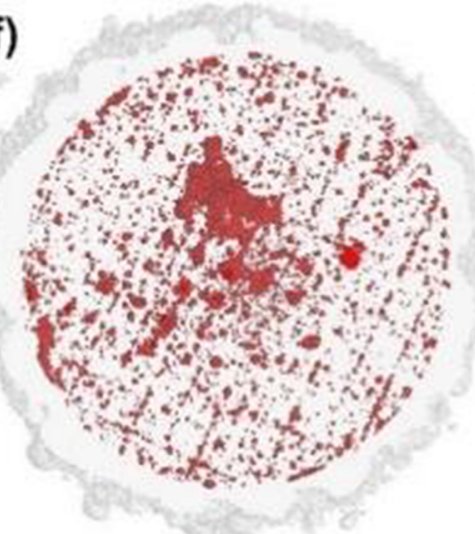

Fig. 11 Stomatal distribution of different scanning strategies [103]. (a, b) Offset scanning from the outside of the sample to its center. (c, d) Chess board scanning. (e, f) Unidirectional vectors, which were rotated by $90^{\circ}$ in superposed layers

dimensions. For all samples, more than $95 \%$ of the holes identified above are less than $100 \mu \mathrm{m}$, which is similar to the results of Williams [138] and Maskery [139]. Marattukalam [97] also believed that the energy density increased after the statistics of Zr-based amorphous 3D printing products, and the number of pore diameters was smaller and the sphericity was higher. Ouyang [108] studied the influence of energy density on defect evolution in SLM of $\mathrm{Zr}_{60.14} \mathrm{Cu}_{22.31} \mathrm{Fe}_{4.85} \mathrm{Al}_{9.7} \mathrm{Ag}_{3}$ alloys. The results show that insufficient energy input led to the formation of balling due to incomplete melting of particles, while modest energy densities could reduce balling, but produced large-size open pores and interlayer pores appeared instead owing to incomplete re-melting and insufficient filling between neighboring layers. When an appropriate energy density is applied (i.e., over $20.83 \mathrm{~J} / \mathrm{mm}^{3}$ ), only small-sized metallurgical pores exist, which are due to gases escaping out of the molten pool during melt consolidation. Deng [102] considered that when the defect exhibited spherical geometry, it
Fig. $123 \mathrm{D}$ pore morphology and space distribution of a Zr-based additively manufactured BMG [99]. a Sample $1(3000 \mu \mathrm{m} \times$ $2000 \mu \mathrm{m} \times 268 \mu \mathrm{m}) ;$ b sample 2 $(3000 \mu \mathrm{m} \times 2000 \mu \mathrm{m} \times 215 \mu \mathrm{m})$; c sample $3(3000 \mu \mathrm{m} \times 2000 \mu \mathrm{m}$ $\times 277 \mu \mathrm{m})$; d sample $4(3000 \mu \mathrm{m}$ $\times 2000 \mu \mathrm{m} \times 206 \mu \mathrm{m})$. The colors facilitate the visualization only. (for interpretation of the references to color in this figure legend, the reader is referred to the web version of this article) (a)

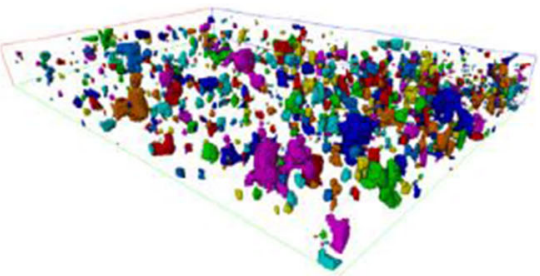

(c)

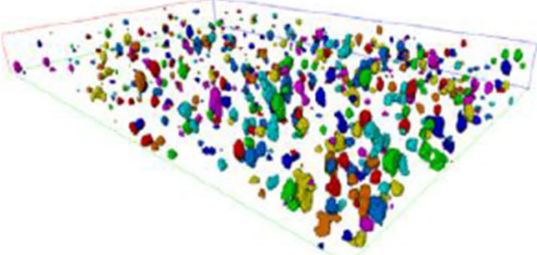

(b)

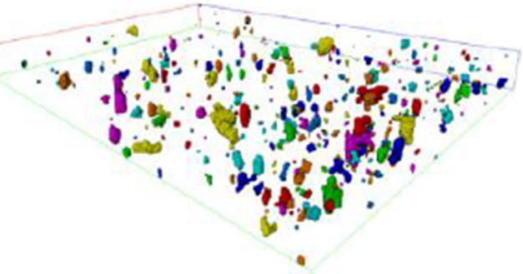

(d)

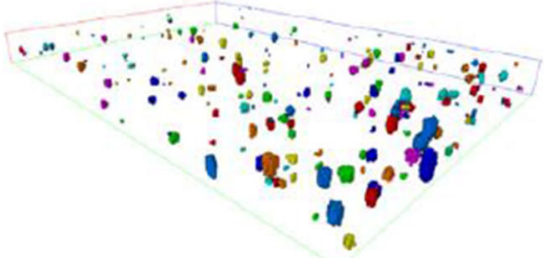


indicated that the energy input was sufficient. Figure 13 a shows the defect size (i.e., pore size) distribution and a full $\mu$-CT reconstruction of a representative SLM sample. The pores distribute uniformly across the sample and no pore aggregation can be found, which is different from another work [103]. During SLM, the formation of pores is inevitable. There are many factors, which influence the formation of defects such as the powder deposition itself, the laser power distribution, and the quality of the powder particles [140]. A slightly enhanced laser power in combination with an optimized scanning velocity apparently reduces the likelihood to locally not melt powder particles. In addition, the proper amount of relatively small powder particles increases the packing density in the powder bed. Figure $13 \mathrm{~b}$ shows the distribution of pores in $\mathrm{Zr}_{55} \mathrm{Cu}_{30} \mathrm{Ni}_{5} \mathrm{Al}_{10}$ part [88]. No cracks were observed, while some tiny pores were probed. It revealed volume fraction of about $0.12 \pm 0.01 \%$ pores dispersed randomly in the 3D-printed sample, indicating that 3D-printed parts are almost fully densified. The result has shown that density of 3D-printed sample is $6.83213 \mathrm{~g} / \mathrm{cm}^{3}$; by comparing the density of casting sample $\left(6.83966 \mathrm{~g} / \mathrm{cm}^{3}\right)$ [141], the relative density of 3D-printed sample is $99.89 \%$, which is almost in consistent with the results of XRT.

Up to now, it is still a challenge to produce a whole BMG sample with a large size and without any cracks and pores.

Owing to the high cooling rates effective during SLM [142], the corresponding BMGs show a lower atomic packing density readily reflected in larger relaxation enthalpies [105]. However, understanding the behavior of SLMed BMGs at elevated temperatures is of importance because they could be post-processed via thermoplastic forming (TPF) [143]. Thus, BMGs can be processed similarly to plastics [144]. The temperature dependence of viscosity of the $\mathrm{Zr}_{52.5} \mathrm{Cu}_{17.9} \mathrm{Ni}_{14.6} \mathrm{Al}_{10} \mathrm{Ti}_{5}$ metallic glass fabricated by casting and SLM was investigated by Kosiba [106]. Minor differences in the viscous flow of the specimens fabricated by the different techniques were found and that can be ascribed to the higher porosity of the SLMed metallic glass. It revealed a similar overall variation of viscosity in the cast and SLMed materials, which offers the opportunity to shape additively manufactured BMGs using already-developed thermoplastic forming techniques [106]. Another unresolved issue is how the metallic glass affects the short-range structure sequence of the amorphous material during laser processing in the SLM process, which is a key intermediate parameter for the deformation of metallic glass. Best used synchrotron X-ray microdiffraction to study the structural heterogeneity of $\mathrm{Zr}_{59.3} \mathrm{Cu}_{28.8} \mathrm{Nb}_{1.5} \mathrm{Al}_{10.4}$ (AMZ4-BMG) manufactured by SLM on the entire generation plane [145]. The observed small periodic changes are on the order of $40-80 \mu \mathrm{m}$. It can be expected that this structural insight will help rationalize the microscopic deformation effect caused by the periodic structural changes of BMG produced by selective laser melting.

\subsection{Al-based BMGs by SLM}

There are few studies on the Al-based BMGs produced by SLM. Li created a precedent in the research of aluminumbased BMGs by SLM additive manufacturing method and did some studies on processing, microstructure evolution, and mechanical properties of SLM Al-based amorphous alloys $[43,110,111]$. It was found that the substrate temperature played a crucial role in determining the interface between the carrier and the substrate and the ultimate solidified microstructure. A higher substrate temperature is more conducive to the formation of amorphous properties, which is due to the high cooling rate and larger melt volume [111]. At the same time, the densification, microstructural evolution, phase
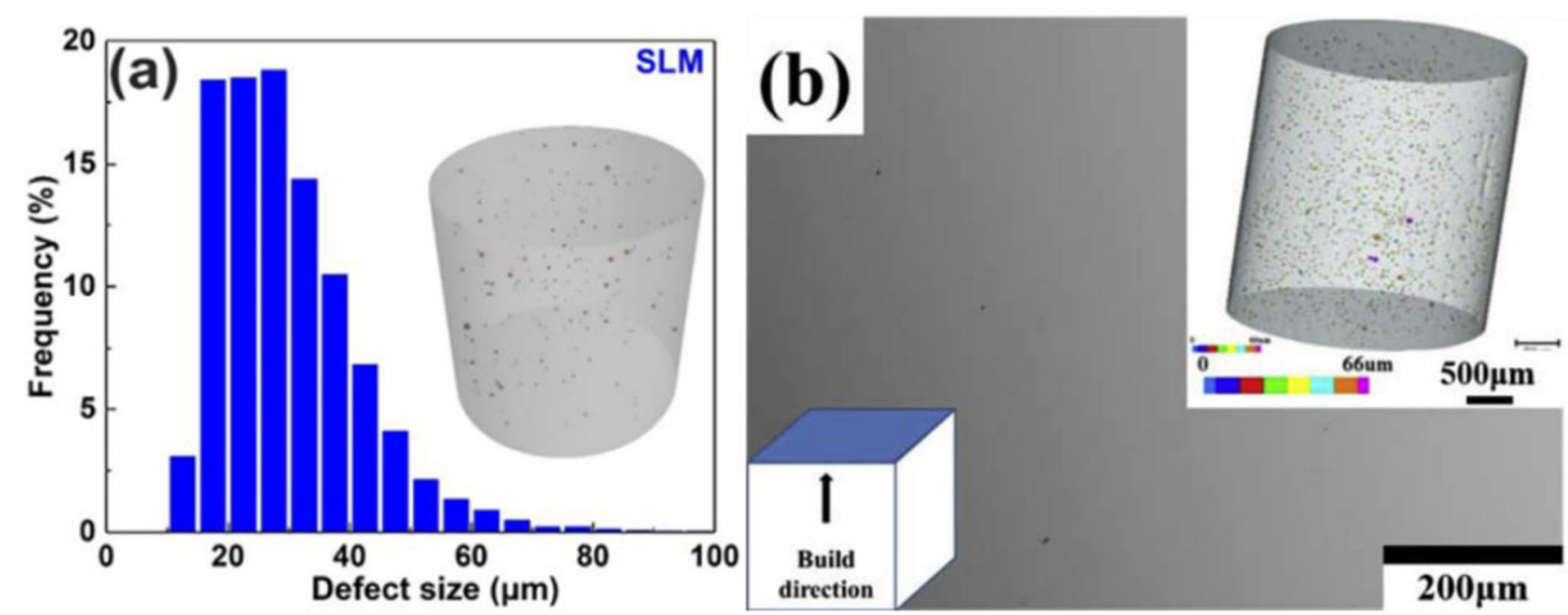

Fig. 13 Defects distribution of zirconium-based amorphous alloys produced by SLM. a Defect size distribution of $\mathrm{Zr}_{52.5} \mathrm{Cu}_{17.9} \mathrm{Ni}_{14.6} \mathrm{Al}_{10} \mathrm{Ti}_{5}$ [102]; $\mathbf{b}$ distribution of pores of $\mathrm{Zr}_{55} \mathrm{Cu}_{30} \mathrm{Ni}_{5} \mathrm{Al}_{10}$ [88] 
transformation, and mechanical properties of the same alloy studied as [111] were systematically investigated. For $\mathrm{Al}_{86} \mathrm{Ni}_{6} \mathrm{Y}_{4.5} \mathrm{Co}_{2} \mathrm{La}_{1.5}$ BMGs by SLM, it is difficult to obtain a crack-free and whole amorphous alloy [110]. Too high laser power will cause cracks due to excessive stress, and low laser power is beneficial to increase the amorphous phase ratio. However, low laser power can cause a large number of unmelted powder particles, which can also cause cracks and pores. Subsequently, Li conducted a component without obvious cracks, including a gear with a diameter $\sim 25 \mathrm{~mm}$ and height $\sim 10 \mathrm{~mm}$, which is shown in Fig. 14 [43]. The reason for the success of this preparation can be attributed to the combination of low input energy and repeated scanning strategies. This proved that crack propagation can be prevented by using a high-power initial scan (in order to melt the material) and then using a low-power rescan (to eliminate stress). Around the same time, a team of researchers from IFW in Dresden of Germany carried out similar work. They prepared massive, high-strength, and thermally stable $\mathrm{Al}_{85} \mathrm{Nd}_{8} \mathrm{Ni}_{5} \mathrm{Co}_{2}$ samples by SLM [112]. The alloy exhibited composites like microstructure, consisting of submicron stable intermetallic phases dispersed in the Al matrix, and has high compressive strength. These results indicated that SLM is an effective alternative to the traditional route and can be used to produce dense, heatstable, and near-net formed components from high-strength aluminum-based alloys.

\subsection{Other-based BMGs by SLM}

\subsubsection{Parameters of SLM}

Gao [55] studied the SLM Ti/Zr-based bulk metallic glass matrix composites (BMGCs) as $\left(\mathrm{Ti}_{0.65} \mathrm{Zr}_{0.35}\right)_{90} \mathrm{Cu}_{10}$ alloy. The main processing parameters were a laser power of 200 $\mathrm{W}$, layer thickness of $30 \mu \mathrm{m}$, and scan speed of $500 \mathrm{~mm} / \mathrm{s}$.
The point distance and hatch length were 105 and $40 \mu \mathrm{m}$, respectively. Gao [114] continued to study the SLM Ti/Zrbased BMGCs with $\left(\mathrm{Ti}_{0.65} \mathrm{Zr}_{0.35}\right)_{100-x} \mathrm{Cu}_{x}(x=5,10,15$ at.\%) alloys systematically. The parameters used in SLM process are basically the same as those used in previous work. With the change of $\mathrm{Cu}$ content, the microstructure and phase composition of the samples prepared by SLM changed obviously. Gao's [116] research showed that SLM can successfully produce $\mathrm{Cu}_{46} \mathrm{Zr}_{47} \mathrm{Al}_{6} \mathrm{Co}_{1}$ metallic glass composite materials without cracks. The layer thickness was $50 \mu \mathrm{m}$. The power and diameter of the laser were $200 \mathrm{~W}$ and $75 \mu \mathrm{m}$, respectively. The hatch spacing between scanning lines was $60 \mu \mathrm{m}$ and $85 \mu \mathrm{m}$, respectively. Compared to previous work [55], the sample sizes of $\mathrm{Cu}_{46} \mathrm{Zr}_{47} \mathrm{Al}_{6} \mathrm{Co}_{1}$ metallic glass can be obtained are larger. Deng [113] studied the biocompatible glass as $\mathrm{Ti}_{47} \mathrm{Cu}_{38} \mathrm{Zr}_{7.5} \mathrm{Fe}_{2.5} \mathrm{Sn}_{2} \mathrm{Si}_{1} \mathrm{Ag}_{2}$ alloy by SLM. It is worth noting that although the cooling rate should be similar to gas atomization, the alloy will vitrify during the SLM process. A complete glass structure can be obtained by SLM and it eliminated the crystalline phases in the powder by remelting the powder in the SLM process. For additively manufacturing Ti-based BMGs, it could be of high interest for a wide variety of applications in biomedical materials. Recently, a monolithic bulk metallic glass and glass matrix composites with a relative density above $98 \%$ were produced by processing $\mathrm{Cu}_{46} \mathrm{Zr}_{46} \mathrm{Al}_{8}$ (at.\%) via SLM by Deng [118]. For laser powers ranging from 90 to $110 \mathrm{~W}$ at a scanning velocity around $1000 \mathrm{~mm} \mathrm{~s}^{-1}$, a relative density above $98 \%$ can be achieved and the maximum relative density measured was $98.6 \%$. The 3D-printed BMGC components had large dimensions with complex geometries, demonstrating the good manufacturability of the chosen $\mathrm{Zr}_{50} \mathrm{Cu}_{50}$ system by SLM [117]. $\mathrm{Cu}_{50} \mathrm{Zr}_{43} \mathrm{Al}_{7}$ alloy specimens were manufactured by the SLM method from corresponding gas-atomized amorphous powders, and the laser energy density was in the range of $20.8-31.7 \mathrm{~J} / \mathrm{mm}^{3}$ [115]. (a)

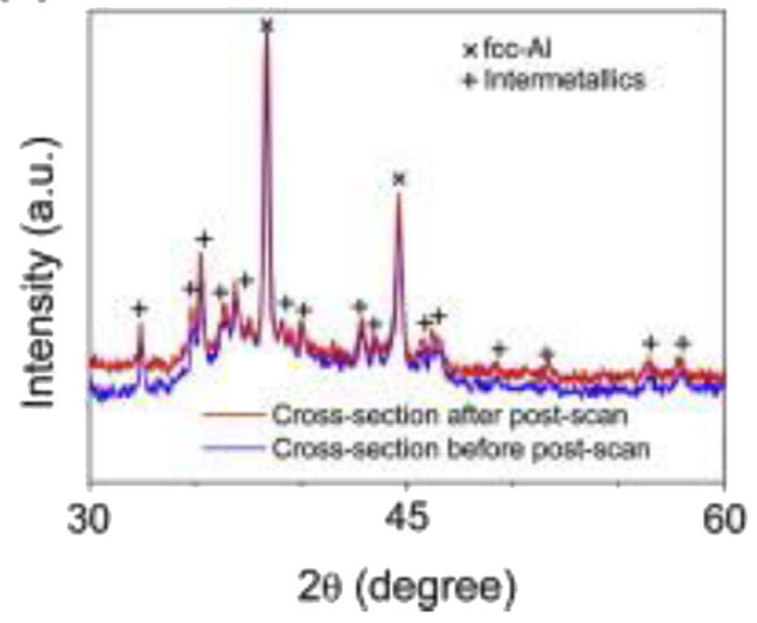

(b)

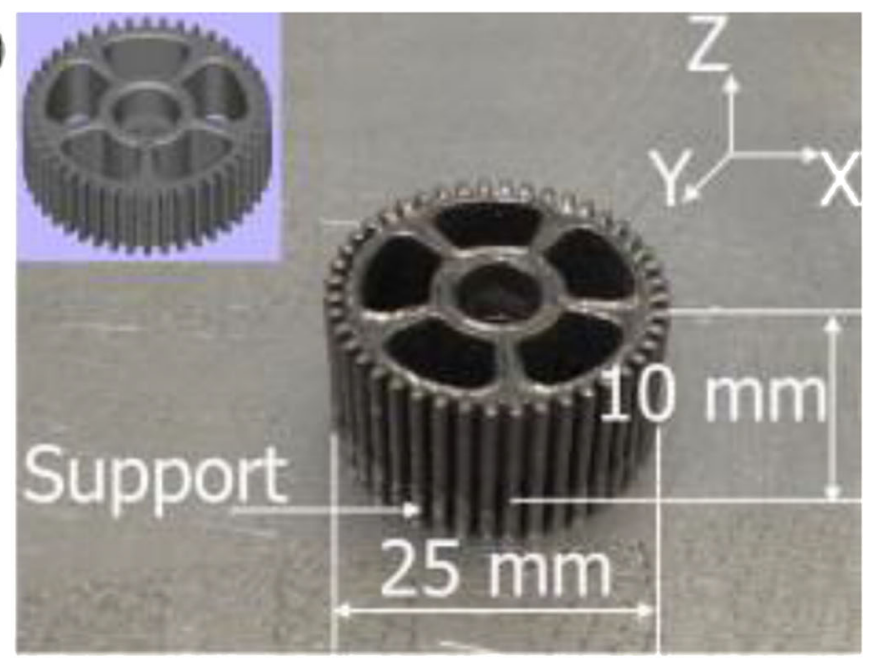

Fig. 14 a XRD patterns of the SLM processed material using single and re-scanning strategies. b A photo of an $\mathrm{Al}_{85} \mathrm{Ni}_{5} \mathrm{Y}_{6} \mathrm{Co}_{2} \mathrm{Fe}_{2} \mathrm{BMGC}_{\mathrm{gear}}$ [43] 
The size of the SLM-fabricated cylinder samples was $4 \mathrm{~mm}$ in diameter and $8 \mathrm{~mm}$ in height. For the first time, a high-density amorphous and crack-free bulk metallic glass (BMG) based on a precious metal $\left(\mathrm{Pd}_{43} \mathrm{Cu}_{27} \mathrm{Ni}_{10} \mathrm{P}_{20}\right)$ was produced via SLM by Sohrabi [119]. The samples produced with a power of $40 \mathrm{~W}$ and $60 \mathrm{~W}$ have more regular shapes. As power increases, the surface becomes curved and irregular, and thus reduces the accuracy of the part.

\subsubsection{Crystallization in SLM}

Figure 15 shows the microstructure evolution of the SLM with Ti/Zr-based BMGCs [55]. There are amorphous phase, $\beta$ phase, and a small fraction of the $(\mathrm{Ti}, \mathrm{Zr})_{2} \mathrm{Cu}$ phase in the alloy. For the SLM of $\mathrm{T}\left(\mathrm{Ti}_{0.65} \mathrm{Zr}_{0.35}\right)_{100-x} \mathrm{Cu}_{x}(x=5,10,15$ at.\%) BMG alloys, with the increase of copper content, the average volume fraction and width of the $\beta$ phase decreased, and the morphology of $\beta$ phase changes from spherical to continuous slender sphere and network [114]. With the increase of copper content, the decrease of the average volume fraction and size of the $\beta$ phase is not conducive to hindering the rapid propagation of the shear band, and the plasticity of the alloy decreases rapidly. Figure 15 a shows the pseudo binary phase diagram of $\left(\mathrm{Ti}_{0.65} \mathrm{Zr}_{0.35}\right)_{100-x} \mathrm{Cu}_{x}$. $\mathrm{Cu}_{46} \mathrm{Zr}_{47} \mathrm{Al}_{6} \mathrm{Co}_{1}$ metallic glass composite materials without cracks can be prepared by SLM, and the CuZr phase is deposited in a glassy matrix and some micrometer-sized crystalline phases already exit in the overlapping area for the latter laser scanning [116]. The fracture strength of the SLM samples is lower than that by conventional copper mold cast method [146]. In this research, when the stress is parallel to the printed layer, some special deformations may occur in the elastic region according to the stress-strain curve. The abnormal stressstrain curve may be related to the internal stress release between the layers. This can be attributed to the thermal stress accumulates layer by layer in SLM process [43]. When SLM is performed with a lower energy input, B2 CuZr nanocrystals (30-100 nm in diameter) are uniformly dispersed in the metallic glass matrix $\left(\mathrm{Cu}_{46} \mathrm{Zr}_{46} \mathrm{Al}_{8}\right)$ [118]. These $\mathrm{B} 2 \mathrm{CuZr}$ nanocrystals became the nucleation centroid of the large cubic phase with stable oxygen content during the remelting step. The presence of these nanocrystals increases structural heterogeneity, which can be indirectly revealed by microhardness and nanoindentation measurements. Zhang applied the SLM
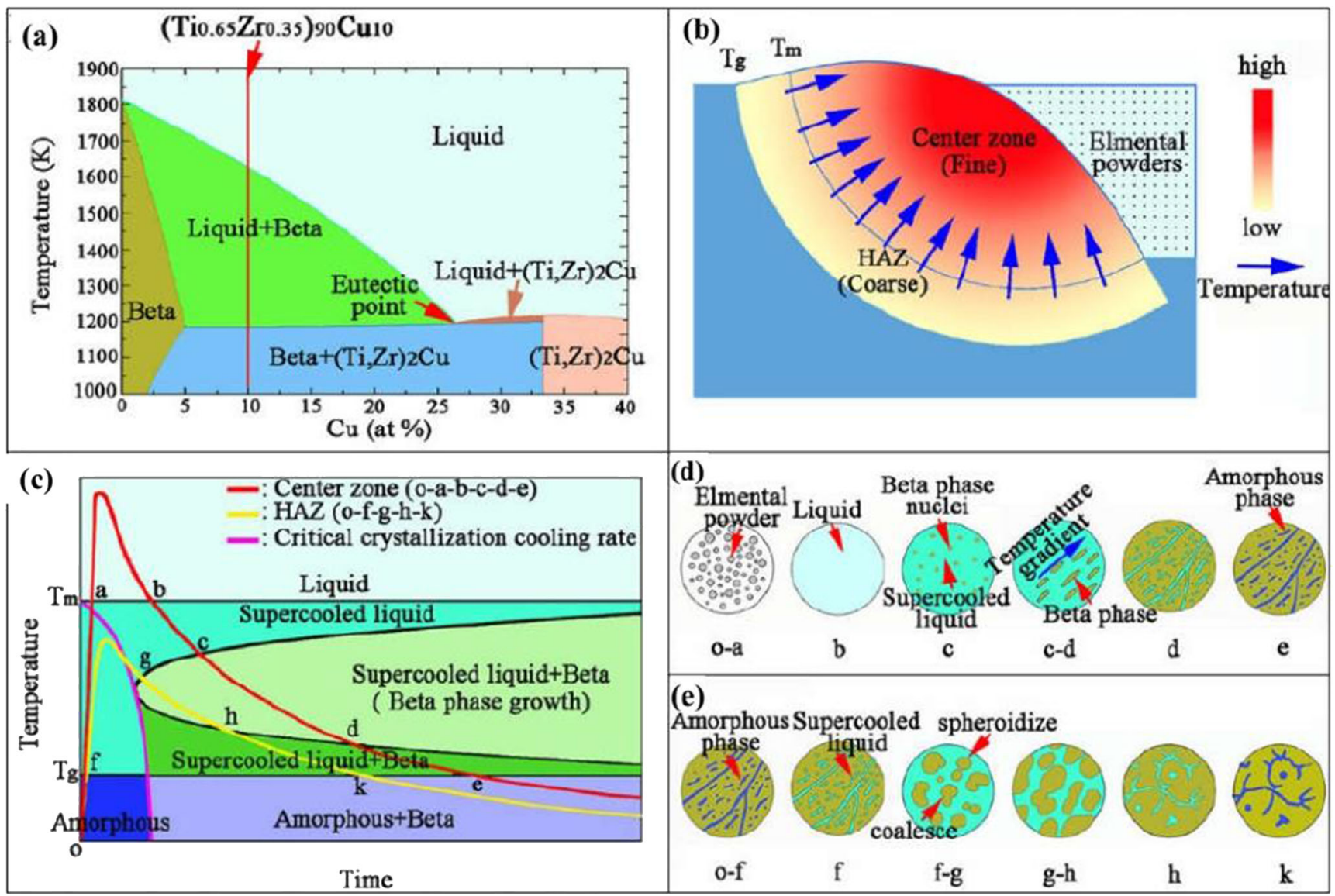

Fig. 15 a Pseudo binary phase diagram of $\left(\mathrm{Ti}_{0.65} \mathrm{Zr}_{0.35}\right)_{100-x} \mathrm{Cu}_{x} ; \mathbf{b}$ schematic of temperature distribution in the molten pool; $\mathbf{c}$ schematic of TTT in the molten pool; $\mathbf{d}$ schematic of fine microstructure evolution in the center zone; e schematic of coarse microstructure evolution in the HAZ [55] 
technique to fabricate a $\mathrm{Zr}_{50} \mathrm{Cu}_{50}$ bulk metallic glass composite reinforced with in situ-generated B2 austenite in HAZs, where the $\mathrm{B} 2$ phase could transform to B19' martensite during deformation and enhance the ductility due to the transformation-induced plasticity (TRIP) effect [117]. The fraction of the amorphous phase in the 3D-printed samples was $64 \mathrm{wt} \%$ and the phases such as $\mathrm{B} 2-\mathrm{ZrCu}, \mathrm{B} 19^{\prime}-\mathrm{ZrCu}$, and $\mathrm{Cu}_{5} \mathrm{Zr}$ intermetallics can be found.

\subsubsection{Defects in SLM}

Some cracks were found in $\left(\mathrm{Ti}_{0.65} \mathrm{Zr}_{0.35}\right)_{90} \mathrm{Cu}_{10}$ and $\left(\mathrm{Ti}_{0.65} \mathrm{Zr}_{0.35}\right)_{85} \mathrm{Cu}_{15}$ BMGs prepared by SLM, but no crack was found in the $\left(\mathrm{Ti}_{0.65} \mathrm{Zr}_{0.35}\right)_{95} \mathrm{Cu}_{5}$ BMG [114]. However, when $\mathrm{Cu}$ content was 5 , the amorphous content in the sample is very low. The relative densities of the specimens (Archimedean) range from 98.5 to $98.7 \%$ and small pores with a typical diameter of 10-30 $\mu \mathrm{m}$ can be found in the $\mathrm{SLM}_{\text {of }} \mathrm{Ti}_{47} \mathrm{Cu}_{38} \mathrm{Zr}_{7.5} \mathrm{Fe}_{2.5} \mathrm{Sn}_{2} \mathrm{Si}_{1} \mathrm{Ag}_{2}$ BMGs [113]. The pores were uniformly distributed throughout the sample. It is the presence of these holes that reduces the density of the sample. The pore sizes range from 10 to $90 \mu \mathrm{m}$ and most pores (above $50 \%$ ) have an equivalent diameter between 15 and $30 \mu \mathrm{m}$ when energy input was $14.3 \mathrm{~J} / \mathrm{mm}^{-3}$ for SLM of $\mathrm{Cu}_{46} \mathrm{Zr}_{46} \mathrm{Al}_{8}$ [118]. The pore sizes of the specimens produced with energy input of $17.4 \mathrm{~J} / \mathrm{mm}^{-3}$ (relative density about 98\%) mainly range between 20 and $35 \mu \mathrm{m}$. Lu [115] found that many nanoscale crystal phases precipitated from the glass matrix during the SLM process. Due to the high viscosity of BMG melt, the prepared BMG sample without big external cracks has many micro-scale pores at the boundary of solidification pool, which may be the main reason for the low relative density and high porosity of $\mathrm{Cu}_{50} \mathrm{Zr}_{43} \mathrm{Al}_{7} \mathrm{BMG}$ prepared by SLM. A porosity of approximately $0.76 \%$ with pores dispersed randomly in the printed sample [117]. The size of the major pores is $5-30 \mu \mathrm{m}$ with a mean size of $15 \mu \mathrm{m}$, similar to the results observed previously for other 3D-printed Zr-based BMGs [107].

\subsection{Simulation of BMGs by SLM}

Due to the huge differences in time and length scales, finite element modeling (FEM) and phase modeling (PM) of SLM melting process is a difficult task [147]. For example, the size and thickness of the heat source of a single powder layer is on the order of micrometers, so hundreds or thousands of layers are needed to build a component in millimeters [148]. If there are a large number of mathematical units in each layer of the model, the model will become large and difficult to manage. Another challenge of SLM process simulation is the experimental verification of the model. The working space of the existing SLM machine is enclosed in a working room, and it is difficult to obtain various parameters of the sample in real time when preparing the sample [149]. SLM process can be used to produce BMGs because it can provide a high cooling rate. However, there is a risk that when BMGs fail to be reheated at a sufficiently high temperature to cause secondary melting, crystallization may occur; that is, it may become devitrified. Therefore, accurate thermal process simulation can enhance the understanding of the process of preparing BMG by SLM and avoid the aforementioned risks. The accuracy of these models in key areas is very important to be able to predict crystallization and devitrification [150].

\subsubsection{Thermomechanical model of BMGs by SLM}

Many results have revealed that partial crystallization occurred at heat-affected zones (HAZ) around the molten pools in BMGs by SLM. Obviously, it is important to deeply understanding the thermal cycle in HAZ. FEM simulations were performed by Ouyang [88] and Xing [91] using a moving heat source which obeys Gaussian distribution. In the SLM process, the maximum temperature in the center of the molten pool can reach $2200^{\circ} \mathrm{C}$, which is much higher than the melting point of $892^{\circ} \mathrm{C}$ of the alloy system $\left(\mathrm{Zr}_{55} \mathrm{Cu}_{30} \mathrm{Ni}_{5} \mathrm{Al}_{10}\right)$. Note that the critical cooling rate required to form the amorphous phase in the $\mathrm{Zr}_{55} \mathrm{Cu}_{30} \mathrm{Ni}_{5} \mathrm{Al}_{10}$ system is about $10^{\circ} \mathrm{C} / \mathrm{s}$ [151], so the high cooling rate can ensure the formation of a complete amorphous structure in the molten pool during the SLM process. However, although the cooling rate in the HAZ is also high enough, the occurrence of crystallization is not determined by the cooling rate but by the elevated temperature. If the temperature in the HAZ is higher than the glass transition temperature $\left(T_{g}\right)$, it is difficult to prevent crystallization. In addition, the reheating of the heated area only lasts about $5 \mathrm{~ms}$, which results in the formation of nanocrystals in the amorphous matrix due to lack of growth time, which explains why HAZ usually has a composite structure of amorphous and nanocrystalline. The Xing's model analysis shows that reducing the thermal gradient and preheating the substrate through the $\mathrm{XY}$ cross-scan strategy can enhance the uniform shrinkage during the rapid cooling process, thereby reducing the residual stress [72]. In the current 3D-printed $\mathrm{Fe}_{43.7} \mathrm{Co}_{7.3} \mathrm{Cr}_{14.7} \mathrm{Mo}_{12.6} \mathrm{C}_{15.5} \mathrm{~B}_{4.3} \mathrm{Y}_{1.9}$ $\mathrm{BMG}$ components, if the size of the micro-pore reaches $30 \mu \mathrm{m}$ or more, micro-cracks will occur in the alloy which can be seen in Fig. 16 a-d. Xing also used a computational fluid dynamics (CFD) model to verify that the various defects formed in the 3Dprinted Zr-based BMG are related to the melt flow behaviors in the molten pools under different energy densities [108]. The present work provides in-depth understandings of defect formation in the SLM process and provides methods for eliminating these defects in order to enhance the mechanical performance of 3D-printed BMGs. Ouyang [94] also introduced a model to calculate the stress field during the post heat treatment process of SLM $\mathrm{Zr}_{55} \mathrm{Cu}_{30} \mathrm{Ni}_{5} \mathrm{Al}_{10}$ BMG with the purpose of revealing the mechanism of microcracks. The thermal stress field during the heat treatment of 3D-printed metallic glass is obtained, as shown 


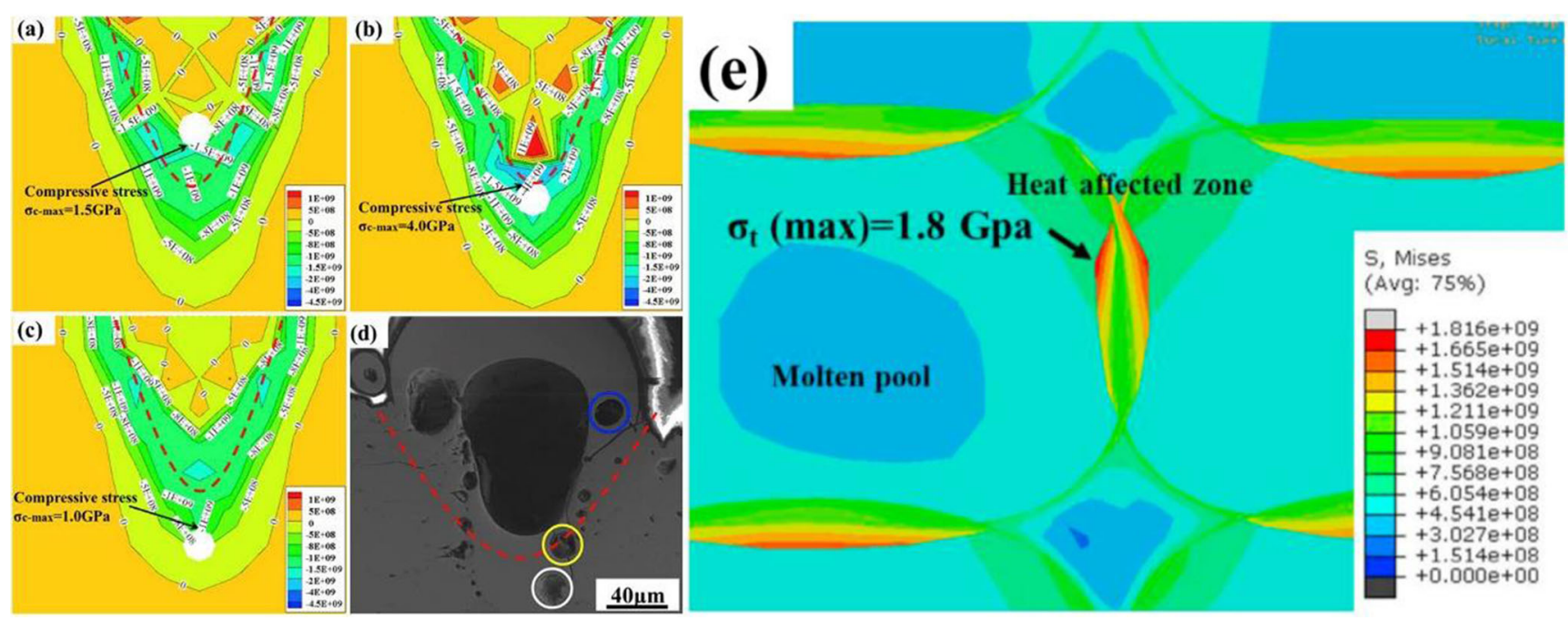

Fig. 16 Thermal stress fields around molten pools with micro-pores in different locations: a inside, $\mathbf{b}$ at the edge, and $\mathbf{c}$ outside of the molten pool; $\mathbf{d}$ distribution of micro-cracks around micro-pores [72]; e FEM simulated thermal stress field around molten pool and HAZ during heat treatment [94]

in Fig. 16 e. Obviously, there will be a huge stress concentration around the heat-affected zone, and the maximum tensile stress is higher than the tensile strength of $\mathrm{Zr}_{55} \mathrm{Cu}_{30} \mathrm{Ni}_{5} \mathrm{Al}_{10} \mathrm{BMG}(1.53$ $\mathrm{GPa}$ [152]), which proves the cause of the microcracks.

Lindwall [150] presented three models which was refer to computational welding mechanics (CWM) and compared regarding predicted temperature history and computational time. The CWM model can be used in combination with other models to obtain microstructure evolution and other characteristics, so that the microstructure can be predicted [153]. But because the simulation of the welding process is very complicated, its calculation model is also too complicated. When applying the CWM model to SLM process of $\mathrm{Zr}_{59.3} \mathrm{Cu}_{28.8} \mathrm{Al}_{10.4} \mathrm{Nb}_{1.5} \mathrm{BMG}$, it is necessary to improve the computational efficiency of the model. Afazov [154] combined the re-division of the layer group and the analysis of the temperature field to improve the calculation speed. This method was introduced into the modeling of SLM by Lindwall. After the simplified model, the calculation can be completed in $0.2 \%$ of the original calculation time, but the thermal simulation of the SLM can still be ensured.

\subsubsection{Crystallization modeling of BMGs by SLM}

Finite element modeling Żrodowski [77] has proposed a new crystallization model for SLM processing of $\mathrm{Fe}_{71} \mathrm{Si}_{10} \mathrm{~B}_{11} \mathrm{C}_{6} \mathrm{Cr}_{2}$ BMGs based on Ozawa equation [155]. The model focused on constant heating conditions; during the cooling process of the molten pool, the crystallites may increase due to Marangoni convection and promote crystallization to become a homogeneous nucleus. Under different pulse time $(20 \mu \mathrm{s}$ and $500 \mu \mathrm{s})$ laser irradiation conditions, the crystal difference in the heat-affected zone is caused by the different heating rate, which is the effect of devitrification kinetics. The use of keyhole mode for remelting is advantageous for the SLM treatment of low GFA metallic glass. In addition, the amorphization of BMGs during SLM is limited by the heating rate. Ouyang [71] proposed a mathematical model based on the phase transition curve to roughly predict the relationship between process parameters and volume fraction which is shown in Fig. 17. Theoretical amorphous content in different zone of component can be obtained by this model. The results showed that high laser energy density caused the tendency of crystallization and reduced the volume fraction of the amorphous phase. This phenomenon can be attributed to the prolongation of nucleation and growth time, thereby increasing the crystallization fraction in the heat-affected zone based on crystallization kinetics. This not only explains why nanocrystals only appear in the heat-affected zone, but also explains how the laser energy density affects the crystallinity

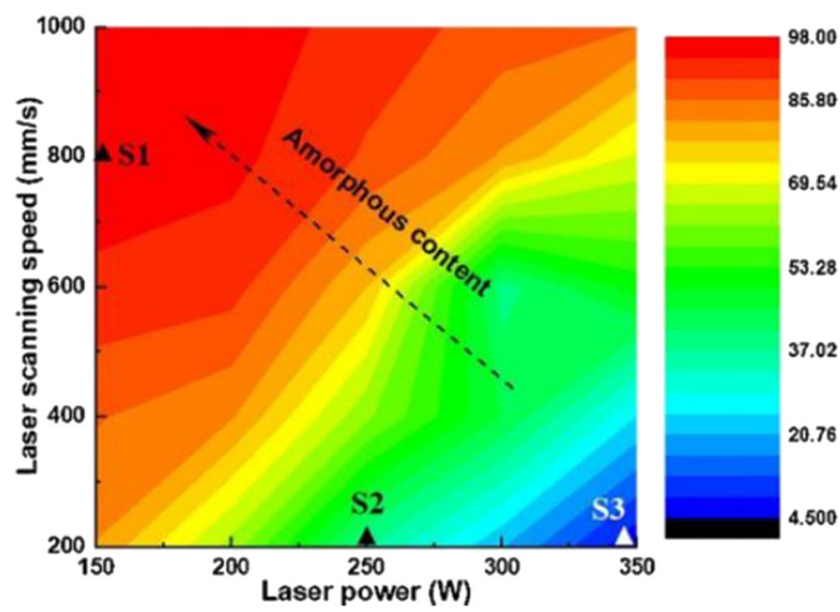

Fig. 17 Amorphous content of 3D-printed Fe-based BMGs under different process parameters; the relationship of laser energy density and amorphous content [71] 
in the heat-affected zone. Lindwall [156] focused on predicting the formation of crystalline phases in the glass alloy AMZ4 during SLM. This method combines a thermal finite element model for predicting the temperature field [150] and a phase model for predicting crystallization and devitrification. It can predict the formation of crystalline phases in nonisothermal processes. The key position of devitrification is located several layers below the top surface. Then, a new numerical model of transient nucleation which takes into account the rapid temperature changes associated with SLM process, based on classical nucleation theory (CNT), was established and employed by Ericsson and Lindwall [157] to study transient nucleation effects during SLM processing of AMZ4 alloy. The model used the Johnson-Mehl-AvramiKolmogrov (JMAK) [158] theory and calibrates the model based on the thermodynamic parameters obtained from the AMZ4 alloy DSC measurement. It also used the temperature-dependent expression of the interface energy proposed by Mondal et al. for model calibration [159]. It should be noted that the higher heating and cooling rates in the SLM process can cause transient nucleation effects [160]. According to the calculation results, the difference between steady-state and transient nucleation rates is very large. At lower temperatures, the transient nucleation rate is 15 orders of magnitude lower than the steady-state rate, which is caused by cluster size distribution. The calculated crystal volume fraction of the heat-affected zone is a function of the applied laser power which is shown in Fig.18, and as the laser power decreases, the volume fraction decreases. The crystal volume fraction calculated based on this model is consistent with the experimentally results. Considering that the crystallization in the HAZ is based on the three-dimensional growth of a fixed number of quenched clusters/nuclei, and the subsequent
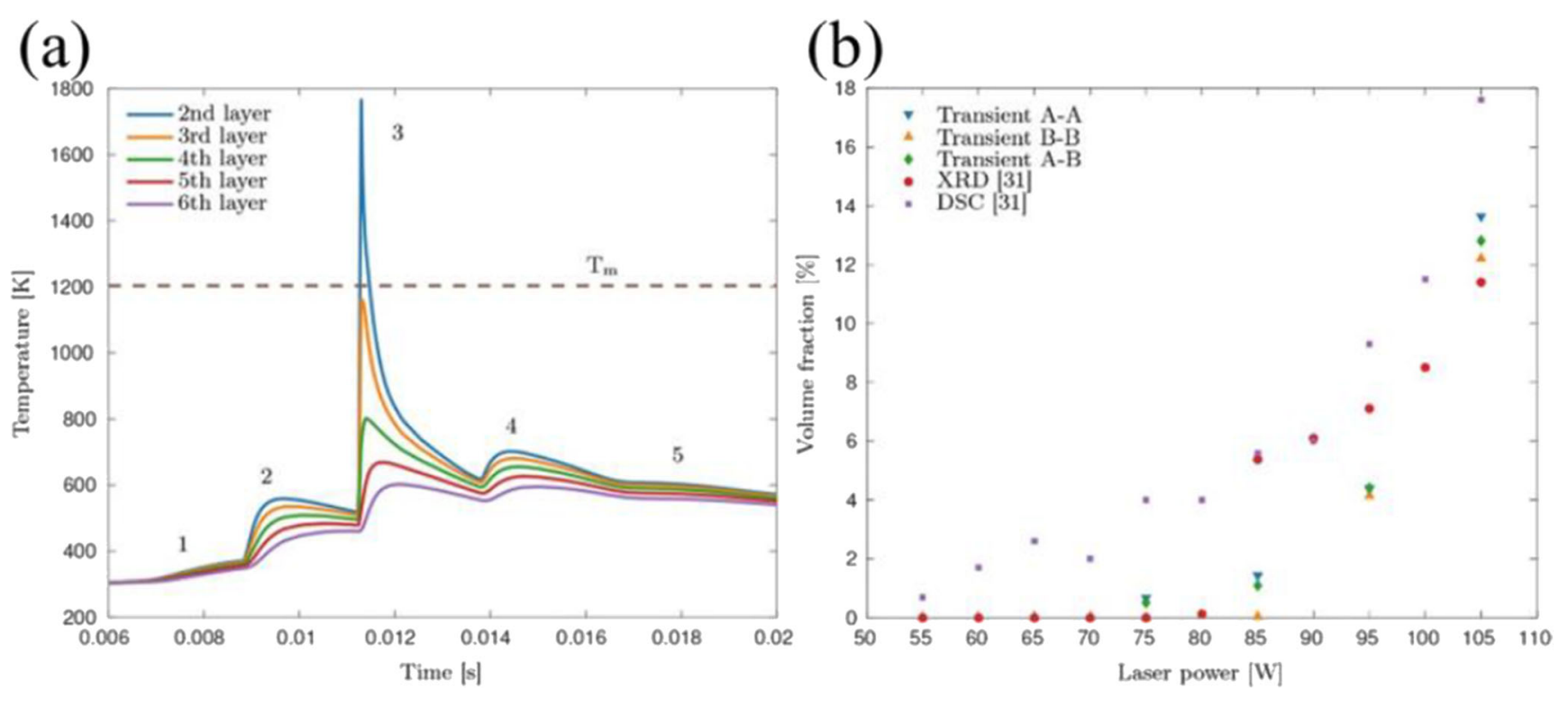

Fig. 18 Simulation result; a temperature in each layer using a laser power of $105 \mathrm{~W}$; $\mathbf{b}$ the maximum crystalline volume fraction as a function of laser power for the different remelting scenarios [157]

nucleation and growth of new embryos, Zhang [92] developed a model to calculate crystallized volume fraction of HAZ in SLM of $\mathrm{Zr}_{55} \mathrm{Cu}_{30} \mathrm{Al}_{10} \mathrm{Ni}_{5}$ BMG. The number density $(N)$ of the pre-existing and quenched clusters/nuclei is set to a value calculated from the average size and number of dendritic eutectic phases per unit volume at the top of the HAZ.

Molecular dynamics modeling Guo $[161,162]$ used molecular dynamics (MD) simulation to study the microstructure evolution of $\mathrm{Ni}_{75} \mathrm{Al}_{25}$ metallic glass during cyclic heating at different temperature. The results show that at a relatively low rate of temperature change, the time to start crystallization depends on the relaxation time between the glass transition temperature and the maximum heating temperature during heating or cooling. The relaxation time also affects the transition mode of the crystal structure after the crystallization behavior is completed. When the temperature change rate rises to $5 \times 10^{13} \mathrm{~K} / \mathrm{s}$, the phenomenon of nucleation decline will occur, and this behavior will delay or even prevent the occurrence of crystallization which can be seen in Fig. 19. The existence of nucleation recession provides a new possibility for studying the inhibition of heat-affected zone crystallization behavior during the preparation of SLM-containing BMG. But it is still a challenge to control the crystallization behavior in HAZ especially in Fe-based BMGs due to the low GFA compared with $\mathrm{Zr}$ based BMGs [19].

Zhang simulated the SLM fabrication of $\mathrm{Cu}_{50} \mathrm{Zr}_{50}$ [163], $\mathrm{Cu}_{10} \mathrm{Zr}_{90}$ [164], and $\mathrm{Fe}_{50} \mathrm{Ni}_{50}$ [165] BMGs by using MD simulations to clarify the atomic-level crystallization mechanism and the effect of laser processing on the crystallization. The result implied local ordering and the formation of amorphous structure can be found in the SLM parts. Also, no significant changes happened in the characteristics of amorphous 


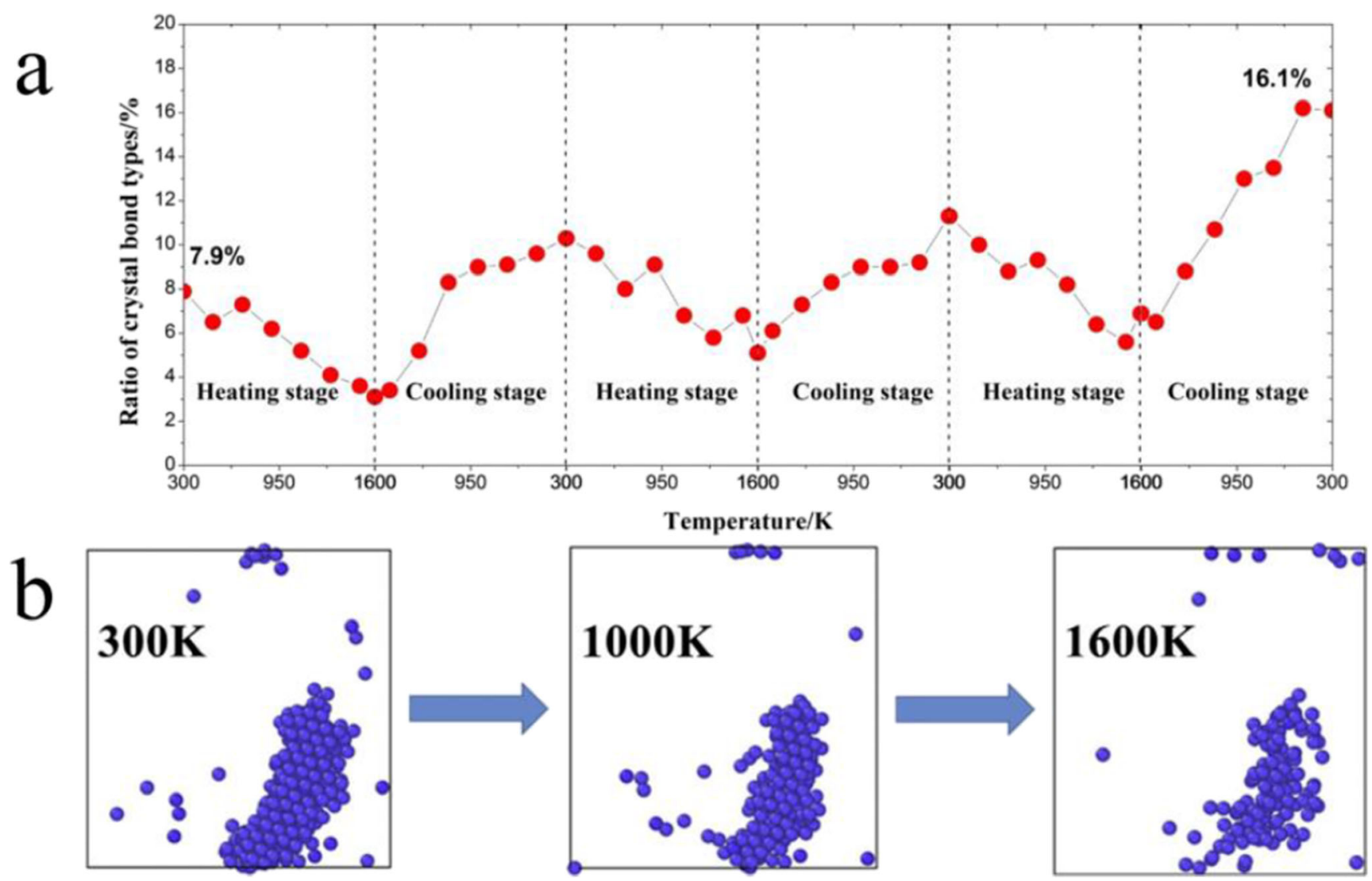

Fig. 19 a The variation of ratio of crystal bond types during the cyclic heating process; $\mathbf{b}$ the extraction of crystal structure in the system during the first heating process at the temperature variation rate of $5 \times 10^{13} \mathrm{~K} / \mathrm{s}[161]$

structures, despite the rearrangement of some atoms during SLM process. For CuZr BMGs, as scan speed increases, more icosahedron-like clusters are formed, leading to the formation of the MG, while the nucleation of the crystal phase is suppressed. The suppression of crystallization is further attributed to a higher average temperature variation rate induced by higher scan speed, which reduces the relaxation time, preventing the nucleation and growth of crystal phases in $\mathrm{CrZr}$ and FeNi BMGs [166]. It is precisely because of the increase in relaxation time caused by the icosahedral clusters generated under the conditions of rapid laser scanning that the crystal phase is suppressed, which makes the GFA in the additive manufacturing of BMG increase sharply [167].

\section{Properties of BMGs by SLM}

\subsection{Mechanical properties}

\subsubsection{Mechanical properties of BMGs}

Fe-based BMGs SLM technique was used to prepare the $\mathrm{Fe}_{43.7} \mathrm{Co}_{7.3} \mathrm{Cr}_{14.7} \mathrm{Mo}_{12.6} \mathrm{C}_{15.5} \mathrm{~B}_{4.3} \mathrm{Y}_{1.9}$ (at.\%) of bulk metallic glass [86]; nano indentation test results show that the maximum nano hardness can be up to $17.2 \mathrm{GPa}$, with higher than the casting samples (1253 HV) [168]. $\mathrm{Fe}_{55} \mathrm{Cr}_{25} \mathrm{Mo}_{16} \mathrm{~B}_{2} \mathrm{C}_{2} \mathrm{BMG}$ was prepared by SLM and the nano-hardness reached $14 \mathrm{GPa}$, equivalent to $1260 \mathrm{HV}$ [75]. The hardness is already more than $30 \%$ higher than that of metallic glass prepared by direct metal deposition, and higher than that of coatings prepared by supersonic plasma spraying [169]. Results of micropillar compression test showed that a few "pop-ins" were observable from the curve, implying that microfracture may have occurred during the loading procedure, which phenomenon was usually associated with brittle materials. The yield strength of the as-printed BMG is $\sim 4500 \mathrm{MPa}$. For $\left\{\left(\mathrm{Fe}_{0.6} \mathrm{Co}_{0.4}\right)_{0.75} \mathrm{~B}_{0.2} \mathrm{Si}_{0.05}\right\}_{96} \mathrm{Nb}_{4}$ BMG prepared by SLM, the highest nano hardness can reach $16.9 \pm 1.1$ GPa and the highest Young's modulus is 312.1 $\pm 11.2 \mathrm{GPa}$ [85]. Therefore, SLM-processed samples with a higher amorphous fraction with area energy input decreasing showed a lower hardness and Young's modulus. The lower hardness and Young's modulus of the LPBF-processed samples were mainly attributed to the microcracks and pores.

The composite structures of FeCrMoBC alloys with amorphous and dendrite phases were prepared by SLM technique [74]. The alloy can be made into a dendrite-reinforced composite with global hardness of $740 \mathrm{HV}$ ( $573 \mathrm{HV}$ dendrite and 1096 HV matrix) or into a fully crystalline alloy with hardness 
as high as $1300 \mathrm{HV}$. Its microhardness is lower than that of arc melting and absorption casting samples, but its fracture toughness is much higher than that of other methods. Obviously, the composite materials produced by the in situ reaction in the preparation process of SLM have unique characteristics and advantages in the microscopic interface and overall performance of the material, which suggests potential for fabricating tough BMG matrix composites in future work [10].

Some studies believed that the micro-cracks in the 3Dprinted Fe-based BMG are caused by the concentration of thermal stress around the micro-holes, and it is difficult to eliminate such cracks through process optimization [72]. By introducing low yield strength and high toughness materials into the BMG matrix to form a composite material, the microcracks are highly suppressed or even disappear, thereby significantly improving the mechanical properties [170]. More importantly, the combination of strength, ductility, and fracture toughness of 3D-printed iron-based BMG composites can be optimized on a large scale by adjusting the fraction or category of the second phase [62]. In short, the introduction of heterogeneous microstructures into the BMG material combination can suppress microcracks and can also optimize the mechanical properties of the inherently brittle iron-based BMG, which proves that selective laser melting technology can be used as a promising technology to produce BMG parts. The feasibility of preparation may not be limited by size, complexity, or inherent fragility [171-173].

Wang [174] and Liu [175] added copper particles to BMGs to improve mechanical properties. Zou used SLM fabricating FeCrMoCB BMGs and $\mathrm{Cu}$ was mixed in the powder [80]. The mechanical properties of Fe-based BMGs were improved. This is due to the uniform distribution of $\mathrm{Cu}$ particles and amorphous phases, forming a unique transition bonding interface in the composite structure. Multiple shear bands are generated during the deflection movement, which can prevent rapid expansion of the shear bands in the sample, and the plasticity is improved by the interaction of shear deformation after the shear band expands. Wang conducted performance tests on the as-printed $\mathrm{Fe}_{55} \mathrm{Cr}_{25} \mathrm{Mo}_{16} \mathrm{~B}_{2} \mathrm{C}_{2} \mathrm{BMG}$ [75]. It presented high relative density ( $\sim 99.0 \%)$, large nanohardness (14 $\mathrm{GPa})$, and high yield strength ( $\sim 500 \mathrm{MPa})$. This hardness is even higher than that of direct metal laser sintering samples (902 HV), supersonic plasma spraying coatings (1005 HV) [169], or similar alloy compositions of atmospheric plasma spraying samples (731 $\pm 77 \mathrm{HV})$ [176]. Compared with BMGs made by traditional technology [177], the hardness and elastic modulus of the molded phase and the amorphous phase of the BMG made by SLM are relatively high. In addition, the microstructure of BMGs prepared by the SLM method has high yield strength. Therefore, although the volume fraction of the amorphous phase is only about $20 \%$, the average Vickers hardness of the BMGs prepared by SLM is almost close to the average Vickers hardness containing 57\% of the amorphous phase prepared by the traditional method. Due to the difference in hardness and elastic modulus, during plastic deformation, the stress is usually concentrated on the interface between the amorphous phase and the crystalline phase, which promotes the generation of shear zones [178]. Li mixed $\mathrm{Cu}$ and $\mathrm{Cu}-\mathrm{Ni}$ alloy powders with low yield strength and high toughness with $\mathrm{Fe}_{43.7} \mathrm{Co}_{7.3} \mathrm{Cr}_{14.7} \mathrm{Mo}_{12.6} \mathrm{C}_{15.5} \mathrm{~B}_{4.3} \mathrm{Y}_{1.9}$ amorphous alloy powders, and uses SLM technology to prepare composite materials [73]. The results showed that due to the shielding and anti-shielding effects of the crack tip, the uneven structure of the composite material reduces the crack driving force and improves the fracture toughness. In particular, the maximum fracture toughness of BMGCs after mixing with $\mathrm{Cu}$ particles reached $47 \mathrm{MPa} \mathrm{m}^{1 / 2}$, which is about 20 times higher than that of Fe-based BMG (2.2 MPa m $\left.{ }^{1 / 2}\right)$. Interestingly, $\mathrm{Li}$ also used SLM technology to combine an iron-based highentropy alloy with an iron-based glass to produce a composite with both high strength and high toughness [79]. The strength and toughness of the composite can be effectively adjusted with the difference of metal glass content. The ratio of the amorphous phase to the newly generated high entropy phase is relatively low, and the structure of the high entropy alloy composite can be regarded as the iron-based amorphous phase dispersed in the high entropy alloy matrix. Zhang prepared the 316L stainless steel by SLM method by adding the amorphous alloy $\mathrm{FeCoCrMoCBY}$, which has good mechanical properties such as high hardness and wear resistance [87]. The addition of amorphous alloy $(10 \mathrm{wt} \%)$ to $316 \mathrm{~L}$ increases the tensile strength to $1090 \mathrm{MPa}$, which has good ductility, wear resistance by about $20 \%$, and pitting resistance by about $200 \mathrm{mV}$. In the above SLM studies on metallic glass composites, metallic glass shows good comprehensive properties, whether it is formed by in situ precipitation of crystalline phase of metallic glass to form amorphous/crystalline phase composites, or it is used as the strengthening phase of soft materials (such as high entropy alloy, $316 \mathrm{~L}$ stainless steel).

Zr-based BMGs As shown in Fig. 20 a, the mechanical properties of $\mathrm{Zr}_{55} \mathrm{Cu}_{30} \mathrm{Ni}_{5} \mathrm{Al}_{10}$ (at.\%) samples produced by SLM in the molten pool and HAZ are characterized by nanoindentation. The indentation hardness of the HAZ is relatively high $(6.27 \pm 0.24 \mathrm{GPa})$ and modulus (75.16 $\pm 1.58 \mathrm{GPa})$ [93]. The as-cast BMG possesses yield strength of $1870 \pm 45 \mathrm{MPa}$ and plastic strain of $0.5 \%$, consistent with the data in literature [179]. Though the 3D-printed Zr-based BMGC cylinders exhibit little plasticity, the sample still remains sufficient high yield strength of about $1504 \pm 103 \mathrm{Mpa}$ [88]. The lower yield strength may be due to the defects found in the 3D-printed samples. In addition to the yield strength, the fracture angles of the two are also different. The fracture angles is $90^{\circ}$ for printed sample and $42^{\circ}$ for as-cast one, respectively. This can be related to the layered structure as well as brittle crystallized phases in the SLM process. Then, the sample after 
heat treatment exhibited a much lower fracture strength as 491Mpa which can be seen in Fig. 20 b [94]. The reason for this low strength can be the form of cracks initiated at the boundaries between molten pools and HAZ. Other alloys with different composition $\left(\mathrm{Zr}_{60.14} \mathrm{Cu}_{22.31} \mathrm{Fe}_{4.85} \mathrm{Al}_{9.7} \mathrm{Ag}_{3}\right)$ by SLM were tested by Ouyang, and the compressive strength can reach the value of $1715 \mathrm{MPa}$ with $0.96 \%$ modest plasticity which are comparable to those of the as-cast BMG $1710 \mathrm{MPa}$ in strength and $1.81 \%$ in plastic strain [107]. The fracture angle is about $43^{\circ}$ and it is quite similar to the as-cast BMG [180]. Another test did by Zhang showed that yielding strength was above $1600 \mathrm{MPa}$ which was even higher than that of as-cast samples [107]. A trace amount of plasticity in the range of $0.46-1.43 \%$ was found and it can be attributed to the partial crystallization in HAZs [100] and the results are shown in Fig. $20 \mathrm{c}$ and d. The composite of SLM BMGs is a feasible way to improve the plasticity of amorphous alloys, which has a similar principle to bulk amorphous alloys [181].
Room-temperature compression tests for $\mathrm{Zr}_{52.5} \mathrm{Cu}_{17.9} \mathrm{Ni}_{14.6} \mathrm{Al}_{10} \mathrm{Ti}_{5}$ SLM samples and as-cast one were carried out by Pauly [103]. The yield strength of the specimens manufactured by SLM can reach that of as-cast, but the plastic deformation rate is only one-sixth or lower than that of as-cast. This can be attributed to the defects such as holes and unmelt powder. The flexural strength of the $\mathrm{Zr}_{59.3} \mathrm{Cu}_{28.8} \mathrm{Nb}_{1.5} \mathrm{Al}_{10.4}$ printed parts is approximately $1300 \mathrm{MPa}$, compared to $1940 \mathrm{MPa}$ in the laboratory grade cast samples, despite samples being fully amorphous for both cases [100]. The cylindrical SLM samples showed a comparatively lower yield stress of about $1710 \pm 40 \mathrm{MPa}$ and a typical plastic strain of around $0.5 \%$. The rectangular SLM specimen yielded at lower stresses of $1420 \pm 20 \mathrm{MPa}$ and failed at stress of $1540 \pm 10 \mathrm{MPa}$ with very limited irreversible flow [102]. In the fracture surface, only straight shear bands can be observed, and they form an angle of $45^{\circ}$ with respect to the loading axis. It means the shear bands propagate in a straight manner and are not affected by the layer
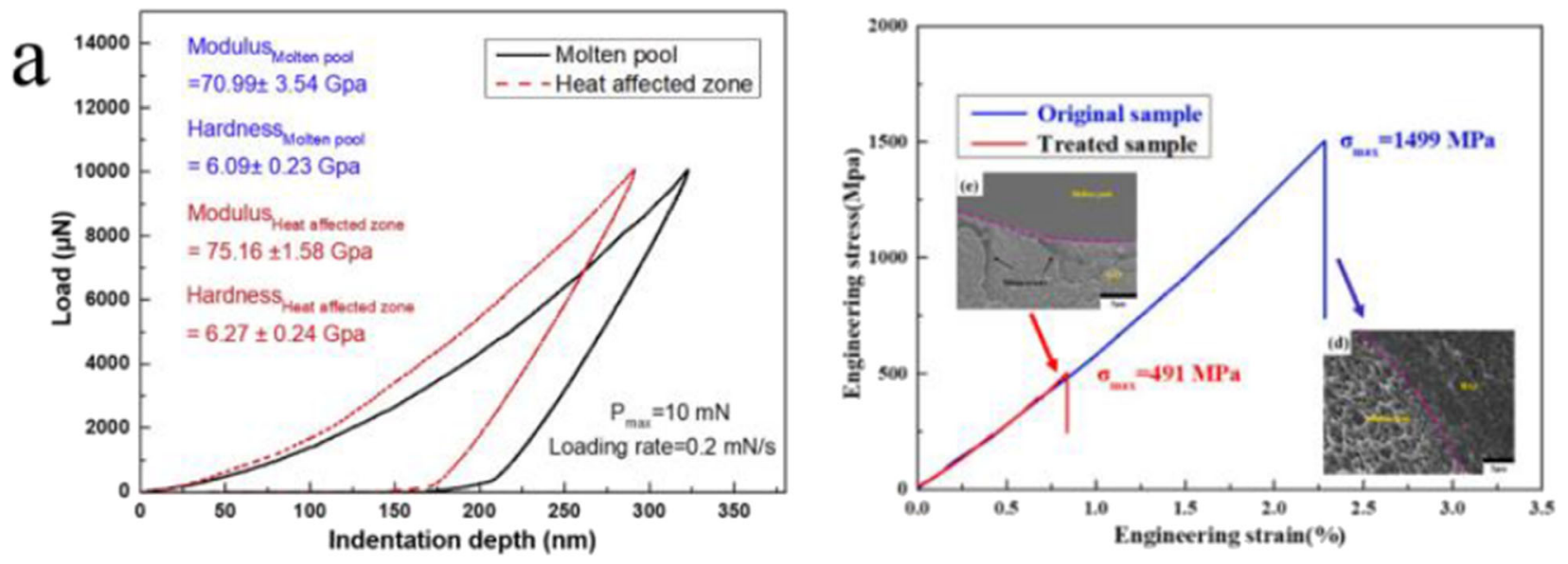

b

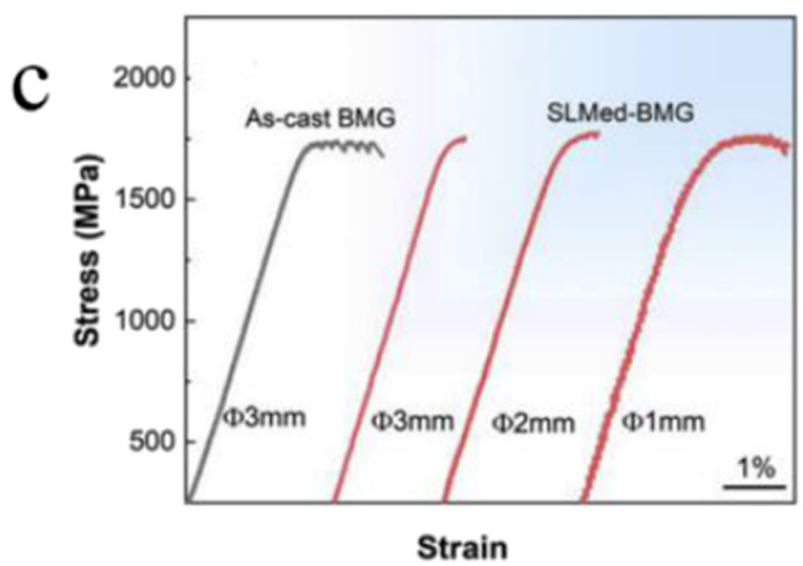

Fig. 20 a Comparison of the indentation load e depth curves of amorphous phase in molten pool and heat-affected zone respectively [93]; b compressive stress-strain curves of the 3D-printed $\mathrm{Zr}_{55} \mathrm{Cu}_{30} \mathrm{Ni}_{5} \mathrm{Al}_{10} \mathrm{BMG}$ rods after heat treatment $\left(410{ }^{\circ} \mathrm{C}-20 \mathrm{~min}\right.$, water quench), as compared with the original one [94]; c compressive stress

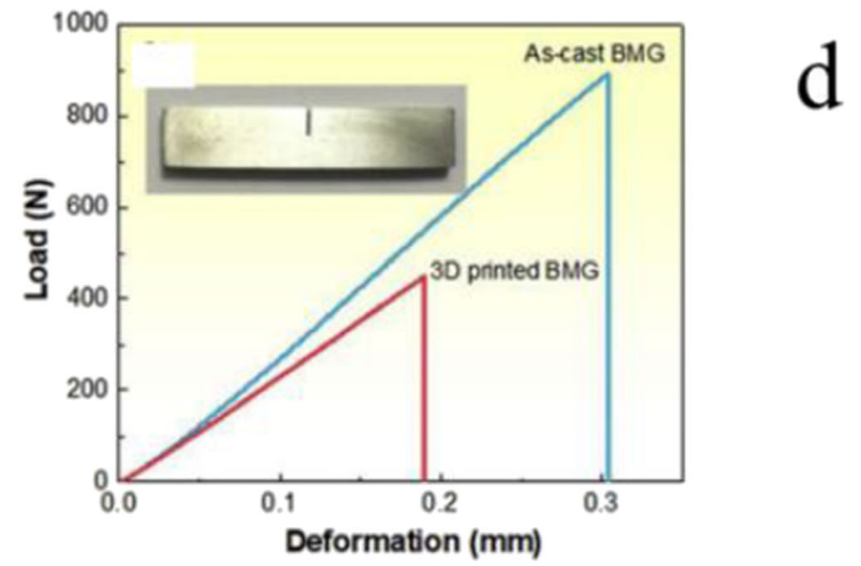

strain curves for the 3D-printed BMG samples with different rod diameters, in comparison with the as-cast BMG with a diameter of $3 \mathrm{~mm}$ [107]; d load-deformation curves for as-notched as-cast and 3Dprinted BMG samples under 3-point bending [107] 
processing, since this is a strong implication for the fact that the SLM samples are homogeneous even beyond the atomic level [102]. Moreover, the shear band cuts through the pore which can be regarded as a second phase decreasing the stress concentration during mechanical loading. Differences in the shear band propagation at the early stages of compressive loading have been also observed in glassy Zr-based micropillars obtained by casting and SLM [105]. A lower plastic strain of SLM samples compared with as-cast one can be shear bands are more stable in SLM samples, and the structural heterogeneity and uniform distribution of pores detected by nanoindentation can explain this phenomenon. In particular, the pores will change the stress state, so that the generation of shear bands is more uniform. According to the results of relationship between pores and shear band movement, it can be believed that SLM can be used to systematically manipulate the structure (heterogeneity) of metallic glasses and to study the effect of the structure on the deformation process.

Mahbooba found that the boron content has a great influence on the production of iron and boron component SLM [57]. When more than $1.5 \%$ boron is added, the plastic deformation before failure can be eliminated, and the fracture surface of the alloy presents a vein-like morphology, indicating the existence of plastic flow. When studying the SLM manufacturing of $\mathrm{Zr}_{57.4} \mathrm{Ni}_{8.2} \mathrm{Cu}_{6.4} \mathrm{Ta}_{8} \mathrm{Al}_{10}$ component, Zhang also found that the addition of plastic tantalum particles can indeed improve the plasticity of 3D-printed zirconiumbased BMG components [96]. Tantalum particles have two functions: generating multiple shear bands and preventing crack propagation. But its research still has limitations, with plastic strain reaching $2.15 \%$ and fracture toughness reaching $60 \mathrm{MPa}$. It is still too low to meet the needs of practical engineering applications. To further improve the plasticity and toughness, one method is to increase the number of tantalum particles in the amorphous powder. Unfortunately, the method of increasing the content of tantalum particles in the powder does not work because adding too much tantalum will reduce the GFA of the alloy system. But it is true that reasonable addition of tantalum can improve its mechanical properties. Li used SLM to produce $\mathrm{Zr}_{52.5} \mathrm{Ti}_{5} \mathrm{Cu}_{17.9} \mathrm{Ni}_{14.6} \mathrm{Al}_{1}$, and also found that small dark aluminum-enriched phases would affect the ductility of Zr-based BMG [104].

Interestingly, when compressing a columnar sample made by SLM, Ouyang [88], Deng [102], and Pauly [103] found the different patterns. In Fig. 21 b, Ouyang found that the fracture angle is about $90^{\circ}$, which is significantly different from the typical as-cast $\mathrm{BMG}$ (about $42^{\circ}$ ). This may be due to the layered structure and brittle crystalline phase of the 3Dprinted BMG composites dispersed in HAZ. As shown in Fig. 21 c, Deng's fracture is similar to a typical as-cast BMG (about $45^{\circ}$ ). In Pauly's experiment, there is no longer a single fracture surface. As shown in Fig. 21 a, the same as the top are two intersecting crack surfaces. Similarly, the fracture strength and plasticity of SLM specimens are lower than those of as-cast fractures. The closer the fracture morphology is to the as-cast state, the closer the fracture strength is to the as-cast state. In Fig. 21 b, the breaking strength is $80.4 \%$ of that in the as-cast state. In Fig. 21 a, the breaking strength is $87.6 \%$ of that in the as-cast state, and in Fig. 21 c, the breaking strength is $80.4 \%$ of that in the as-cast state. Regardless of fracture, the volume degree of freedom (DOF) is considered to have the greatest influence on mechanical properties. Porosity is undoubtedly one of the important factors affecting DOF. Shi believes that the macroscopic hardness is inversely proportional to the total porosity [99]. In addition, when Deng studied the friction and wear properties, it was found that the friction coefficient of the SLM sample has a more obvious numerical dispersion than the as-cast sample, which may also be related to the higher porosity [102]. Of course, this may also be related to the small range of structural heterogeneity.

In order to improve mechanical properties, many researchers tried to use other methods besides optimizing process parameters. Ouyang found that heat treatment of 3Dprinted $\mathrm{Zr}$-based BMG at the temperature of the supercooled liquid zone will strengthen the molten pool and heat affected zone [94]. Li increased the average hardness of the produced BMG and the uniformity of the hardness distribution by multiple scans [104]. The addition of the second-phase particles can also significantly improve the mechanical properties, which is similar to the mechanism of ferro-based glass described above. The interaction of the shear bands in the multi-sliding system makes the stress distribution more uniform. Under the interaction of these complex shear bands, the amorphous phase and the crystalline phase undergo threedimensional deformation during the nanoindentation test. This is the reason for increasing the yield strength of SLM BMGs. Best [182] produced AMZ4 components by SLM and studied the relationship between fracture behavior and defects of alloys. Micro X-ray computed tomography results together with electron microscopy imaging revealed porous processing defects in SLMed AMZ4 that led to a loss in tensile strength. Fatigue crack growth studies revealed a fatigue threshold, $\Delta K_{\mathrm{th}}$, of $\sim 1.33 \mathrm{MPa} \sqrt{\mathrm{m}}$ and a Paris law exponent of $m=$ 1.14 , which are relatively low values for metallic materials. A $K_{\text {IC }}$ fracture toughness of SLMed BMG samples is much lower than that of cast alloy with the same composition. The lower fracture toughness of the laser processed AMZ4 was attributed to $\sim 7.5 \times$ higher dissolved oxygen in the structure when compared to the cast AMZ4. Despite the higher level of oxygen, the formation of oxide nanocrystals was not observed by transmission electron microscopy. Structural and mechanical characterizations were performed on the X-ray amorphous commercial BMG-forming alloy, AMZ4, produced using both SLM-processing and suction-casting by Best [183]. Fracture toughness of the SLM-processed BMG was found to be lower than the as-cast material; $29 \mathrm{MPa} V_{\mathrm{m}}$ is 

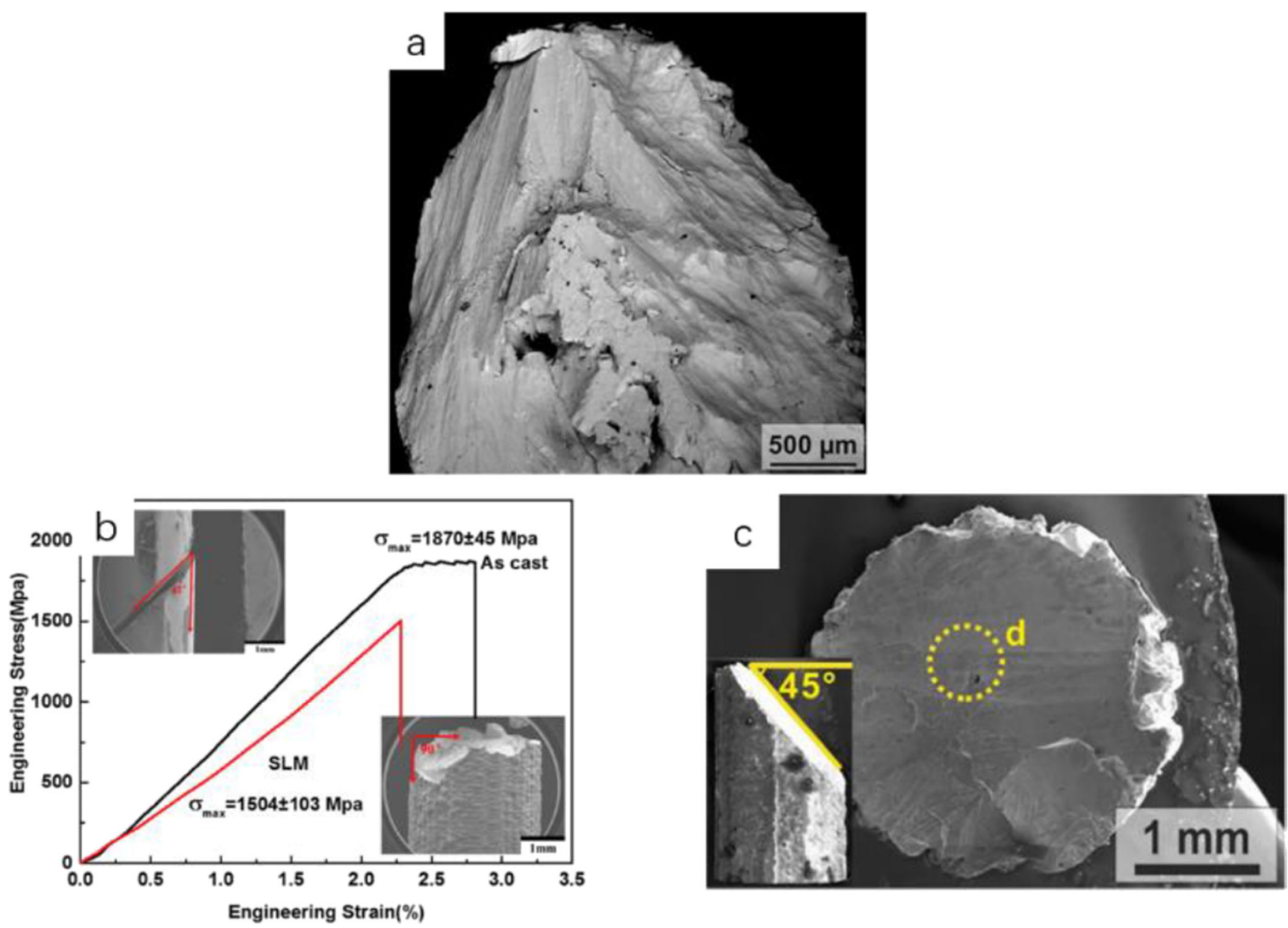

Fig. 21 Different fracture patterns; a roof fracture [103], b flat fracture [88], c 45 fracture [102]

comparable to many commonly used engineering alloys. This suggested that SLM processing may be a viable method for producing large BMG components with damage tolerance properties sufficient for engineering applications. Largescale and fully amorphous Zr-based BMG tensile specimens with different levels of porosity were successfully fabricated through SLM [184]. The tensile strength decreases rapidly from pore-free to pore-containing BMG, while Young's modulus is less sensitive to the porosity, especially in the low porosity scope. The FEM model showed the pore-free BMG prepared by SLM had abundant uniformly distributed shear bands, with a fracture angle of $50^{\circ}$ between the tensile axis, while the pore-containing BMGs first developed plastic deformation around some of the pores, forming shear transformation zones (STZ). As these STZ were interconnected during further loading, highly localized shear bands are formed, which quickly lead to the final fracture surface, which is the main fracture mechanism in pore-containing BMG. The size and spatial distribution of the pores are considered to be the main factors determining the direction of the fracture surface.
Other-based BMGs by SLM High-strength and thermally stable $\mathrm{Al}_{85} \mathrm{Nd}_{8} \mathrm{Ni}_{5} \mathrm{Co}_{2}$ samples were prepared by SLM [112]. At room temperature, it showed a very high yield strength of $0.94 \mathrm{GPa}$ and an ultimate compressive strength of $1.08 \mathrm{GPa}$ along with $2.45 \%$ plastic strain. The alloy exhibited high compressive strength (1-0.5 GPa) at high temperatures (303-573 K). Additionally, interfacial strengthening, the crack arrest, and crack deflection mechanisms also contribute to the superior strength observed in the $\mathrm{Al}_{85} \mathrm{Nd}_{8} \mathrm{Ni}_{5} \mathrm{Co}_{2}$ alloy. BMGCs that underwent a re-scan exhibited a higher average hardness $(\sim 1.41 \mathrm{GPa})$ compared to those for a single scan $(\sim 1.07 \mathrm{GPa})$ [43]. In particular, the stress relief provided by the re-scan is likely to reduce the free volume of the material, which is well known to increase the hardness of BMGCs [185]. This could also be due to a Gaussian distribution of laser energy, which means that the amount of stress relief across the material is not constant. This in turn leads to a different amount of increase in hardness (due to the aforementioned reduction in free volume), and thus a greater change in hardness [110]. The elastic modulus of the MG was almost identical with different laser power $(\sim 100,85$, and $105 \mathrm{GPa}$ for center, middle, and edge, 
respectively). The serrated flow behavior of the SLM processed $\mathrm{Al}_{86} \mathrm{Ni}_{6} \mathrm{Y}_{4.5} \mathrm{Co}_{2} \mathrm{La}_{1.5} \mathrm{MG}$ with different laser powers.

All SLM samples with $\mathrm{Ti}_{47} \mathrm{Cu}_{38} \mathrm{Zr}_{7.5} \mathrm{Fe}_{2.5} \mathrm{Sn}_{2} \mathrm{Si}_{1} \mathrm{Ag}_{2}$ glass reach a high relative density above $98.5 \%$ and a high compressive strength around $1700 \mathrm{MPa}$ which was lower than that of cast sample (2000MPa) [113]. Unlike the as-cast rods, one cannot identify a clear fracture plane for the SLM samples. The defects introduced during additive manufacturing seem responsible for the premature failure and the differences in the fracture morphology. No plastic strain can be observed in the case of the additively manufactured $\mathrm{Cu}_{46} \mathrm{Zr}_{46} \mathrm{Al}_{8}$ BMGs, irrespective of the processing condition [118]. The SLM samples prepared with different energy input fractured at stresses ranging from 1180 to $1560 \mathrm{MPa}$, and their Young's modulus ranges between 76 and $84 \mathrm{GPa}$. The fracture surface of the compressed SLM sample is rugged and manifold, and inclined fracture planes can be observed, indicating a complex fracture process differing from a pure shear fracture [103]. A crack started from the lateral surface and stopped within the glass. It may be initiated from stress concentrators at the rough lateral surface and subsequently propagated towards the interior of the rod.

Compared with those of the BMGCs fabricated using traditional technologies [177], Gao's work showed that the hardness and elastic modulus of the $\beta$ and amorphous phases in the BMGC fabricated via SLM are both higher [55]. It should be noted that the volume fraction of the amorphous phase in BMGCs is only approximately $20 \%$. As we know, during the plastic deformation of the composite material, the amorphous phase is the hard phase, which enhances the flow resistance [186]. The $\beta$ phase is a soft phase, which can hinder the propagation of the shear band [187]. Due to the difference between hardness and elastic modulus, the stress tends to concentrate on the interface between the amorphous phase and the $\beta$ phase during the plastic deformation process [188], where it promotes the initiation of shear bands. If the number of such interfaces in the material is large enough, the interaction of the shear bands in multiple sliding systems will result in a more uniform stress distribution [189]. Under the action of these multiplying and interacting shear bands, the amorphous phase and $\beta$ phase may undergo coordinated deformation during the indentation process, which will greatly improve the plasticity of the material [190].

The hardness improved significantly with increasing $\mathrm{Cu}$ content, and the plasticity decreased correspondingly [114]. Cracks appeared in $\left(\mathrm{Ti}_{0.65} \mathrm{Zr}_{0.35}\right)_{90} \mathrm{Cu}_{10}$ and $\left(\mathrm{Ti}_{0.65} \mathrm{Zr}_{0.35}\right)_{85} \mathrm{Cu}_{15}$ BMGs. Although the average volume fraction of the $\beta$ phase was about $90 \%$, the yield strength of $\left(\mathrm{Ti}_{0.65} \mathrm{Zr}_{0.35}\right)_{95} \mathrm{Cu}_{5}$ was $1386 \pm 64 \mathrm{MPa}$ reached a similar yield strength like samples fabricated using conventional technologies. This could be attributed to two factors: (1) a finer microstructure in $\left(\mathrm{Ti}_{0.65} \mathrm{Zr}_{0.35}\right)_{95} \mathrm{Cu}_{5}$; (2) twinning and martensitic transformation of the $\beta$ phase.
Interestingly, the study found that loading direction and scanning hatching space also play an important role in the fracture strength of the sample [116]. Figure 22 a shows the stress-strain curve of an alloy with a $60-\mu \mathrm{m}$ hatch spacing. Figure $22 \mathrm{~b}$ shows the stress-strain curve of the alloy with a hatch spacing of $85 \mu \mathrm{m}$. When perpendicular to the layer, the breaking strength of the test piece in the load direction perpendicular to the layer was $0.93 \mathrm{GPa}$, and when perpendicular to the layer, the breaking strength of the test piece was 0.67 $\mathrm{GPa}$. It is worth noting that under the condition that the stress is parallel to the layer, some special deformations may occur in the elastic region according to the stress-strain curve. According to reports, in SLM, thermal stress is accumulated layer by layer [191]. In research, if the specimen is loaded parallel to the horizontal line, the specimen will usually break in the horizontal direction. The stress-strain abnormal curve may be related to the stress release between the layers.

The 3D-printed BMGs exhibited excellent mechanical properties with a compressive strength of $1.8 \mathrm{GPa}$, plastic strain of $3.17 \%$, and notched fracture toughness of 33.4 $\mathrm{MPa} \cdot \mathrm{m}^{1 / 2}[117]$. The enhanced plasticity and fracture toughness are attributed to the cooperation of the TRIP effect from B2 to B19' phase transformation in HAZs and the block effect of the "brick-and-mortar" structure in the printed samples. This provides a new idea of plasticized material design for the SLM additive manufacturing of large-sized components of metal glass composite materials.

\subsubsection{Wear resistance}

The tribological properties of SLM-BMGs were studied, and it was found that the friction coefficient showed a similar trend to the friction coefficient of as-cast samples [102]. The coefficient of friction and the surfaces of the SLM samples at different stages of wear testing are illustrated in Fig. 23. The coefficient of friction (Fig. 23a, b) shows a similar trend like the as-cast specimen. In addition, when the initial steady-state ends, the wear pattern changes after $35 \mathrm{~min}$. But compared with as-cast glass, the friction coefficient fluctuated more obviously after $80 \mathrm{~min}$, and the maximum value was significantly higher than as-cast glass. As long as the wear mode is pure wear (within the first $60 \mathrm{~min}$ ), the wear surface of the SLM sample cannot be distinguished from the as-cast sample. In the later period of wear, more plastic deformation materials with smaller area were found. The study found that in the later stage of wear, the wear form of metallic glass changed to a "brittletough" mixed phase. It is worth noting that the friction coefficient scattering of SLM samples is more obvious than that of as-cast materials. This may be related to high porosity at small scales or inherent structural heterogeneity. Zhang observed many furrows parallel to the sliding direction in the friction and wear experiment, and found some flaky wear debris around the wear track [107]. EDX analysis shows that in 
(a)

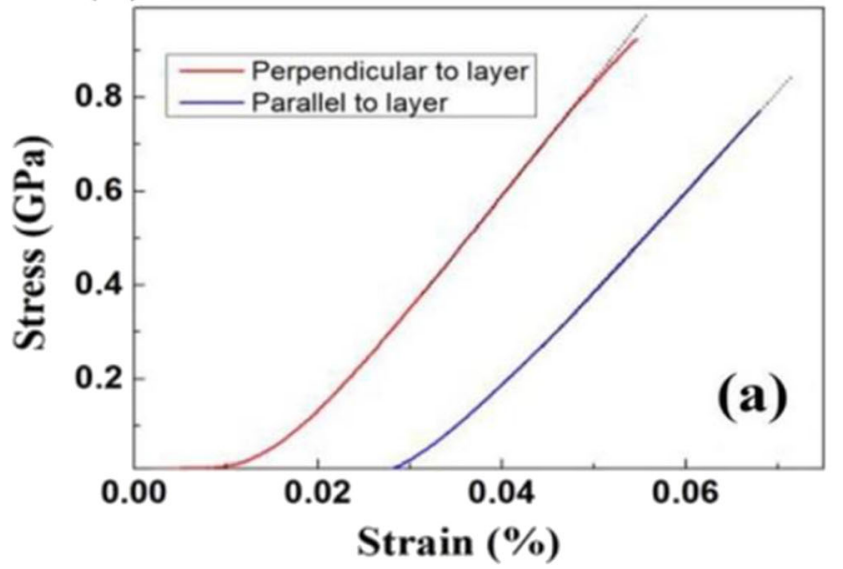

(b)

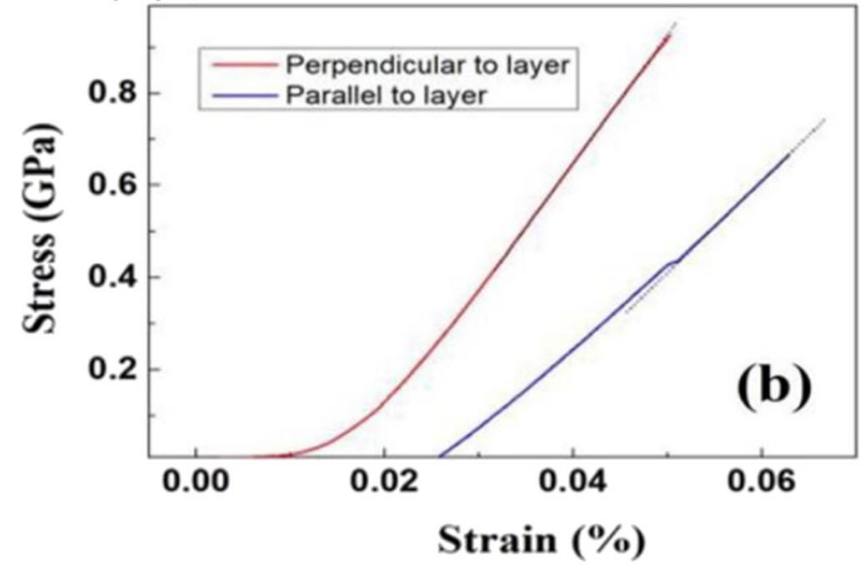

Fig. 22 a Stress-strain curves of the alloys with a hatch spacing of $60 \mu \mathrm{m}$; b stress-strain curves of the alloys with a hatch spacing of $85 \mu \mathrm{m}$ [116]

addition to metal elements such as $\mathrm{Zr}, \mathrm{Cu}$, and $\mathrm{Al}$ (base metals in 3D-printed BMG), wear debris also contains rich oxygen, indicating that complex metal oxide SBF was formed during the oxidation process in the wear test. These patterns illustrate the mechanism of simultaneous abrasive wear and oxidative wear during 3D printing BMG wear. In general, the resulting
Fig. 23 a, b Display the coefficient of friction for the Zr52.5Cu17.9Ni14.6Al10Ti5 sample produced by SLM. A similar trend as in panels a and $\mathbf{b}$ becomes obvious. Panels $\mathbf{c}$ to $\mathbf{f}$ show the SEM images of the worn surfaces after 30, 60, 120, and $480 \mathrm{~min}$ of wear testing. The SLM samples exhibit a comparable wear performance as the as-cast samples [102]
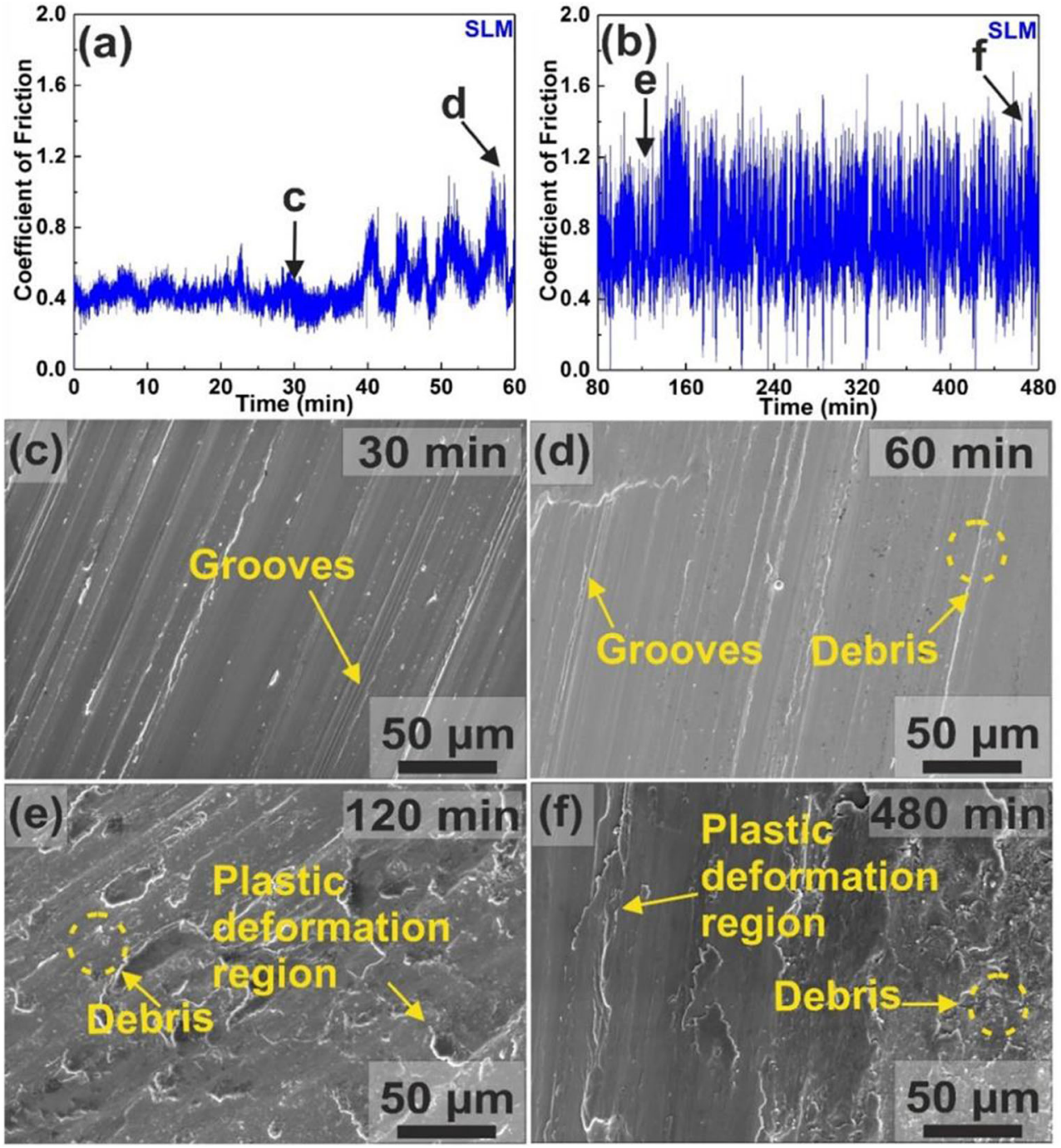
oxide film is easily broken due to brittleness, which can further promote the accumulation of wear debris and plows. In the experiment of strengthening $316 \mathrm{~L}$ composite material with SLM-BMG, Zhang found that the COF curve of the composite material tends to be stable, while the $316 \mathrm{~L}$ COF curve has been fluctuating throughout the wear test [87]. The average value of composite $\mathrm{COF}$ is 0.49 , which is $21 \%$ lower than $316 \mathrm{~L}$ (0.62). Compared with $316 \mathrm{~L}$, the wear quality loss of the composite material is also reduced by about $20 \%$, indicating that the amorphous alloy strengthening can significantly improve the wear resistance of the 316L matrix. The effect of normal load and sliding speed on the microstructure, tribological properties, and wear mechanisms of ex situ additively manufactured $\mathrm{FeCrMoCB} / \mathrm{Cu} \mathrm{BMG}$ was systematically investigated [81]. The unique amorphous-crystalline microstructure gave rise to a well wear resistance. The friction coefficient fluctuated due to the different shear stress on the amorphous matrix and crystal phase at the initial stage of friction and wear.

\subsection{Physicochemical properties}

\subsubsection{Magnetic property}

Conventional properties such as magnetism $[64,192]$ and corrosion resistance [193-195] have been extensively studied in as-cast amorphous. Jung [70] found that the geometrical structure and microstructure of the magnetic material have a certain influence on the shape hysteresis of $\mathrm{M}-\mathrm{H}$. As mentioned above, micropores and cracks were often observed in the SLM samples. These structural defects will generate a large demagnetizing field and inhibit the movement of domain walls. Therefore, the micropores and cracks formed in the SLM sample delayed the magnetic response to the applied magnetic field. Similarly, the thermal history of the material is the main factor affecting the external magnetism. The high cooling rate and residual stress caused by the directional solidification process introduce stress-induced magnetic anisotropy into the material. A double-scan strategy has been employed with the aim of amorphous phase fraction enhancement as well as densification [50]. The results shown that double scanning effectively fills voids generated due to partial melting of powders, and leads to relative density of up to $96 \%$ and corresponding saturated magnetization of $1.22 \mathrm{~T}$. More importantly, the double-scan strategy stimulates reflow in the melt pool, securing compositional uniformity, and eventually enhances amorphous phase fraction to a value as high as $47 \%$. Consequently, coercivity has been significantly decreased, which in turn reduces core loss and increases permeability. In Fig. 24(a, b), $M_{\mathrm{s}}$ and coercivity as a function of $E_{\mathrm{d}} . M_{\mathrm{s}}$ has a linear dependence on the density, and maximum $M_{\mathrm{s}}$ of $1.22 \mathrm{~T}$ was obtained with double scanning.

\subsubsection{Corrosion resistance}

Deng [102] believed that the polarization curve of the sample prepared by SLM is generally similar to that of the as-cast sample, as shown in Fig. 25. However, the susceptibility to pitting corrosion of BMG prepared by SLM is slightly reduced, and the surface repair ability is slightly improved. The main reason is that the common structural defects in the as-cast samples are more harmful to the corrosion stability than the pore defects in the SLM samples. The former is characterized by a clear chemical discontinuity with the vitreous matrix phase boundary, while the latter is a geometric discontinuity, leading to low chloride ion erosion driving, leading to the formation and diffusion of pits. Luo [109] compares amorphous and polycrystalline components of the same component. Large metallic glasses with amorphous structures usually exhibit good corrosion resistance. Two orders of magnitude are higher than polycrystalline alloys of the same composition, which can be explained by the absence of structural defects, such as dislocations or grain boundaries [196]. A variety of corrosion-resistant zirconium-based BMGs have been developed, and corrosion resistance has been shown to depend on the above two factors. Therefore, the corrosion rate of SLM samples increases with the increase of exposure time, which is related to the decrease of amorphous content caused by laser thermal effect. In order to further explore the SLM process, amorphous has a positive effect on corrosion resistance. By measuring the potential polarization curves of as-cast $316 \mathrm{~L}$, SLMed 316L, and SLMed composite, the corrosion behavior of these three materials were studied [87]. The pitting potential $\left(E_{\mathrm{pit}}\right)$ values of the two samples are shown in Fig. 25 . The $E_{\mathrm{pit}}$ value of the SLMed $316 \mathrm{~L}$ is $0.64 \mathrm{v}$, which is about $100 \mathrm{mV}$ higher than that of the as-cast $316 \mathrm{~L}$ sample $(0.55 \mathrm{v})$. In addition, the $E_{\mathrm{pit}}$ value of the composite sample is $0.75 \mathrm{~V}$, which is about $200 \mathrm{mV}$ higher than the as-cast $316 \mathrm{~L}$ sample. Therefore, the amorphous alloy $316 \mathrm{~L}$ manufactured with SLM has the highest corrosion resistance.

\subsubsection{Catalytic property}

BMGs with advanced catalytic properties have attracted increasing attention in the field of catalysis due to their disordered atomic packing structure (compared with the wellarranged structure in crystal alloy) [68, 197]. The attractive catalytic power of BMGs stems from the low thermal activation barrier [198]. Liang [75] made porous Fe-based BMG matrix composites with complex diamond-shaped dodecahedron microstructure. The iron-based metallic glass composite porous material produced by SLM has been used for catalytic activation in Fenton-like processes and sulfate-based reactions. The results show that up to 45 times the reusability can be achieved in the sulfate-based reaction without any obvious efficiency degradation, which is the highest reusability 
(a)

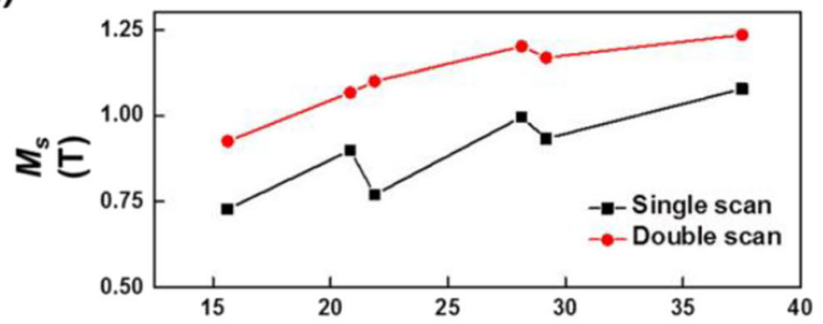

(b)

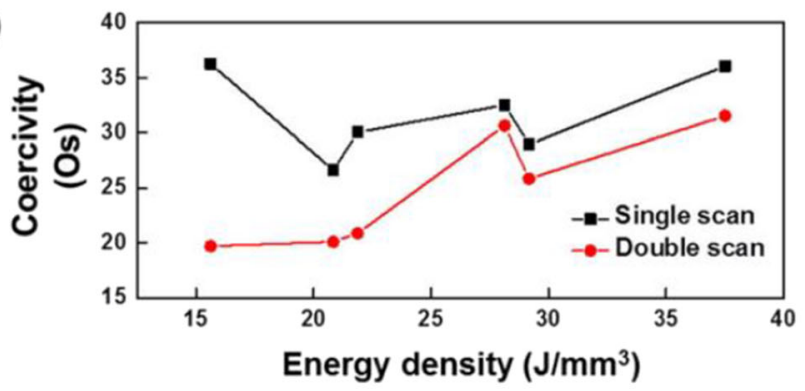

(c)

(d)
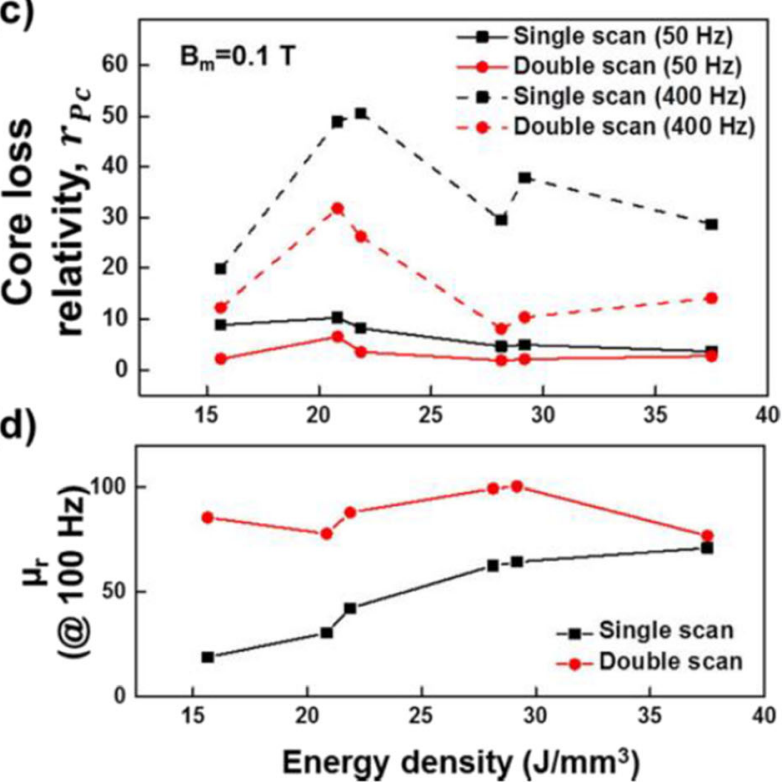

Fig. 24 (a) Saturated magnetization $\left(M_{\mathrm{s}}\right)$, (b) coercivity, (c) core loss relativity, and (d) relative permeability as a function of energy density for the SLMed alloys [50]

of the catalyst under high efficiency so far. Studies believe that the excellent catalytic reusability comes from the extremely low surface attenuation in the sulfate radical reaction. In addition, structural analysis shows that $\alpha$-Fe nanocrystals can trigger more electron transfer, but too much $\alpha$-Fe will cause the catalytic effect of the metal glass matrix composite to be inhibited. Catalytic performance of SLM-produced Fe-based MG matrix composite in the Fenton-like process is shown in Fig. 26. Yang $[89,90]$ found SLM 3D printing may be a promising way to produce BMG with complex geometry and enhanced catalytic properties. In order to make use of the complex geometry of BMGs in 3D printing, the printed $\mathrm{Zr}_{55} \mathrm{Cu}_{30} \mathrm{Ni}_{5} \mathrm{Al}_{10}$ BMG specimens were treated with chemical dealloying to generate the nano-pore structure of $\mathrm{Cu}$ on the surface of BMG. It was found that the nanostructured structure showed outstanding catalytic performance for MO degradation [89]. In addition, lattice structure has better catalytic performance than hollow structure and cubic structure, as shown in Fig. 27. The resulting 3D-printed nanoporous $\mathrm{Cu}$ (3D NP$\mathrm{Cu})$ has a specific surface area that is 660 times that of conventional $2 \mathrm{D}$ belts or powder catalysts. The 3D NP-Cu catalyst shows high degradation efficiency for azo dyes, and its kinetic reaction constant is $0.147 \mathrm{~min}^{-1}$, which is 14 times that of commercial $\mathrm{Cu} 2+$ catalysts and 4 times that of $\mathrm{CuO}$ powder. What is impressive is that the 3D-printed NP-Cu exhibits quite good reusability and excellent versatility [90]. These two
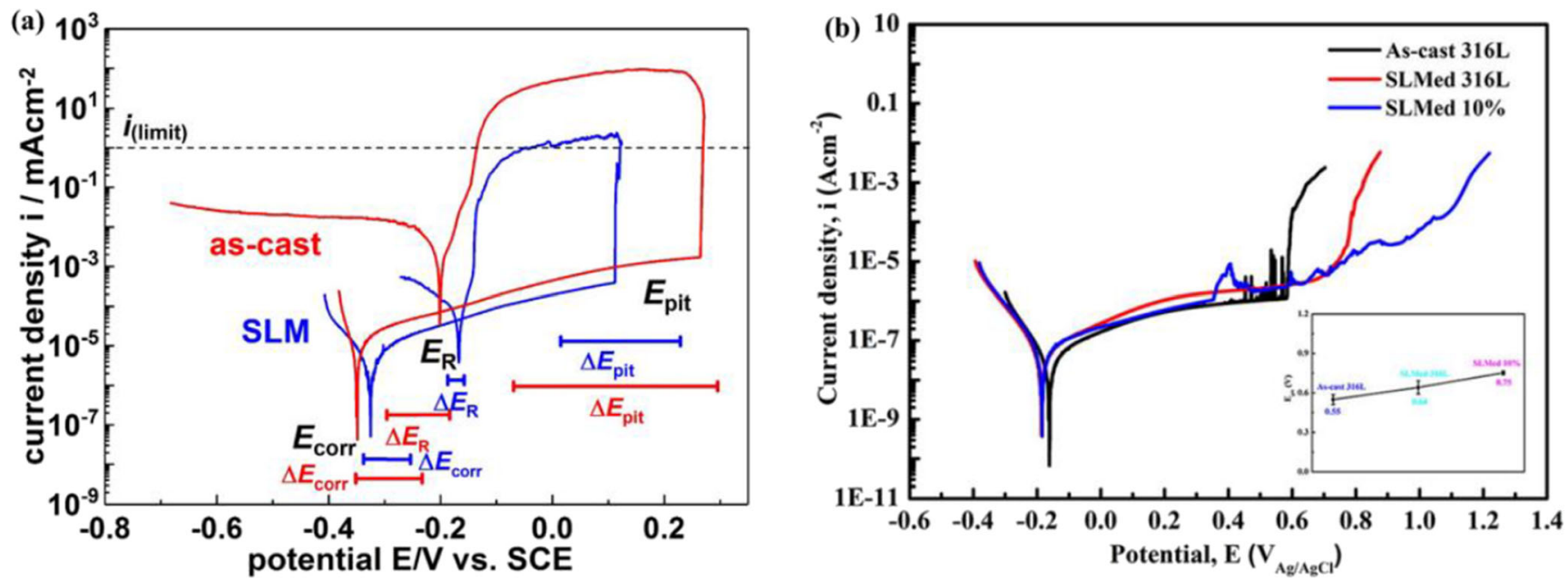

Fig. 25 a Anodic polarization curves recorded for $\mathrm{Zr}_{52.5} \mathrm{Cu}_{17.9} \mathrm{Ni}_{14.6} \mathrm{Al}_{10} \mathrm{Ti}_{5} \mathrm{SLM}$ and as-cast samples in $0.01 \mathrm{M} \mathrm{Na}_{2} \mathrm{SO}_{4}+0.1 \mathrm{M} \mathrm{NaCl}$ solution [102]; b potentiodynamic polarization curves and pitting potentials (Epit) of as-cast 316L, SLMed 316L, and SLMed composite [87] 

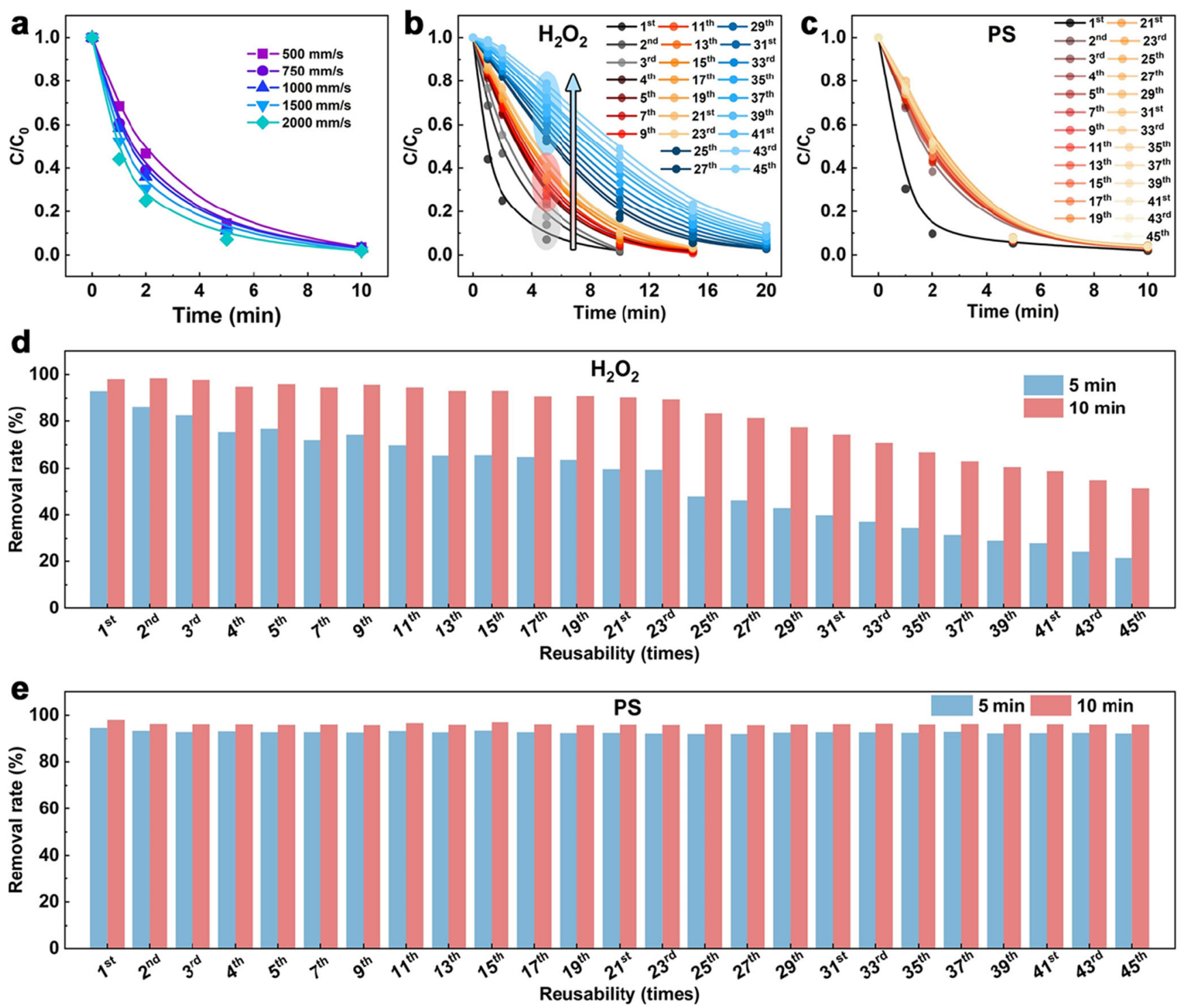

Fig. 26 a Effect of laser scan speed on the catalytic performance of SLMproduced Fe-based MG matrix composite in the Fenton-like process. b The reusability (up to 45 times) of SLM-produced Fe-based MG matrix composite (at laser scan speed of $2000 \mathrm{~mm} / \mathrm{s}$ ) in b Fenton-like process
$\left(\mathrm{H}_{2} \mathrm{O}_{2}\right)$ and $\mathbf{c}$ sulfate radical-based reaction (PS) for degrading BR3B-A dye (peroxide concentration: $1 \mathrm{mM}$, dye concentration: $20 \mathrm{ppm}$ ). $\mathbf{d}$ and $\mathbf{e}$ are corresponding dye removal rates of $\mathbf{b}$ and $\mathbf{c}$, respectively, at 5 and $10 \mathrm{~min}[83$ ] works of Yang may stimulate new 3D printing micro/nanostructured metal catalysts to treat wastewater as a new academic hotspot. These present studies also demonstrate that the SLM 3D printing technique could be a promising approach for manufacturing BMGs with complex geometries and enhanced catalytic properties. In addition, Yang has developed a 3D porous $\mathrm{MG} / \mathrm{Cu}$ catalyst structure prepared by SLM, which exhibits extraordinary catalytic efficiency in the degradation of $\mathrm{RhB}$, and its normalized rate constant is about 620 times higher than that of commercially available nano-zero-valent iron. This performance parameter exceeds the Fenton type catalyst that has been reported the most so far. Surprisingly, these catalysts have excellent reusability and can be used more than 100 times (the highest record so far) without a significant drop in efficiency [82].

\subsubsection{Biocompatibility}

Schroers [199] reported that BMGs exhibited better cell growth and adhesion support than the crystals. But the technology has never been used because BMGs have been stuck with a problem that is hard to process. However, with the development of SLM technology, it is possible to apply BMGs to biological materials. Zhang [107] made a comprehensive study of the relevant properties in the application of SLM-Zr BMG biological materials. The SLMed BMGs in 

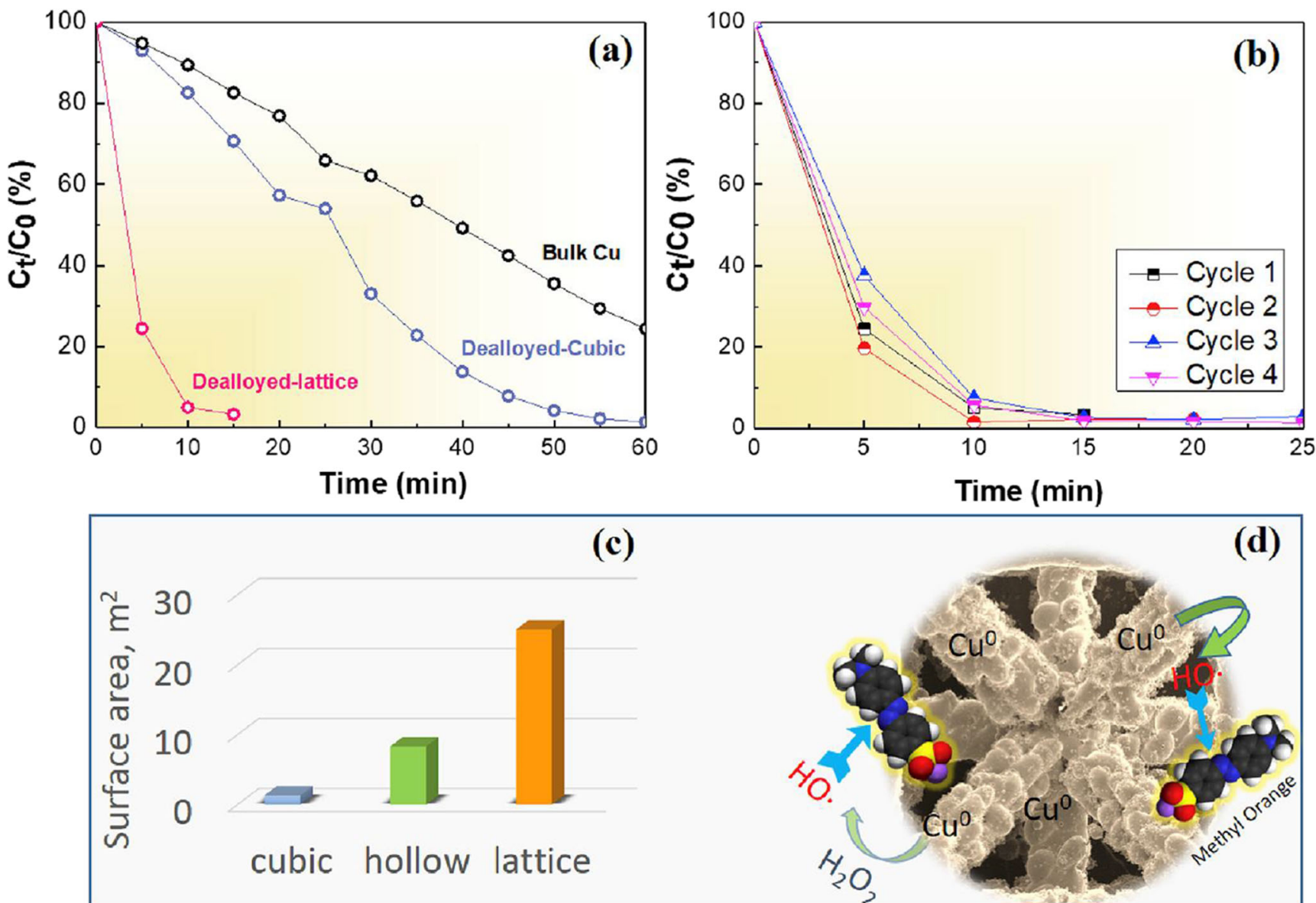

Fig 27 a Degradation rate as a function of time for the 3D-printed cubic and lattice samples with a nanoporous surface, compared to a polycrystalline $\mathrm{Cu}$. b The cycling stability of the dealloyed lattice sample. c The surface area of the 3D-printed BMG components with

SBF solution also showed excellent anti-biological corrosion performance and the results can be seen in Fig. 28. The metal ions released after soaking in SBF for 30 days were lower than the safety limit for biological implantation applications. In vitro cell culture assessment showed that 3D-printed BMG has good biocompatibility and cell proliferation support, which is also comparable to the commercial Ti6Al4V alloy. In addition, the 3D-printed BMG with Ag also showed outstanding antibacterial ability against Escherichia coli. Deng [113] applied Ti-based BMGs without the toxic element Be by SLM to be potential biological materials and also obtained positive results. The SLM samples fracture at lower stress $(1690 \pm 50 \mathrm{MPa})$ without any significant plastic deformation.

\section{Prospective and challenge}

The layer-by-layer fabrication process renders SLM attractive for fabricating large-size MGs with complex geometries. This article provides a comprehensive review of the current various geometries under equivalent sample mass (27.2 g); and d schematic illustration of the benefit of the hierarchical-porous-structure in the degradation of methyl orange [89]

research on the process and performance evaluation of the structure of bulk metallic glass prepared by SLM, including the current research status, unresolved problems, main challenges, potential applications, and prospects for future research.

In the past 10 years, researchers all over the world have made great efforts to explore the possibility of using different emerging AM technologies to manufacture various BMGs, and strive to reveal relationship between the processing technology and microstructure of BMGs prepared by these AM methods. At present, there are still great technical difficulties in the manufacture of metallic glass powder for SLM. On the one hand, it is the crystallization and particle size control of the powder, and on the other hand, the production cost of the powder. The current research is mainly BMG powder materials prepared by conventional manufacturing techniques (gas atomization or elemental powder mixture). Therefore, not all currently available BMG powders are suitable for SLM manufacturing, which severely limits process development and the quality of manufactured BMG components. Therefore, especially for BMG additive manufacturing, the 
Fig. 28 a Acetabular cup; b femoral prosthesis; c potentiodynamic polarization curves of 3D-printed BMG sample, as compared to that of the as-cast BMG and Ti6Al4V alloy in the SBF solution at $37^{\circ} \mathrm{C}[107]$

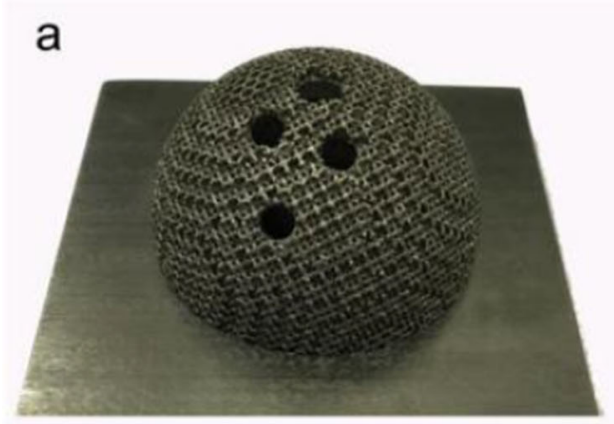

b

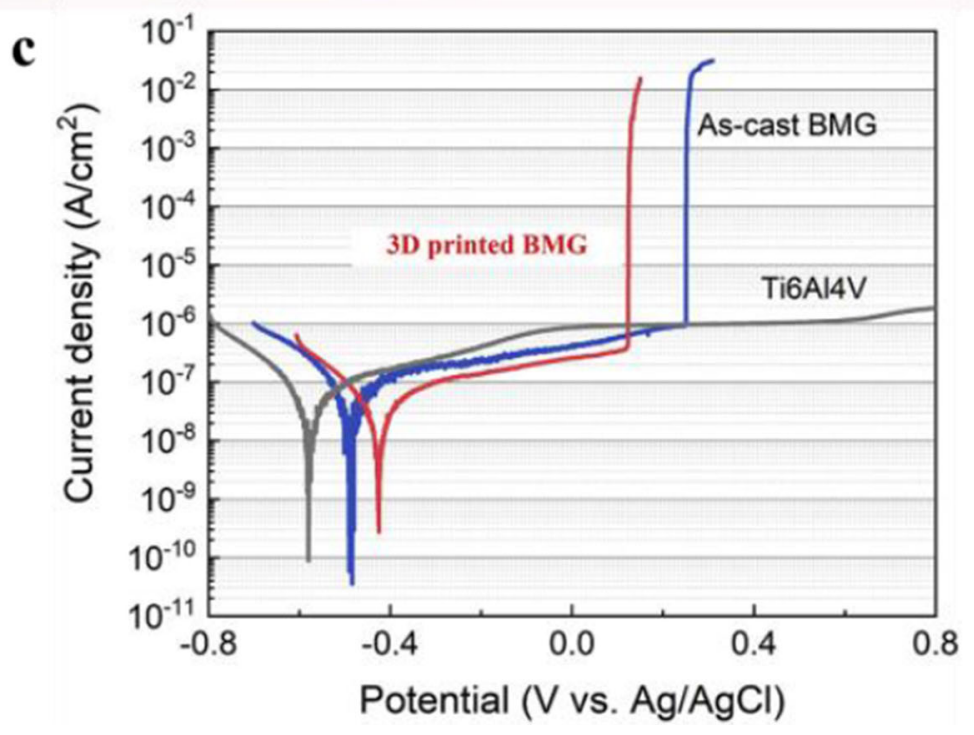

design and development of SLM-specific BMG powder materials is very important and necessary, which will require further research [33].

In addition to zirconium-based amorphous alloys with the strongest ability to form amorphous alloys, there have been a certain number of laboratory production of alloys with multiple component systems. Other alloy systems such as ironbased amorphous alloys and aluminum-based and nickelbased amorphous alloys have basically failed to form stable production, which adds a relatively high technical threshold to the subsequent SLM manufacturing of bulk metallic glasses. Completely amorphous alloys can already be achieved in the preparation of SLM in some alloy systems, but it is still a challenge due to the low glass forming ability or poor thermal stability of most MG systems. In terms of the HAZ in each layer during SLM, the crystallization problem becomes more serious and more difficult to completely avoid. Since the thermal history of different regions of MG manufactured by SLM (such as molten pool and HAZ) is different, different regions have different crystallization mechanisms. The current research on crystallization mainly relies on finite element simulation and molecular dynamics simulation to understand the crystallization kinetics of the SLM bath during laser irradiation through calculations to help the development and optimization of BMGs. Although the onset of crystallization has been predicted by some simulations, the situation is more complicated when considering vaporization, plasma effects, temperature dependence of material properties, and changes in the chemical composition of BMGs. Therefore, it is still a big challenge to establish a complete temperature field model in the laser irradiation process of SLM. If the crystalline and amorphous phase ratios of the metallic glass SLM manufacturing process can be controlled, the application fields of this new composite material will be greatly expanded, such as the design and development of new BMG materials, customization or complex geometric structures, multiple BMG structures, and functional components and equipment, such as detectors, sensors, actuators and medical, mechanical energy consumption, catalysis, and micro-electromechanical and magnetostrictive equipment. According to the current research results on the preparation process, a large energy density input is not conducive to the retention of the amorphous phase, and a small heat input will reduce the density, which is a contradiction. Through precise calculation and control of laser energy input, the expected tissue structure and performance can be obtained.

Although SLM still faces arduous challenges in preparing powders for metallic glass and its own processing technology, 
the efforts of scholars all over the world have proved that SLM can break through the size limit of bulk metallic glass manufacturing, which is the main limitation of producing BMG through traditional manufacturing methods. Based on the existing SLM manufacturing of bulk metallic glass, its forming accuracy can reach $40 \mu \mathrm{m}$. The application of various bulk metallic glasses, such as zirconium-based BMG, can be applied to sports goods, pressure sensor diaphragms, computers, smart phones, etc. Due to their high durability and excellent wear resistance, they can be used in complex gear mechanisms and micro gear motors. Due to their high elastic strain, they can be applied to coil springs. Based on the excellent scratch resistance and mechanical properties of zirconium-based BMG, they can also be used in the jewelry field. In addition to reducing the roughness in the AM process, post-treatment steps, such as those involving the formation of a coating or oxide on the surface, are generally not required. At present, the research trend of amorphous alloy SLM manufacturing is that on the one hand, the development of new materials is in progress, and on the other hand, the research results of material forming in the early stage have promoted the continuous development of new structures, such as the honeycomb structure [137] and metal frame reinforced BMG composites [31]. The composite material greatly improves the specific strength, quasi-plasticity, and elastic elongation of the metallic glass SLM structure. Greer even used sputtered $\mathrm{Zr}-\mathrm{Ni}-\mathrm{Al}$ metallic glass to prepare nano-sized (less than $100 \mathrm{~nm}$ ) three-dimensional periodic structures [200]. Frey reported for the first time the application of thermoplastic molding to SLM molded parts to reduce surface roughness, and to imprint fine structured surface patterns without complex abrasive processing [201]. Due to the unique amorphous structure of BMG, it is the only metal material that can be thermoplastically molded. This is a clear advantage compared to crystalline alloys and allows novel production routes, especially for medical and jewelry applications. This BMGspecific post-processing method can perform functional processing on the metallic glass surface of the bulk structure formed by the highly complex SLM processing. Another latest application of SLM to prepare BMGs is that SLM was used to prepare a zirconium-based amorphous alloy in the first step, and in the second step, a ZrN film was plated on the surface of the alloy by magnetron sputtering [202]. The roughness of the film has a decisive influence on the bonding strength of the film. A novel approach for the fabrication of 3D MG structures using laser-induced forward transfer (LIFT) is developed to make micrometer-scale structure. Inherent tremendous cooling rates associated with the metal LIFT process $\left(\approx 10^{10} \mathrm{k} \mathrm{s}^{-1}\right)$ make the formation of a variety of BMGs accessible and it is very attractable for the application in microelectromechanical system devices [203].

The abovementioned combination of SLM preparation BMGs technology and other material processing technologies is another new technical route for BMG preparation in the future. This not only provides new ideas for the preparation of BMG complex structures, but also expands the application of BMG from structural materials to functional materials. At last, some research opportunities and directions related to SLM manufacturing of BMG, including processing defect detection, mechanical performance evaluation, functional material application, low-cost metallic glass powder, and new additive manufacturing technology, are also worthy of indepth study.

Author contribution Dr. Peilei Zhang is the main author in organizing and drafting this paper. Dr. Jie Tan particularly contributes to reviewing the simulation works in Section 2.5. Dr. Hua Yan mainly contributes to reviewing the properties of BMGs in Section 3. Prof. Zhishui Yu and Dr. Yingtao Tian contribute to structuring, drafting, and editing the manuscript.

Funding This research was supported by the Natural Science Foundation of China (52075317), the Royal Society through International Exchanges 2018 Cost Share (China) scheme (IEC\NSFC \181278), and the Shanghai Science and Technology Committee Innovation Grant (19511106400, 19511106402).

Data availability Not applicable

Code availability Not applicable

\section{Declarations}

Ethics approval Not applicable

Consent to participate Not applicable

Consent for publication Not applicable

Conflict of interest The authors declare no competing interests.

Open Access This article is licensed under a Creative Commons Attribution 4.0 International License, which permits use, sharing, adaptation, distribution and reproduction in any medium or format, as long as you give appropriate credit to the original author(s) and the source, provide a link to the Creative Commons licence, and indicate if changes were made. The images or other third party material in this article are included in the article's Creative Commons licence, unless indicated otherwise in a credit line to the material. If material is not included in the article's Creative Commons licence and your intended use is not permitted by statutory regulation or exceeds the permitted use, you will need to obtain permission directly from the copyright holder. To view a copy of this licence, visit http://creativecommons.org/licenses/by/4.0/.

\section{References}

1. Peilei Z, Yunlong L, Hua Y, Kai M, Peiquan X, Zhishui Y, Yingying C, Min D (2013) Effect of Nb addition on Fe-Ni-B-Si amorphous and crystalline composite coatings by laser 
processing. Surf Coat Technol 236:84-90. https://doi.org/10. 1016/j.surfcoat.2013.09.032

2. Cheng J, Feng Y, Yan C, Hu X, Li R, Liang X (2020) Development and characterization of Al-based amorphous coating. JOM. 72:745-753. https://doi.org/10.1007/s11837-01903966-y

3. Cheng J, Sun B, Ge Y, Hu X, Zhang L, Liang X, Zhang X (2020) Effect of $\mathrm{B} / \mathrm{Si}$ ratio on structure and properties of high-entropy glassy Fe25Co25Ni25(BxSi1-x)25 coating prepared by laser cladding. Surf Coat Technol 402:126320. https://doi.org/10.1016/j. surfcoat.2020.126320

4. Saji VS (2018) Electrodeposition in bulk metallic glasses. Materialia. 3:1-11. https://doi.org/10.1016/j.mtla.2018.09.021

5. Klement W, Willens RH, Duwez P (1960) Non-crystalline structure in solidified gold-silicon alloys. Nature. 187:869-870. https://doi.org/10.1038/187869b0

6. Makino A, Hatanai T, Inoue A, Masumoto T (1997) Nanocrystalline soft magnetic Fe-M-B ( $\mathrm{M}=\mathrm{Zr}$, Hf, $\mathrm{Nb}$ ) alloys and their applications. Mater Sci Eng A 226-228:594-602. https://doi.org/10.1016/S0921-5093(96)10693-6

7. Inoue A, Shinohara Y, Gook JS (1995) Thermal and magnetic properties of bulk Fe-based glassy alloys prepared by copper mold casting. Mater Trans JIM 36:1427-1433. https://doi.org/10.2320/ matertrans 1989.36.1427

8. Sun BA, Wang WH (2015) The fracture of bulk metallic glasses. Prog Mater Sci 74:211-307. https://doi.org/10.1016/j.pmatsci. 2015.05.002

9. Johnson WL (1996) Bulk metallic glasses - a new engineering material. Curr Opin Solid State Mater Sci 1:383-386. https://doi. org/10.1016/S1359-0286(96)80029-5

10. Hofmann DC, Suh JY, Wiest A, Duan G, Lind ML, Demetriou MD, Johnson WL (2008) Designing metallic glass matrix composites with high toughness and tensile ductility. Nature. 451: 1085-1089. https://doi.org/10.1038/nature06598

11. Li R, Li Z, Huang J, Zhang P, Zhu Y (2011) Effect of Ni-to-Fe ratio on structure and properties of $\mathrm{Ni}-\mathrm{Fe}-\mathrm{B}-\mathrm{Si}-\mathrm{Nb}$ coatings fabricated by laser processing. Appl Surf Sci 257:3554-3557. https:// doi.org/10.1016/j.apsusc.2010.11.073

12. Zhang P, Yan H, Yao C, Li Z, Yu Z, Xu P (2011) Synthesis of Fe$\mathrm{Ni}-\mathrm{B}-\mathrm{Si}-\mathrm{Nb}$ amorphous and crystalline composite coatings by laser cladding and remelting. Surf Coat Technol 206:1229-1236. https://doi.org/10.1016/j.surfcoat.2011.08.039

13. Johnson WL (2002) Bulk amorphous metal - an emerging engineering material. JOM. 54:40-43. https://doi.org/10.1007/ BF02822619

14. Löffler JF (2003) Bulk metallic glasses. Intermetallics. 11:529540. https://doi.org/10.1016/S0966-9795(03)00046-3

15. Telford M (2004) The case for bulk metallic glass. Mater Today 7: 36-43. https://doi.org/10.1016/S1369-7021(04)00124-5

16. Zhang Q, Zhang P, Yan H, Yu Z, Wu D, Shi H, Li S, Tian Y (2020) Magnetic-field-assisted laser cladding in the preparation of a crack-free $\mathrm{Fe}-\mathrm{Cr}-\mathrm{Mo}-\mathrm{C}-\mathrm{Y}-\mathrm{B}$ amorphous coating on steel. Philos Mag Lett 100:86-93. https://doi.org/10.1080/09500839.2020. 1725245

17. Zhang P, Yan H, Xu P, Yu Z, Li C (2012) Microstructure and tribological behavior of amorphous and crystalline composite coatings using laser melting. Appl Surf Sci 258:6902-6908. https://doi.org/10.1016/j.apsusc.2012.03.130

18. Zhang P, Yan H, Yao C, Li Z, Yu Z, Xu P (2012) Relationship between the $\gamma$ and some parameters of Fe-based bulk metallic glasses. Int J Mater Res 103:336-340. https://doi.org/10.3139/ 146.110649

19. Zhang P, Yan H, Xu P, Lu Q, Li C, Yu Z (2012) Influence of different annealing temperatures and cooling rates on amorphous and crystalline composite coating. Surf Coat Technol 206:49814987. https://doi.org/10.1016/j.surfcoat.2012.05.142
20. Langlet A, (2011) US8052923B2-Method of producing products of amorphous metal- Google Patents, 2. https://patents.google. com/patent/US8052923 (accessed November 8, 2011).

21. Inoue A, Kong FL, Man QK, Shen BL, Li RW, Al-Marzouki F (2014) Development and applications of Fe- and Co-based bulk glassy alloys and their prospects. J Alloys Compd 615:S2-S8. https://doi.org/10.1016/j.jallcom.2013.11.122

22. Lou HB, Wang XD, Xu F, Ding SQ, Cao QP, Hono K, Jiang JZ (2011) $73 \mathrm{~mm}$-diameter bulk metallic glass rod by copper mould casting. Appl Phys Lett 99:051910. https://doi.org/10.1063/1. 3621862

23. Nishiyama N, Takenaka K, Miura H, Saidoh N, Zeng Y, Inoue A (2012) The world's biggest glassy alloy ever made. Intermetallics. 30:19-24. https://doi.org/10.1016/j.intermet.2012.03.020

24. Trexler MM, Thadhani NN (2010) Mechanical properties of bulk metallic glasses. Prog Mater Sci 55:759-839. https://doi.org/10. 1016/j.pmatsci.2010.04.002

25. Jia H, Wang G, Chen S, Gao Y, Li W, Liaw PK (2018) Fatigue and fracture behavior of bulk metallic glasses and their composites. Prog Mater Sci 98:168-248. https://doi.org/10.1016/j. pmatsci.2018.07.002

26. Wang G, Huang YJ, Makhanlall D, Shen J (2012) Friction joining of Ti 40Zr 25Ni 3Cu 12Be 20 bulk metallic glass. J Mater Process Technol 212:1850-1855. https://doi.org/10.1016/j.jmatprotec. 2012.04.006

27. Wu W, Jiang J, Li G, Fuh JYH, Jiang H, Gou P, Zhang L, Liu W, Zhao J (2019) Ultrasonic additive manufacturing of bulk Ni-based metallic glass. J Non-Cryst Solids 506:1-5. https://doi.org/10. 1016/j.jnoncrysol.2018.12.008

28. Shao L, Datye A, Huang J, Ketkaew J, Sohn SW, Zhao S, Wu S, Zhang Y, Schwarz UD, Schroers J (2017) Pulsed laser beam welding of Pd43Cu27Ni10P20 bulk metallic glass. Sci Rep 7: 7989. https://doi.org/10.1038/s41598-017-08460-6

29. Wang DJ, Huang YJ, Wu LZ, Shen J (2013) Mechanical behaviors of diamond reinforced Ti-based bulk metallic glassy composites prepared by spark plasma sintering. Mater Sci Eng A 560: 841-846. https://doi.org/10.1016/j.msea.2012.10.067

30. Wang G, Huang YJ, Shagiev M, Shen J (2012) Laser welding of Ti 40Zr 25Ni 3Cu 12Be 20 bulk metallic glass. Mater Sci Eng A 541:33-37. https://doi.org/10.1016/j.msea.2012.01.114

31. Li Z, Zhang M, Li N, Liu L (2020) Metal frame reinforced bulk metallic glass composites. Mater Res Lett 8:60-67. https://doi.org/ 10.1080/21663831.2019.1695684

32. Wu W, Liu W, Du H, Wang B, Li G, Sun B, Zhang S, Zhao J (2018) Optimization of sintering time and holding time for 3D printing of Fe-based metallic glasses. Metals (Basel) 8:429. https://doi.org/10.3390/met8060429

33. Li X (2018) Additive manufacturing of advanced multicomponent alloys: bulk metallic glasses and high entropy alloys. Adv Eng Mater 20:1700874. https://doi.org/10.1002/adem. 201700874

34. Williams E, Lavery N (2017) Laser processing of bulk metallic glass: a review. J Mater Process Technol 247:73-91. https://doi. org/10.1016/j.jmatprotec.2017.03.034

35. DebRoy T, Wei HL, Zuback JS, Mukherjee T, Elmer JW, Milewski JO, Beese AM, Wilson-Heid A, De A, Zhang W (2018) Additive manufacturing of metallic components - process, structure and properties. Prog Mater Sci 92:112-224. https://doi. org/10.1016/j.pmatsci.2017.10.001

36. Cheng X, Liu S, Chen C, Chen W, Liu M, Li R, Zhang X, Zhou K (2019) Microstructure and mechanical properties of additive manufactured porous $\mathrm{Ti}-33 \mathrm{Nb}-4 \mathrm{Sn}$ scaffolds for orthopaedic applications. J Mater Sci Mater Med 30:91. https://doi.org/10.1007/ s10856-019-6292-0

37. Yang D, Li H, Liu S, Song C, Yang Y, Shen S, Lu J, Liu Z, Zhu Y (2020) In situ capture of spatter signature of SLM process using 
maximum entropy double threshold image processing method based on genetic algorithm. Opt Laser Technol 131:106371. https://doi.org/10.1016/j.optlastec.2020.106371

38. Montero-Sistiaga ML, Godino-Martinez M, Boschmans K, Kruth JP, Van Humbeeck J, Vanmeensel K (2018) Microstructure evolution of $316 \mathrm{~L}$ produced by HP-SLM (high power selective laser melting). Addit Manuf 23:402-410. https://doi.org/10.1016/j. addma.2018.08.028

39. Wang J, Zhou XL, Li J, Brochu M, Zhao YF (2020) Microstructures and properties of SLM-manufactured $\mathrm{Cu}-15 \mathrm{Ni}-$ 8Sn alloy. Addit Manuf 31:100921. https://doi.org/10.1016/j. addma.2019.100921

40. Qian G, Li Y, Paolino DS, Tridello A, Berto F, Hong Y (2020) Very-high-cycle fatigue behavior of Ti-6Al-4V manufactured by selective laser melting: effect of build orientation. Int J Fatigue 136:105628. https://doi.org/10.1016/j.ijfatigue.2020.105628

41. Qian G, Jian Z, Qian Y, Pan X, Ma X, Hong Y (2020) Very-highcycle fatigue behavior of AlSi10Mg manufactured by selective laser melting: effect of build orientation and mean stress. Int J Fatigue 138:105696. https://doi.org/10.1016/j.ijfatigue.2020. 105696

42. Gu DD, Meiners W, Wissenbach K, Poprawe R (2012) Laser additive manufacturing of metallic components: materials, processes and mechanisms. Int Mater Rev 57:133-164. https://doi. org/10.1179/1743280411Y.0000000014

43. Li XP, Kang CW, Huang H, Sercombe TB (2014) The role of a low-energy-density re-scan in fabricating crack-free A185Ni5Y6Co2Fe2 bulk metallic glass composites via selective laser melting. Mater Des 63:407-411. https://doi.org/10.1016/j. matdes.2014.06.022

44. Panwisawas C, Tang YT, Reed RC (2020) Metal 3D printing as a disruptive technology for superalloys. Nat Commun 11:1-4. https://doi.org/10.1038/s41467-020-16188-7

45. Galy C, Le Guen E, Lacoste E, Arvieu C (2018) Main defects observed in aluminum alloy parts produced by SLM: From causes to consequences. Addit Manuf 22:165-175. https://doi.org/10. 1016/j.addma.2018.05.005

46. Zhang D, Wang W, Guo Y, Hu S, Dong D, Poprawe R, Schleifenbaum JH, Ziegler S (2019) Numerical simulation in the absorption behavior of Ti6A14V powder materials to laser energy during SLM. J Mater Process Technol 268:25-36. https://doi.org/ 10.1016/J.JMATPROTEC.2019.01.002

47. Alvi S, Saeidi K, Akhtar F (2020) High temperature tribology and wear of selective laser melted (SLM) 316L stainless steel. Wear. 448-449:203228. https://doi.org/10.1016/j.wear.2020.203228

48. Majeed A, Zhang Y, Lv J, Peng T, Atta Z, Ahmed A (2020) Investigation of $\mathrm{T} 4$ and $\mathrm{T} 6$ heat treatment influences on relative density and porosity of AlSil0Mg alloy components manufactured by SLM. Comput Ind Eng 139:106194. https:// doi.org/10.1016/J.CIE.2019.106194

49. Qian G, Lei WS, Niffenegger M, González-Albuixech VF (2018) On the temperature independence of statistical model parameters for cleavage fracture in ferritic steels. Philos Mag 98:959-1004. https://doi.org/10.1080/14786435.2018.1425011

50. Nam YG, Koo B, Chang MS, Yang S, Yu J, Park YH, Jeong JW (2020) Selective laser melting vitrification of amorphous soft magnetic alloys with help of double-scanning-induced compositional homogeneity. Mater Lett 261:127068. https://doi.org/10. 1016/j.matlet.2019.127068

51. AlMangour B, Baek MS, Grzesiak D, Lee KA (2018) Strengthening of stainless steel by titanium carbide addition and grain refinement during selective laser melting. Mater Sci Eng A 712:812-818. https://doi.org/10.1016/j.msea.2017.11.126

52. Sing SL, Yeong WY, Wiria FE, Tay BY (2016) Characterization of titanium lattice structures fabricated by selective laser melting using an adapted compressive test method. Exp Mech 56:735748. https://doi.org/10.1007/s11340-015-0117-y

53. Zhang D, Zhang P, Liu Z, Feng Z, Wang C, Guo Y (2018) Thermofluid field of molten pool and its effects during selective laser melting (SLM) of Inconel 718 alloy. Addit Manuf 21:567578. https://doi.org/10.1016/j.addma.2018.03.031

54. Yin J, Zhu H, Ke L, Lei W, Dai C, Zuo D (2012) Simulation of temperature distribution in single metallic powder layer for laser micro-sintering. Comput Mater Sci 53:333-339. https://doi.org/ 10.1016/j.commatsci.2011.09.012

55. Gao X, Lin X, Yu J, Li Y, Hu Y, Fan W, Shi S, Huang W (2019) Selective laser melting (SLM) of in-situ beta phase reinforced Ti/ Zr-based bulk metallic glass matrix composite. Scr Mater 171:2125. https://doi.org/10.1016/j.scriptamat.2019.06.007

56. Ritchie RO (2011) The conflicts between strength and toughness. Nat Mater 10:817-822. https://doi.org/10.1038/nmat3115

57. Mahbooba Z, Thorsson L, Unosson M, Skoglund P, West H, Horn T, Rock C, Vogli E, Harrysson O (2018) Additive manufacturing of an iron-based bulk metallic glass larger than the critical casting thickness. Appl Mater Today 11:264-269. https://doi.org/10. 1016/j.apmt.2018.02.011

58. Tonelli L, Fortunato A, Ceschini L (2020) CoCr alloy processed by selective laser melting (SLM): effect of laser energy density on microstructure, surface morphology, and hardness. J Manuf Process 52:106-119. https://doi.org/10.1016/j.jmapro.2020.01. 052

59. Ibrahim MZ, Sarhan AAD, Kuo TY, Yusof F, Hamdi M, Lee TM (2020) Developing a new laser cladded $\mathrm{FeCrMoCB}$ metallic glass layer on nickel-free stainless-steel as a potential superior wearresistant coating for joint replacement implants. Surf Coat Technol 392:125755. https://doi.org/10.1016/j.surfcoat.2020. 125755

60. Zhang W, Wang L, Feng Z, Chen Y (2020) Research progress on selective laser melting (SLM) of magnesium alloys: A review. Optik (Stuttg) 207:163842. https://doi.org/10.1016/j.ijleo.2019. 163842

61. Plocher J, Panesar A (2019) Review on design and structural optimisation in additive manufacturing: Towards next-generation lightweight structures. Mater Des 183:108164. https://doi.org/10. 1016/j.matdes.2019.108164

62. Zhang C, Ouyang D, Pauly S, Liu L (2021) 3D printing of bulk metallic glasses. Mater Sci Eng R Rep 145:100625. https://doi. org/10.1016/J.MSER.2021.100625

63. Sohrabi N, Jhabvala J, Logé RE (2021) Additive manufacturing of bulk metallic glasses - process, challenges and properties: a review. Metals (Basel) 11:1279. https://doi.org/10.3390/ met1 1081279

64. Li HX, Lu ZC, Wang SL, Wu Y, Lu ZP (2019) Fe-based bulk metallic glasses: glass formation, fabrication, properties and applications. Prog Mater Sci 103:235-318. https://doi.org/10.1016/j. pmatsci.2019.01.003

65. Rafique MMA, Qiu D, Brandt M (2019) Development of bulk metallic glasses and their composites by additive manufacturing - evolution, challenges and a proposed novel solution. Adv Mater Res 1155:1-28. https://doi.org/10.4028/www.scientific.net/amr. 1155.1

66. Liu H, Jiang Q, Huo J, Zhang Y, Yang W, Li X (2020) Crystallization in additive manufacturing of metallic glasses: a review. Addit Manuf 36:101568. https://doi.org/10.1016/j. addma.2020.101568

67. Halim Q, Mohamed NAN, Rejab MRM, Naim WNWA, Ma Q (2021) Metallic glass properties, processing method and development perspective: a review. Int J Adv Manuf Technol 112:12311258. https://doi.org/10.1007/s00170-020-06515-Z

68. Zhang LC, Jia Z, Lyu F, Liang SX, Lu J (2019) A review of catalytic performance of metallic glasses in wastewater treatment: 
recent progress and prospects. Prog Mater Sci 105:100576. https:// doi.org/10.1016/j.pmatsci.2019.100576

69. Pauly S, Löber L, Petters R, Stoica M, Scudino S, Kühn U, Eckert J (2013) Processing metallic glasses by selective laser melting. Mater Today 16:37-41. https://doi.org/10.1016/j.mattod.2013. 01.018

70. Jung HY, Choi SJ, Prashanth KG, Stoica M, Scudino S, Yi S, Kühn U, Kim DH, Kim KB, Eckert J (2015) Fabrication of Febased bulk metallic glass by selective laser melting: a parameter study. Mater Des 86:703-708. https://doi.org/10.1016/j.matdes. 2015.07.145

71. Ouyang D, Xing W, Li N, Li Y, Liu L (2018) Structural evolutions in 3D-printed Fe-based metallic glass fabricated by selective laser melting. Addit Manuf 23:246-252. https://doi.org/10.1016/j. addma.2018.08.020

72. Xing W, Ouyang D, Li N, Liu L (2018) Insight into microcracking in 3D-printed Fe-based BMGs by selective laser melting. Intermetallics. 103:101-106. https://doi.org/10.1016/j.intermet. 2018.10.011

73. Li N, Zhang J, Xing W, Ouyang D, Liu L (2018) 3D printing of Fe-based bulk metallic glass composites with combined high strength and fracture toughness. Mater Des 143:285-296. https:// doi.org/10.1016/j.matdes.2018.01.061

74. Hofmann DC, Bordeenithikasem P, Pate A, Roberts SN, Vogli E (2018) Developing processing parameters and characterizing microstructure and properties of an additively manufactured FeCrMoBC metallic glass forming alloy. Adv Eng Mater 20: 1800433. https://doi.org/10.1002/adem.201800433

75. Wang L, Wang H, Liu Y, Fu Z, Peng T, Shen J, Zhou S, Yan M, Wang G, Dai Y (2019) Selective laser melting helps fabricate record-large bulk metallic glass: experiments, simulation and demonstrative part. J Alloys Compd 808:151731. https://doi.org/10. 1016/j.jallcom.2019.151731

76. Żrodowski Ł, Wysocki B, Wróblewski R, Krawczyńska A, Adamczyk-Cieślak B, Zdunek J, Błyskun P, Ferenc J, Leonowicz M, Święszkowski W (2019) New approach to amorphization of alloys with low glass forming ability via selective laser melting. J Alloys Compd 771:769-776. https://doi.org/ 10.1016/j.jallcom.2018.08.075

77. Żrodowski Ł, Wysocki B, Wróblewski R, Kurzydłowski KJ, Święszkowski W, (2016) The novel scanning strategy for fabrication metallic glasses by selective laser melting, Fraunhofer Direct Digit. Manuf Conf (DDMC 2016). 1-6.

78. Nong XD, Zhou XL, Ren YX (2019) Fabrication and characterization of Fe-based metallic glasses by selective laser melting. Opt Laser Technol 109:20-26. https://doi.org/10.1016/j.optlastec. 2018.07.059

79. Li N, Wu S, Ouyang D, Zhang J, Liu L (2020) Fe-based metallic glass reinforced $\mathrm{FeCoCrNiMn}$ high entropy alloy through selective laser melting. J Alloys Compd 822:153695. https://doi.org/10. 1016/j.jallcom.2020.153695

80. Zou Y, Qiu Z, Tan C, Wu Y, Li K, Zeng D (2020) Microstructure and mechanical properties of Fe-based bulk metallic glass composites fabricated by selective laser melting. J Non-Cryst Solids 538:120046. https://doi.org/10.1016/j.jnoncrysol.2020.120046

81. Zou Y, Qiu Z, Zheng Z, Wang G, Yan X, Yin S, Liu M, Zeng D (2021) Ex-situ additively manufactured $\mathrm{FeCrMoCB} / \mathrm{Cu}$ bulk metallic glass composite with well wear resistance. Tribol Int 162: 107112. https://doi.org/10.1016/J.TRIBOINT.2021.107112

82. Yang C, Zhang C, Chen Z-J, Li Y, Yan W-Y, Yu H-B, Liu L, (2021) Three-dimensional hierarchical porous structures of metallic glass/copper composite catalysts by $3 \mathrm{D}$ printing for efficient wastewater treatments. ACS Appl Mater Interfaces acsami.0c20832. https://doi.org/10.1021/acsami.0c20832.

83. Liang S-XX, Wang X, Zhang W, Liu Y-JJ, Wang W, Zhang L-CC (2020) Selective laser melting manufactured porous Fe-based metallic glass matrix composite with remarkable catalytic activity and reusability. Appl Mater Today 19:100543. https://doi.org/10. 1016/j.apmt.2019.100543

84. Zou YM, Wu YS, Li KF, Tan CL, Qiu ZG, Zeng DC (2020) Selective laser melting of crack-free Fe-based bulk metallic glass via chessboard scanning strategy. Mater Lett 272:2-5. https://doi. org/10.1016/j.matlet.2020.127824

85. Luo N, Scheitler C, Ciftci N, Galgon F, Fu Z, Uhlenwinkel V, Schmidt M, Körner C (2020) Preparation of Fe-Co-B-Si-Nb bulk metallic glasses by laser powder bed fusion: microstructure and properties. Mater Charact 162:110206. https://doi.org/10.1016/j. matchar.2020.110206

86. Zhang Y, Song B, Zhang L, Wang Z, Shi Y, (2017) Microstructure and crack distribution of Fe-based amorphous alloys manufactured by selective laser melting, Solid Free. Fabr. 2017 Proc. 28th Annu. Int. Solid Free. Fabr. Symp. - An Addit. Manuf. Conf. SFF. (2020) 744-754.

87. Zhang Y, Zhang J, Yan Q, Zhang L, Wang M, Song B, Shi Y (2018) Amorphous alloy strengthened stainless steel manufactured by selective laser melting: enhanced strength and improved corrosion resistance. Scr Mater 148:20-23. https://doi. org/10.1016/j.scriptamat.2018.01.016

88. Ouyang D, Li N, Xing W, Zhang J, Liu L (2017) 3D printing of crack-free high strength Zr-based bulk metallic glass composite by selective laser melting. Intermetallics. 90:128-134. https://doi.org/ 10.1016/j.intermet.2017.07.010

89. Yang C, Zhang C, Xing W, Liu L (2018) 3D printing of Zr-based bulk metallic glasses with complex geometries and enhanced catalytic properties. Intermetallics. 94:22-28. https://doi.org/10. 1016/j.intermet.2017.12.018

90. Yang C, Zhang C, Liu L (2018) Excellent degradation performance of 3D hierarchical nanoporous structures of copper towards organic pollutants. J Mater Chem A 6:20992-21002. https://doi. org/10.1039/C8TA07973K

91. Xing W, Ouyang D, Li N, Liu L (2018) Estimation of residual stress in selective laser melting of a Zr-based amorphous alloy. Materials (Basel) 11:1480. https://doi.org/10.3390/ma1 1081480

92. Zhang Y, Lin X, Gao X, Su X, Guo S, Huang W (2020) Crystallization behavior of $\mathrm{Zr} 55 \mathrm{Cu} 30 \mathrm{Al10Ni5}$ amorphous alloys produced by selective laser melting of preannealed powders. J Alloys Compd 819:153013. https://doi.org/10.1016/j.jallcom. 2019.153013

93. Ouyang D, Li N, Liu L (2018) Structural heterogeneity in 3D printed Zr-based bulk metallic glass by selective laser melting. J Alloys Compd 740:603-609. https://doi.org/10.1016/j.jallcom. 2018.01.037

94. Ouyang D, Zheng Q, Wang L, Wang H, Yang C, Zhang P, Li N (2020) The brittleness of post-treatment of 3D printed Zr-based metallic glasses in supercooled liquid state. Mater Sci Eng A 782: 139259. https://doi.org/10.1016/j.msea.2020.139259

95. Shen XJ, Zhang C, Yang YG, Liu L (2019) On the microstructure, mechanical properties and wear resistance of an additively manufactured Ti64/metallic glass composite. Addit Manuf 25: 499-510. https://doi.org/10.1016/j.addma.2018.12.006

96. Zhang P, Ouyang D, Liu L (2019) Enhanced mechanical properties of 3D printed Zr-based BMG composite reinforced with Ta precipitates. J Alloys Compd 803:476-483. https://doi.org/10. 1016/j.jallcom.2019.06.303

97. Marattukalam JJ, Pacheco V, Karlsson D, Riekehr L, Lindwall J, Forsberg F, Jansson U, Sahlberg M, Hjörvarsson B (2020) Development of process parameters for selective laser melting of a Zr-based bulk metallic glass. Addit Manuf 33:101124. https:// doi.org/10.1016/j.addma.2020.101124

98. Wegner J, Frey M, Kleszczynski S, Busch R, Witt G, (2020) Influence of process gas during powder bed fusion with laser beam of Zr-based bulk metallic glasses, in: Procedia CIRP, 
Elsevier B.V., pp. 205-210. https://doi.org/10.1016/j.procir.2020. 09.039 .

99. Shi J, Ma S, Wei S, Best JP, Stolpe M, Beckmann A, Mostafavi S, Korte-Kerzel S, Markert B (2020) 3D pore structure characterization and hardness in a powder bed fusion-processed fully amorphous Zr-based bulk metallic glass. Mater Charact 162:110178. https://doi.org/10.1016/j.matchar.2020.110178

100. Bordeenithikasem P, Stolpe M, Elsen A, Hofmann DC (2018) Glass forming ability, flexural strength, and wear properties of additively manufactured $\mathrm{Zr}$-based bulk metallic glasses produced through laser powder bed fusion. Addit Manuf 21:312-317. https://doi.org/10.1016/j.addma.2018.03.023

101. Sohrabi N, Jhabvala J, Kurtuldu G, Stoica M, Parrilli A, Berns S, Polatidis E, Van Petegem S, Hugon S, Neels A, Löffler JF, Logé RE (2021) Characterization, mechanical properties and dimensional accuracy of a Zr-based bulk metallic glass manufactured via laser powder-bed fusion. Mater Des 199:109400. https://doi. org/10.1016/j.matdes.2020.109400

102. Deng L, Gebert A, Zhang L, Chen HY, Gu DD, Kühn U, Zimmermann M, Kosiba K, Pauly S (2020) Mechanical performance and corrosion behaviour of Zr-based bulk metallic glass produced by selective laser melting. Mater Des 189:108532. https://doi.org/10.1016/J.MATDES.2020.108532

103. Pauly S, Schricker C, Scudino S, Deng L, Kühn U (2017) Processing a glass-forming Zr-based alloy by selective laser melting. Mater Des 135:133-141. https://doi.org/10.1016/j.matdes. 2017.08.070

104. Li XP, Roberts MP, O'Keeffe S, Sercombe TB (2016) Selective laser melting of Zr-based bulk metallic glasses: processing, microstructure and mechanical properties. Mater Des 112:217-226. https://doi.org/10.1016/j.matdes.2016.09.071

105. Deng L, Kosiba K, Limbach R, Wondraczek L, Kühn U, Pauly S (2021) Plastic deformation of a Zr-based bulk metallic glass fabricated by selective laser melting. J Mater Sci Technol 60:139146. https://doi.org/10.1016/j.jmst.2020.06.007

106. Kosiba K, Deng L, Scudino S (2020) Viscous flow of supercooled liquid in a Zr-based bulk metallic glass synthesized by additive manufacturing. Materials (Basel) 13:7-13. https://doi.org/10. 3390/MA13173803

107. Zhang C, Li X, Liu S-Q, Liu H, Yu L-J, Liu L (2019) 3D printing of Zr-based bulk metallic glasses and components for potential biomedical applications. J Alloys Compd 790:963-973. https:// doi.org/10.1016/J.JALLCOM.2019.03.275

108. Xing W, Ouyang D, Chen Z, Liu L (2020) Effect of energy density on defect evolution in 3D printed $\mathrm{Zr}$-based metallic glasses by selective laser melting. Sci China Phys Mech Astron 63:226111. https://doi.org/10.1007/s11433-019-1485-8

109. Luo Y, Xing L, Jiang Y, Li R, Lu C, Zeng R, Luo J, Zhang P, Liu W (2020) Additive manufactured large Zr-based bulk metallic glass composites with desired deformation ability and corrosion resistance. Materials (Basel) 13:28. https://doi.org/10.3390/ ma13030597

110. Li XP, Kang CW, Huang H, Zhang LC, Sercombe TB (2014) Selective laser melting of an A186Ni6Y4.5Co2La1.5 metallic glass: processing, microstructure evolution and mechanical properties. Mater Sci Eng A 606:370-379. https://doi.org/10.1016/j. msea.2014.03.097

111. Li XP, Roberts M, Liu YJ, Kang CW, Huang H, Sercombe TB (2015) Effect of substrate temperature on the interface bond between support and substrate during selective laser melting of AlNi-Y-Co-La metallic glass. Mater Des 65:1-6. https://doi.org/10. 1016/j.matdes.2014.08.065

112. Prashanth KG, Shakur Shahabi H, Attar H, Srivastava VC, Ellendt N, Uhlenwinkel V, Eckert J, Scudino S (2015) Production of high strength $\mathrm{A} 185 \mathrm{Nd} 8 \mathrm{Ni} 5 \mathrm{Co} 2$ alloy by selective laser melting. Addit Manuf 6:1-5. https://doi.org/10.1016/j.addma.2015.01.001
113. Deng L, Wang S, Wang P, Kühn U, Pauly S (2018) Selective laser melting of a Ti-based bulk metallic glass. Mater Lett 212:346349. https://doi.org/10.1016/j.matlet.2017.10.130

114. Gao X, Lin X, Yan Q, Wang Z, Yu X, Zhou Y, Hu Y, Huang W (2021) Effect of $\mathrm{Cu}$ content on microstructure and mechanical properties of in-situ $\beta$ phases reinforced Ti/Zr-based bulk metallic glass matrix composite by selective laser melting (SLM). J Mater Sci Technol 67:174-185. https://doi.org/10.1016/j.jmst.2020.06. 024

115. Lu X, Nursulton M, Du Y, Liao W (2019) Structural and mechanical characteristics of $\mathrm{Cu} 50 \mathrm{Zr} 43 \mathrm{Al} 7$ bulk metallic glass fabricated by selective laser melting. Materials (Basel) 12:06. https://doi.org/ 10.3390/ma12050775

116. Gao X, Liu Z, Li J, Liu E, Yue C, Zhao K, Yang G (2020) Selective laser melting of CuZr-based metallic glass composites. Mater Lett 259:126724. https://doi.org/10.1016/j.matlet.2019. 126724

117. Zhang P, Zhang C, Ouyang D, Liu L (2021) Enhancement of plasticity and toughness of $3 \mathrm{D}$ printed binary $\mathrm{Zr} 50 \mathrm{Cu} 50$ bulk metallic glass composite by deformation-induced martensitic transformation. Scr Mater 192:7-12. https://doi.org/10.1016/j. scriptamat.2020.09.044

118. Deng L, Zhang L, Kosiba K, Limbach R, Wondraczek L, Wang G, Gu D, Kühn U, Pauly S (2021) CuZr-based bulk metallic glass and glass matrix composites fabricated by selective laser melting. J Mater Sci Technol 81:139-150. https://doi.org/10.1016/j.jmst. 2021.01.008

119. Sohrabi N, Jhabvala J, Kurtuldu G, Frison R, Parrilli A, Stoica M, Neels A, Löffler JF, Logé RE (2021) Additive manufacturing of a precious bulk metallic glass. Appl Mater Today 24:101080. https://doi.org/10.1016/j.apmt.2021.101080

120. Langlet A, (2011) US8052923B3-Method of producing objects containing nano metal or composite metal-Google Patents. https://patents.google.com/patent/US8333922 (accessed November 8, 2011).

121. Guo S, Su C (2017) Micro/nano ductile-phases reinforced Febased bulk metallic glass matrix composite with large plasticity. Mater Sci Eng A 707:44-50. https://doi.org/10.1016/j.msea.2017. 09.036

122. Yang G, Lin X, Liu F, Hu Q, Ma L, Li J, Huang W (2012) Laser solid forming Zr-based bulk metallic glass. Intermetallics. 22:110 115. https://doi.org/10.1016/j.intermet.2011.10.008

123. Bordeenithikasem P, Shen Y, Tsai HL, Hofmann DC (2018) Enhanced mechanical properties of additively manufactured bulk metallic glasses produced through laser foil printing from continuous sheetmetal feedstock. Addit Manuf 19:95-103. https://doi. org/10.1016/j.addma.2017.11.010

124. Lee JC, Kim YC, Ahn JP, Kim HS, Lee SH, Lee BJ (2004) Deformation-induced nanocrystallization and its influence on work hardening in a bulk amorphous matrix composite. Acta Mater 52:1525-1533. https://doi.org/10.1016/j.actamat.2003.11. 034

125. Inoue A (2000) Stabilization of metallic supercooled liquid and bulk amorphous alloys. Acta Mater 48:279-306. https://doi.org/ 10.1016/S1359-6454(99)00300-6

126. Li H, Lu Z, Yi S (2009) Estimation of the glass forming ability of $\mathrm{the} F \mathrm{e}-\mathrm{b}$ a s e d bulk metalli c gla s s Fe68.8C7.0Si3.5B5.0P9.6Cr2.1Mo2.0A12.0 that contains nonmetallic inclusions. Met Mater Int 15:7-14. https://doi.org/10. 1007/s12540-009-0007-x

127. Li HX, Gao JE, Jiao ZB, Wu Y, Lu ZP (2009) Glass-forming ability enhanced by proper additions of oxygen in a Fe-based bulk metallic glass. Appl Phys Lett 95:161905. https://doi.org/10.1063/ 1.3248186

128. Li HX, Li CQ, Cao D, Yang WM, Li Q, Lu ZP (2017) Influences of oxygen on plastic deformation of a Fe-based bulk metallic 
glass. Scr Mater 135:24-28. https://doi.org/10.1016/j.scriptamat. 2017.03.018

129. Liu S, Zhang X, Peng HL, Han X, Yang HY, Li TT, Zhu L, Zhang S, Qiu F, Bai ZH, Chen SM, Zhou W, Jiang QC (2020) In situ nanocrystals manipulate solidification behavior and microstructures of hypereutectic Al-Si alloys by Zr-based amorphous alloys. J Mater Res Technol 9:4644-4654. https://doi.org/10.1016/j.jmrt. 2020.02.091

130. Lu Y, Zhang H, Li H, Xu H, Huang G, Qin Z, Lu X (2017) LENSCrystallization prediction on laser three-dimensional printing of Zr-based bulk metallic glass. J Non-Cryst Solids 461:1217. https://doi.org/10.1016/J.JNONCRYSOL.2017.01.038

131. Pacheco V, Karlsson D, Marattukalam JJ, Stolpe M, Hjörvarsson B, Jansson U, Sahlberg M (2020) Thermal stability and crystallization of a Zr-based metallic glass produced by suction casting and selective laser melting. J Alloys Compd 825:153995. https:// doi.org/10.1016/j.jallcom.2020.153995

132. Ouyang D, Zhang P, Zhang C, Liu L (2021) Understanding of crystallization behaviors in laser 3D printing of bulk metallic glasses. Appl Mater Today 23:100988. https://doi.org/10.1016/J. APMT.2021.100988

133. Wegner J, Frey M, Piechotta M, Neuber N, Adam B, Platt S, Ruschel L, Schnell N, Riegler SS, Jiang HR, Witt G, Busch R, Kleszczynski S (2021) Influence of powder characteristics on the structural and the mechanical properties of additively manufactured Zr-based bulk metallic glass. Mater Des 209: 109976. https://doi.org/10.1016/J.MATDES.2021.109976

134. Ericsson A, Pacheco V, Marattukalam JJ, Dalgliesh RM, Rennie AR, Fisk M, Sahlberg M (2021) Crystallization of a Zr-based metallic glass produced by laser powder bed fusion and suction casting. J Non-Cryst Solids 571:120891. https://doi.org/10.1016/j. jnoncrysol.2021.120891

135. Zhang Q, Hao S, Liu Y, Xiong Z, Guo W, Yang Y, Ren Y, Cui L, Ren L, Zhang Z (2020) The microstructure of a selective laser melting (SLM)-fabricated NiTi shape memory alloy with superior tensile property and shape memory recoverability. Appl Mater Today 19:100547. https://doi.org/10.1016/j.apmt.2019.100547

136. Saedi S, Shayesteh Moghaddam N, Amerinatanzi A, Elahinia M, Karaca HE (2018) On the effects of selective laser melting process parameters on microstructure and thermomechanical response of Ni-rich NiTi. Acta Mater 144:552-560. https://doi.org/10.1016/j. actamat.2017.10.072

137. Wegner J, Frey M, Stiglmair P, Kleszczynski S, Witt G, Busch R (2019) Mechanical properties of honeycomb structured zr-based bulk metallic glass specimens fabricated by laser powder bed fusion, South African. J Ind Eng 30:32-40. https://doi.org/10.7166/ 30-3-2265

138. Tammas-Williams S, Zhao H, Léonard F, Derguti F, Todd I, Prangnell PB (2015) XCT analysis of the influence of melt strategies on defect population in Ti-6Al-4V components manufactured by Selective Electron Beam Melting. Mater Charact 102:47-61. https://doi.org/10.1016/j.matchar.2015.02. 008

139. Maskery I, Aboulkhair NT, Corfield MR, Tuck C, Clare AT, Leach RK, Wildman RD, Ashcroft IA, Hague RJM (2016) Quantification and characterisation of porosity in selectively laser melted Al-Si10-Mg using X-ray computed tomography. Mater Charact 111:193-204. https://doi.org/10.1016/j.matchar.2015.12. 001

140. Zhu HH, Fuh JYH, Lu L (2007) The influence of powder apparent density on the density in direct laser-sintered metallic parts. Int J Mach Tools Manuf 47:294-298. https://doi.org/10.1016/j. ijmachtools.2006.03.019

141. Mao J, Zhang HF, Fu HM, Wang AM, Li H, Hu ZQ (2010) Effects of casting temperature on mechanical properties of $\mathrm{Zr}$ - based metallic glasses. Mater Sci Eng A 527:981-985. https:// doi.org/10.1016/j.msea.2009.09.040

142. Pauly S, Wang P, Kühn U, Kosiba K (2018) Experimental determination of cooling rates in selectively laser-melted eutectic Al33Cu. Addit Manuf 22:753-757. https://doi.org/10.1016/j.addma. 2018.05.034

143. Schroers J (2010) Processing of bulk metallic glass. Adv Mater 22: 1566-1597. https://doi.org/10.1002/ADMA.200902776

144. Schroers J, Hodges TM, Kumar G, Raman H, Barnes AJ, Pham Q, Waniuk TA (2011) Thermoplastic blow molding of metals. Mater Today 14:14-19. https://doi.org/10.1016/S1369-7021(11)700189

145. Best JP, Evenson Z, Yang F, Dippel A-CC, Stolpe M, Gutowski O, Hasib MT, Li X, Kruzic JJ (2019) Structural periodicity in laser additive manufactured Zr-based bulk metallic glass. Appl Phys Lett 115:1-5. https://doi.org/10.1063/1.5100050

146. Fu X, Wang G, Wu Y, Song W, Shek CH, Zhang Y, Shen J, Ritchie RO (2020) Compressive ductility and fracture resistance in CuZr-based shape-memory metallic-glass composites. Int $\mathrm{J}$ Plast 128:102687. https://doi.org/10.1016/j.ijplas.2020.102687

147. Zhuang JR, Lee YT, Hsieh WH, Yang AS (2018) Determination of melt pool dimensions using DOE-FEM and RSM with process window during SLM of Ti6A14V powder. Opt Laser Technol 103: 59-76. https://doi.org/10.1016/j.optlastec.2018.01.013

148. Lei H, Li C, Meng J, Zhou H, Liu Y, Zhang X, Wang P, Fang D (2019) Evaluation of compressive properties of SLM-fabricated multi-layer lattice structures by experimental test and $\mu$-CTbased finite element analysis. Mater Des 169:107685. https://doi. org/10.1016/j.matdes.2019.107685

149. Uhlmann E, Pontes RP, Laghmouchi A, Bergmann A, (2017) Intelligent pattern recognition of a SLM machine process and sensor data, in: Procedia CIRP, Elsevier B.V., pp. 464-469. https://doi.org/10.1016/j.procir.2016.06.060.

150. Lindwall J, Malmelöv A, Lundbäck A, Lindgren LE (2018) Efficiency and accuracy in thermal simulation of powder bed fusion of bulk metallic glass. Jom. 70:1598-1603. https://doi.org/ 10.1007/s11837-018-2919-8

151. Zhang QS, Guo DY, Wang AM, Zhang HF, Ding BZ, Hu ZQ (2002) Preparation of bulk $\mathrm{Zr}<$ inf $>55</$ inf $>\mathrm{Al}<$ inf $>10<1$ inf $>\mathrm{Ni}<\inf >5</$ inf $>\mathrm{Cu}<$ inf $>30</$ inf $>$ metallic glass ring by centrifugal casting method. Intermetallics. 10:1197-1201. https:// doi.org/10.1016/S0966-9795(02)00158-9

152. Yoshikawa T, Tokuda M, Inaba T (2008) Influence of thermoplastic deformation on mechanical properties of Zr-based bulk metallic glasses at room temperature. Int J Mech Sci 50:888896. https://doi.org/10.1016/j.jimecsci.2007.09.005

153. Lindgren L-E, (2007) 9 - Modelling options in computational welding mechanics (CWM), in: L.-E.B.T.-C.W.M. Lindgren (Ed.), Woodhead Publ. Ser. Weld. Other Join. Technol., Woodhead Publishing, pp. 119-163. https://doi.org/10.1533/ 9781845693558.119.

154. Afazov S, Denmark WAD, Lazaro Toralles B, Holloway A, Yaghi A (2017) Distortion prediction and compensation in selective laser melting. Addit Manuf 17:15-22. https://doi.org/10.1016/j.addma. 2017.07.005

155. Ozawa T (1970) Kinetic analysis of derivative curves in thermal analysis. J Therm Anal 2:301-324. https://doi.org/10.1007/ BF01911411

156. Lindwall J, Pacheco V, Sahlberg M, Lundbäck A, Lindgren LE (2019) Thermal simulation and phase modeling of bulk metallic glass in the powder bed fusion process. Addit Manuf 27:345-352. https://oi.org/10.1016/j.addma.2019.03.011

157. Ericsson A, Pacheco V, Sahlberg M, Lindwall J, Hallberg H, Fisk M (2020) Transient nucleation in selective laser melting of Zrbased bulk metallic glass. Mater Des 195:108958. https://doi. org/10.1016/j.matdes.2020.108958 
158. Kelton KF (1993) Numerical model for isothermal and nonisothermal crystallization of liquids and glasses. J Non-Cryst Solids 163:283-296. https://doi.org/10.1016/0022-3093(93) 91306-N

159. Mondal K, Kumar A, Gupta G, Murty BS (2009) Temperature and structure dependency of solid-liquid interfacial energy. Acta Mater 57:3422-3430. https://doi.org/10.1016/j.actamat.2009.03.051

160. Olakanmi EO, Cochrane RF, Dalgarno KW (2015) A review on selective laser sintering/melting (SLS/SLM) of aluminium alloy powders: processing, microstructure, and properties. Prog Mater Sci 74:401-477. https://doi.org/10.1016/j.pmatsci.2015.03.002

161. Guo S, Wang M, Zhao Z, Zhang YY, Lin X, Huang WD (2017) Molecular dynamics simulation on the micro-structural evolution in heat-affected zone during the preparation of bulk metallic glasses with selective laser melting. J Alloys Compd 697:443449. https://doi.org/10.1016/j.jallcom.2016.11.393

162. Guo S, Wang M, Lin X, Huang WD, (2019) Research on the crystallization behavior occurred in the process of preparing bulk metallic glass with selective laser melting, Mater. Res Express 6. https://doi.org/10.1088/2053-1591/ab10bc.

163. Zhang Y, Liu H, Mo J, Wang M, Chen Z, He Y, Yang W, Tang C (2018) Atomic-scale structural evolution in selective laser melting of Cu50Zr50 metallic glass. Comput Mater Sci 150:62-69. https:// doi.org/10.1016/j.commatsci.2018.03.072

164. Zhang Y, Liu H, Mo J, Wang M, Chen Z, He Y, Yang W, Tang C (2019) Atomic-level crystallization in selective laser melting fabricated Zr-based metallic glasses. Phys Chem Chem Phys 21: 12406-12413. https://doi.org/10.1039/c9cp02181g

165. Jiang Q, Liu H, Li J, Yang D, Zhang Y, Yang W (2020) Atomiclevel understanding of crystallization in the selective laser melting of Fe50Ni50 amorphous alloy. Addit Manuf 34:101369. https:// doi.org/10.1016/j.addma.2020.101369

166. Wu S, Kramer MJ, Fang XW, Wang SY, Wang CZ, Ho KM, Ding ZJ, Chen LY (2012) Icosahedral short-range order in amorphous $\mathrm{Cu}<\mathrm{inf}>80</$ inf $>\mathrm{Si}<\mathrm{inf}>20<$ inf $>$ by ab initio molecular dynamics simulation study. Intermetallics. 30:122-126. https://doi.org/ 10.1016/j.intermet.2012.03.018

167. Xi XK, Li LL, Zhang B, Wang WH, Wu Y (2007) Correlation of atomic cluster symmetry and glass-forming ability of metallic glass. Phys Rev Lett 99:95501. https://doi.org/10.1103/ PhysRevLett.99.095501

168. Shen J, Chen Q, Sun J, Fan H, Wang G (2005) Exceptionally high glass-forming ability of an FeCoCrMoCBY alloy. Appl Phys Lett 86:1-3. https://doi.org/10.1063/1.1897426

169. An Y, Hou G, Chen J, Zhao X, Liu G, Zhou H, Chen J (2014) Microstructure and tribological properties of iron-based metallic glass coatings prepared by atmospheric plasma spraying. Vacuum. 107:132-140. https://doi.org/10.1016/j.vacuum.2014.04.021

170. Brothers AH, Mangrich B, Cox M, Dunand DC (2011) Effect of crystalline metallic particles on the compressive behavior of a cellular amorphous metal. Scr Mater 64:1031-1034. https://doi. org/10.1016/j.scriptamat.2011.02.014

171. Zhang W, Zhu W, Peng YH, Yang F, Pan RJ, Zhou Y, Wu YJ, Wu L (2020) Effects of second phases on charpy impact energy and crack propagation behavior of hastelloy $\mathrm{N}$ sheet using for molten salt reactor. Key Eng Mater 842:135-142. https://oi.org/ 10.4028/WWW.SCIENTIFIC.NET/KEM.842.135

172. Madge SV (2015) Toughness of bulk metallic glasses. Metals (Basel) 5:1279-1305. https://doi.org/10.3390/met5031279

173. Launey ME, Hofmann DC, Johnson WL, Ritchie RO (2009) Solution to the problem of the poor cyclic fatigue resistance of bulk metallic glasses. Proc Natl Acad Sci 106:4986-4991. https:// doi.org/10.1073/pnas.0900740106

174. Wang K, Fujita T, Pan D, Nieh TG, Inoue A, Kim DH, Chen MW (2008) Interface structure and properties of a brass-reinforced
Ni59Zr20Ti16Si2Sn3 bulk metallic glass composite. Acta Mater 56:3077-3087. https://doi.org/10.1016/j.actamat.2008.02.047

175. Liu YH, Liu CT, Gali A, Inoue A, Chen MW (2010) Evolution of shear bands and its correlation with mechanical response of a ductile $\mathrm{Zr} 55 \mathrm{Pd} 10 \mathrm{Cu} 20 \mathrm{Ni} 5 \mathrm{Al10}$ bulk metallic glass. Intermetallics. 18:1455-1464. https://doi.org/10.1016/j.intermet. 2010.03.037

176. Guo W, Wu Y, Zhang J, Hong S, Li G, Ying G, Guo J, Qin Y (2014) Fabrication and characterization of thermal-sprayed Febased amorphous/nanocrystalline composite coatings: an overview. J Therm Spray Technol 23:1157-1180. https://doi.org/10. 1007/s11666-014-0096-z

177. Narayan RL, Boopathy K, Sen I, Hofmann DC, Ramamurty U (2010) On the hardness and elastic modulus of bulk metallic glass matrix composites. Scr Mater 63:768-771. https://doi.org/10. 1016/j.scriptamat.2010.06.010

178. Lu Y, Ma L, Li SY, Zuo W, Ji ZQ, Ding M (2018) Effect of Cu element addition on the interfacial behavior and mechanical properties of Sn9Zn-1Al2O3 soldering 6061 aluminum alloys: firstprinciple calculations and experimental research. J Alloys Compd 765:128-139. https://doi.org/10.1016/j.jallcom.2018.06. 178

179. He G, Zhang ZF, Löser W, Eckert J, Schultz L (2003) Effect of Ta on glass formation, thermal stability and mechanical properties of a Zr52.25Cu28.5Ni4.75A19.5Ta5 bulk metallic glass. Acta Mater 51:2383-2395. https://doi.org/10.1016/S1359-6454(03)00045-4

180. Li HF, Zheng YF (2016) Recent advances in bulk metallic glasses for biomedical applications. Acta Biomater 36:1-20. https://doi. org/10.1016/j.actbio.2016.03.047

181. Liang H, Luo N, Shen T, Sun X, Fan X, Cao Y (2020) Experimental and numerical simulation study of Zr-based $\mathrm{BMG} / \mathrm{Al}$ composites manufactured by underwater explosive welding. J Mater Res Technol 9:1539-1548. https://doi.org/10. 1016/j.jmrt.2019.11.079

182. Best JP, Ostergaard HE, Li B, Stolpe M, Yang F, Nomoto K, Hasib MT, Muránsky O, Busch R, Li X, Kruzic JJ (2020) Fracture and fatigue behaviour of a laser additive manufactured Zr-based bulk metallic glass. Addit Manuf 36:101416. https://doi. org/10.1016/j.addma.2020.101416

183. Best JP, Ast J, Li B, Stolpe M, Busch R, Yang F, Li X, Michler J, Kruzic JJ (2020) Relating fracture toughness to micro-pillar compression response for a laser powder bed additive manufactured bulk metallic glass. Mater Sci Eng A 770:138535. https://doi.org/ 10.1016/j.msea.2019.138535

184. Shi J, Ma S, Wei S, Best JP, Stolpe M, Markert B (2021) Connecting structural defects to tensile failure in a 3D-printed fully-amorphous bulk metallic glass. Mater Sci Eng A 813: 141106. https://doi.org/10.1016/j.msea.2021.141106

185. Gu J, Song M, Ni S, Guo S, He Y (2013) Effects of annealing on the hardness and elastic modulus of a Cu36Zr48Al8Ag8 bulk metallic glass. Mater Des 47:706-710. https://doi.org/10.1016/J. MATDES.2012.12.071

186. Schuh CA, Hufnagel TC, Ramamurty U (2007) Mechanical behavior of amorphous alloys. Acta Mater 55:4067-4109. https:// doi.org/10.1016/j.actamat.2007.01.052

187. Gouripriya S, Tandaiya $\mathrm{P}$ (2020) Mechanistic origins of work hardening in shape memory alloy particle reinforced ex-situ bulk metallic glass matrix composites. Scr Mater 185:1-6. https://doi. org/10.1016/j.scriptamat.2020.04.013

188. Jiang S, Guo S, Huang Y, Ning Z, Xue P, Ru W, Zhang J, Sun J (2019) In situ study of the shear band features of a CuZr-based bulk metallic glass composite. Intermetallics. 112:106523. https:// doi.org/10.1016/j.intermet.2019.106523

189. Li Z, Wu S, Huang X, Li N (2020) Versatile fabrication of bulk metallic glass composites reinforced by dissimilar secondary 
phase. Mater Sci Eng A 791:139643. https://doi.org/10.1016/j. msea.2020.139643

190. Du Y, Han W, Zhou Q, Xu Y, Zhai H, Bhardwaj V, Wang H (2020) Enhancing the plasticity of a Ti-based bulk metallic glass composite by cryogenic cycling treatments. J Alloys Compd 835: 155247. https://doi.org/10.1016/j.jallcom.2020.155247

191. Gerstgrasser M, Cloots M, Stirnimann J, Wegener K (2021) Focus shift analysis, to manufacture dense and crack-free SLM-processed CM247LC samples. J Mater Process Technol 289:116948. https://doi.org/10.1016/j.jmatprotec.2020.116948

192. Moskowitz BM (1993) Micromagnetic study of the influence of crystal defects on coercivity in magnetite. J Geophys Res Solid Earth 98:18011-18026. https://doi.org/10.1029/93JB01719

193. Gebert A, Gostin PF, Uhlemann M, Eckert J, Schultz L (2012) Interactions between mechanically generated defects and corrosion phenomena of Zr-based bulk metallic glasses. Acta Mater 60:2300-2309. https://doi.org/10.1016/j.actamat.2011.12.044

194. Paillier J, Mickel C, Gostin PF, Gebert A (2010) Characterization of corrosion phenomena of $\mathrm{Zr}-\mathrm{Ti}-\mathrm{Cu}-\mathrm{Al}-\mathrm{Ni}$ metallic glass by SEM and TEM. Mater Charact 61:1000-1008. https://doi.org/10. 1016/j.matchar.2010.06.013

195. Gostin PF, Eigel D, Grell D, Eckert J, Kerscher E, Gebert A (2015) Comparing the pitting corrosion behavior of prominent Zr-based bulk metallic glasses. J Mater Res 30:233-241. https:// doi.org/10.1557/jmr.2014.371

196. Peter W, Buchanan R, Liu C, Liaw P, Morrison M, Horton J, Carmichael C, Wright J (2002) Localized corrosion behavior of a zirconium-based bulk metallic glass relative to its crystalline state. Intermetallics. 10:1157-1162. https://doi.org/10.1016/ S0966-9795(02)00130-9

197. Liang S-X, Jia Z, Liu Y-J, Zhang W, Wang W, Lu J, Zhang L-C (2018) Compelling rejuvenated catalytic performance in metallic glasses. Adv Mater 30:1802764. https://doi.org/10.1002/adma. 201802764

198. Wang J-Q, Liu Y-H, Chen M-W, Xie G-Q, Louzguine-Luzgin DV, Inoue A, Perepezko JH (2012) Rapid degradation of Azo Dye by Fe-based metallic glass powder. Adv Funct Mater 22: 2567-2570. https://doi.org/10.1002/adfm.201103015

199. Schroers J, Kumar G, Hodges TM, Chan S, Kyriakides TR (2009) Bulk metallic glasses for biomedical applications. JOM. 61:2129. https://doi.org/10.1007/s11837-009-0128-1

200. Liontas R, Greer JR (2017) 3D nano-architected metallic glass: size effect suppresses catastrophic failure. Acta Mater 133:393407. https://doi.org/10.1016/j.actamat.2017.05.019

201. Frey M, Wegner J, Neuber N, Reiplinger B, Bochtler B, Adam B, Ruschel L, Riegler SS, Jiang HR, Kleszczynski S, Witt G, Busch $\mathrm{R}$ (2021) Thermoplastic forming of additively manufactured Zrbased bulk metallic glass: a processing route for surface finishing of complex structures. Mater Des 198:109368. https://doi.org/10. 1016/j.matdes.2020.109368

202. Tillmann W, Fehr A, Wegner J, Stangier D, Kleszczynski S, Witt G (2020) LPBF-M manufactured Zr-based bulk metallic glasses coated with magnetron sputtered $\mathrm{ZrN}$ films. Surf Coat Technol 386:125463. https://doi.org/10.1016/j.surfcoat.2020.125463

203. Gorodesky N, Sedghani-Cohen S, Altman M, Fogel O, CohenTaguri G, Fleger Y, Kotler Z, Zalevsky Z (2020) Concurrent formation of metallic glass during laser forward transfer 3D printing. Adv Funct Mater 30:2001260. https://doi.org/10.1002/adfm. 202001260

Publisher's note Springer Nature remains neutral with regard to jurisdictional claims in published maps and institutional affiliations. 